Andrews University

Digital Commons @ Andrews University

\title{
Understanding Multiculturalism in Saudi Education: A Case Study of Two Schools in Mecca
}

Mohammed Alharbi

Andrews University, alharbi@andrews.edu

Follow this and additional works at: https://digitalcommons.andrews.edu/dissertations

Part of the Elementary Education Commons

\section{Recommended Citation}

Alharbi, Mohammed, "Understanding Multiculturalism in Saudi Education: A Case Study of Two Schools in Mecca" (2020). Dissertations. 1741.

https://digitalcommons.andrews.edu/dissertations/1741

https://dx.doi.org/10.32597/dissertations/1741

This Dissertation is brought to you for free and open access by the Graduate Research at Digital Commons @ Andrews University. It has been accepted for inclusion in Dissertations by an authorized administrator of Digital Commons@ Andrews University. For more information, please contact repository@andrews.edu. 


\begin{abstract}
UNDERSTANDING MULTICULTURALISM IN SAUDI EDUCATION: A CASE STUDY OF TWO SCHOOLS IN MECCA
\end{abstract}

by

Mohammed Alharbi

Chair: Larry D. Burton 


\title{
ABSTRACT OF GRADUATE STUDENT RESEARCH
}

Dissertation

\author{
Andrews University \\ College of Education and International Services
}

\section{Title: UNDERSTANDING MULTICULTURALISM IN SAUDI EDUCATION: A CASE STUDY OF TWO SCHOOLS IN MECCA}

Name of researcher: Mohammed Alharbi

Name and degree of faculty chair: Larry D. Burton, Ph.D.

Date completed: July 2020

\section{Problem}

This research investigated the understanding and perceptions of Saudi educators toward multiculturalism and multicultural education in Saudi Arabia. The research had three broad questions. The first question was, "What are Saudi educators' conceptions of culture and multicultural education?" The second research question was, "What practices do educators employ concerning multicultural education?" The third research question was, "How do educators implement multicultural education for their students at schools with different levels of cultural diversity?" 


\section{Method}

In this study, I used the qualitative multiple case study research design to explore the understanding and the attitudes of Saudi educators regarding multiculturalism and multicultural education. The study was applied in the Holy city of Mecca in Saudi Arabia, which is one of the most highly diverse cities in the whole country. The participants of this study were selected from two elementary schools with different levels of cultural diversity. The participants were varied in their school positions, teaching subjects, and levels of education. To collect the data of the study, I developed the interview protocol and conducted semi-structured interviews for teachers and administrators to understand Saudi educators' attitudes and perceptions regarding multicultural education.

\section{Interpretations}

The findings of the study were categorized into four themes. First, culture was defended into three different ways: a gained knowledge, customs and traditions, and an integrated life system. Second, the relationship between culture and education was seen from three different perspectives: the cultural background influences students' learning, the family's background influences students' learning, and the school's culture influences students' learning. Third, participants' perspectives regarding multiculturalism and multicultural education were divided into three viewpoints: multiculturalism empowers the community and it improves students' achievements at schools, multiculturalism empowers the teacher's performance in the classroom, and multiculturalism and multicultural education participate in losing the Islamic and Arabic identities for Saudi students. The fourth theme was related to teachers' professional development. All 
participants agreed that training programs provided form the Educational Training Department did not reach their desired needs.

\section{Implications of the Study}

The findings of this research have implications regarding multiculturalism and multicultural education in Saudi Arabia. First, the meaning of multicultural education used in the western world was not compatible with the culture of Islamic societies, including Saudi people. Therefore, there is a need for developing a multicultural education philosophy for Arab and Muslim societies that take into account the Arabic and Islamic identities. Second, equity in education is the backbone of the education system in Saudi Arabia. However, Saudi teachers need to be informed about equity in education and students' rights to empower all students to succeed. Third, there is a need for developing an Arabic language learning program for non-Arabic speakers. The fourth implication is that teacher professional development programs need to be developed to prepare teachers to participate in building the future of the country. 


\author{
Andrews University \\ College of Education and International Services
}

\title{
UNDERSTANDING MULTICULTURALISM IN SAUDI EDUCATION:
}

A CASE STUDY OF TWO SCHOOLS IN MECCA

\author{
A Dissertation \\ Present in the Partial Fulfillment \\ of the Requirements for the Degree \\ Doctor of Philosophy
}

by

Mohammed Alharbi

July 2020 
(C) Copyright by Mohammed Alharbi 2020

All Rights Reserved 


\title{
UNDERSTANDING MULTICULTURALISM IN SAUDI EDUCATION: A CASE STUDY OF TWO SCHOOLS IN MECCA
}

\author{
A dissertation \\ presented in partial fulfillment \\ of the requirements for the degree \\ Doctor of Philosophy
}

by

Mohammed Alharbi

APPROVAL BY THE COMMITTEE:

Chair: Larry D. Burton

Member: Amani Alghamdi

Member: Lori Imasiku

External: Lionel Matthews
Dean, School of Education

Alayne Thorpe 


\section{TABLE OF CONTENTS}

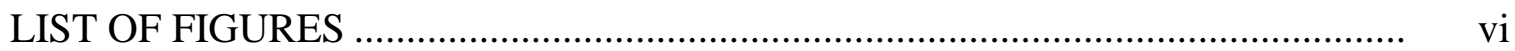

LIST OF TABLES .................................................................................. vi

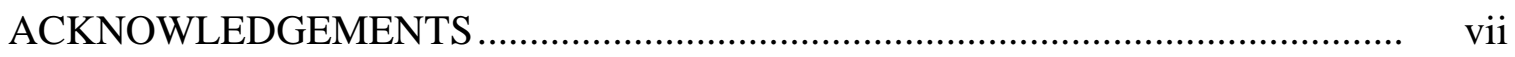

\section{Chapter}

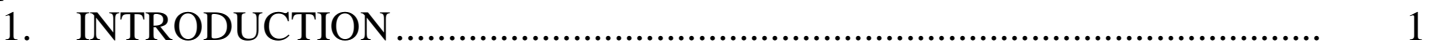

Background of the Problem.......................................................................... 1

Statement of the Problem ............................................................................

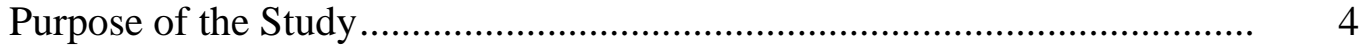

Research Questions ............................................................................. 5

Conceptual Framework ......................................................................... 6

Islamic Worldview .....................................................................

Sociocultural Theory ........................................................................ 9

Multicultural Education....................................................................... 11

Importance of the Study ...................................................................... 13

Nature of the Study ................................................................................ 14

Definition of Terms ............................................................................ 18

Overview of the Remainder Chapters of the Study ..................................... 18

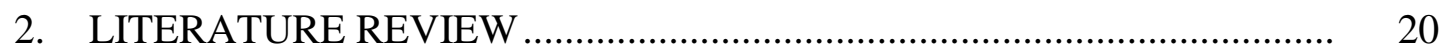

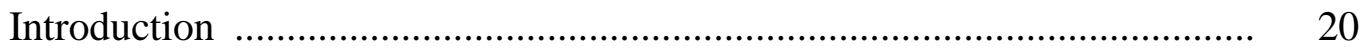

Culture

The Meaning of Culture ………….................................................... 22

Cultural Components........................................................................ 24

Issues of Culture and Identity in the Arab World ................................ 28

Multicultural Education........................................................................ $\quad 30$

The History of Multicultural Education ............................................... 34

Theories and Research in Multicultural Education .............................. 37

Implementation of Multicultural Education ........................................ 38

Education in Saudi Arabia.................................................................... 42

Issues of Education in Saudi Arabia .................................................... 44

Evolvement of Culture in Saudi Arabia ................................................ 45

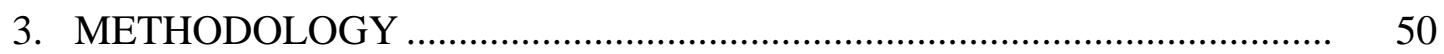




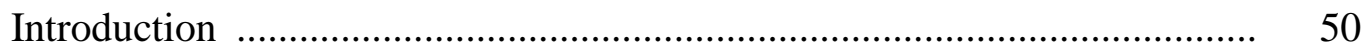

Qualitative Research Design ................................................................ 51

Researcher as an Instrument ................................................................. 52

Ethical Protection of Participants ................................................................ 54

Sample and Data Collection .................................................................... 55

Selection of Settings and Participants ................................................ 55

Sampling Strategy ………………………………....................... 56

Data Collection Method ..................................................................... 58

Strategy for Developing an Interview Protocol ...................................... 61

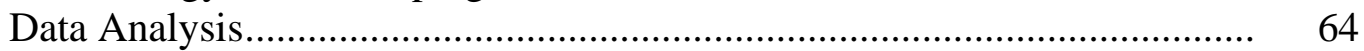

Strategies for Validating Findings ............................................................. 66

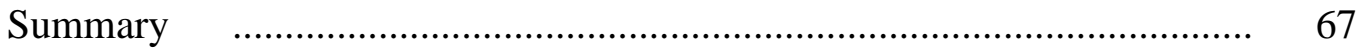

4. CENTRAL MECCA ELEMENTARY SCHOOL_............................................ 69

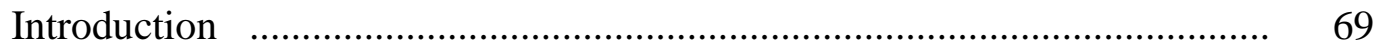

Central Mecca Elementary School ................................................................. 69

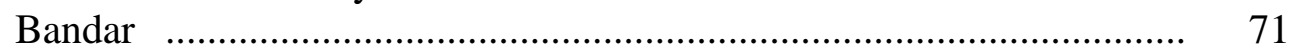

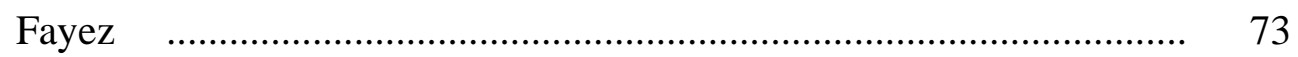

Mosh ……............................................................................ 74

Conceptions of Culture and Multicultural Education.................................... 75

The Definitions of Culture ................................................................ 75

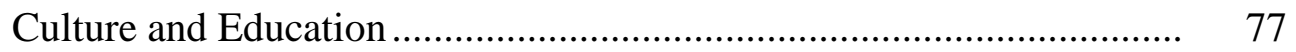

Multiculturalism in Saudi Arabia ....................................................... $\quad 79$

Multicultural Education Practices.............................................................. 82

Culturally Diverse Classroom ............................................................. 83

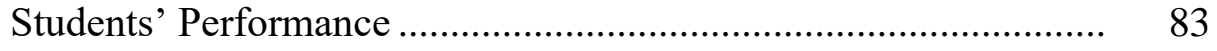

Teaching Practices ................................................................. 85

Education for all .......................................................................... 87

Professional Development.................................................................. $\quad 90$

5. EASTERN MECCA ELEMENTARY SCHOOL ……................................... 93

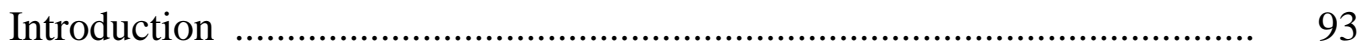

Eastern Mecca Elementary School ............................................................. 93

Khaled …....................................................................... 96

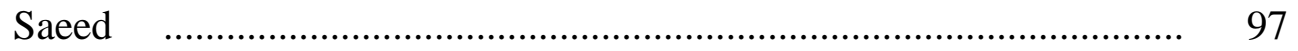

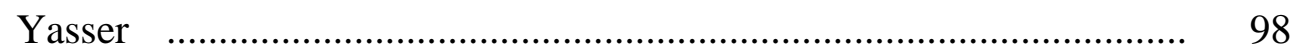

Conceptions of Culture and Multicultural Education.................................... $\quad 99$

The Definitions of Culture ……….................................................... 99

Culture and Education ....................................................................... 101

Multiculturalism in Saudi Arabia ........................................................ 103

Multicultural Education Practices ........................................................... 104

Evening Schools ......................................................................... 104

Multicultural Education.................................................................. 108 
Education for all ......................................................................... 111

Professional Development................................................................. 114

6. CROSS-CASE ANALYSIS, INTERPRETATION, AND CONCLUSION .. 116

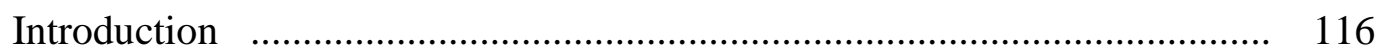

Comparison of Schools ........................................................................... 117

The Meaning of Culture.................................................................................. 119

Culture as Knowledge ................................................................. 120

Culture as Customs and Tradition ...................................................... 121

Culture as a Relationship to People vs. Place ...................................... 121

Culture as an Integrated System: Two Perspectives ............................. 122

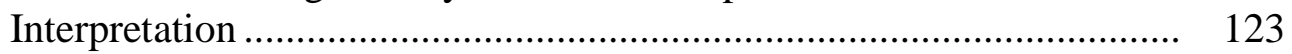

Culture and Education ............................................................................ 128

Culture Shapes Ways of Thinking and Participating .......................... 128

Parent's Background and Student Performance................................... 129

School Culture ......................................................................... 130

Interpretation .............................................................................. 131

Multiculturalism ................................................................................. 133

Multicultural vs. Monocultural ......................................................... 134

Perceptions Toward Multiculturalism .................................................. 135

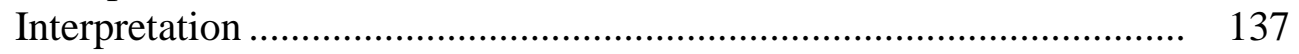

Multicultural Education ......................................................................... 138

Implementation of Multicultural Education ....................................... 141

School Relationship..................................................................... 143

Equity in Education ..................................................................... 145

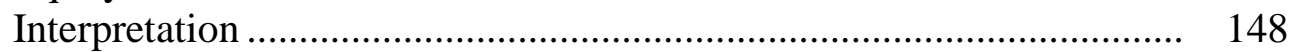

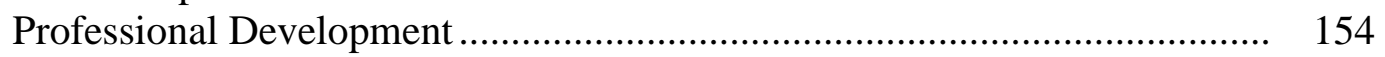

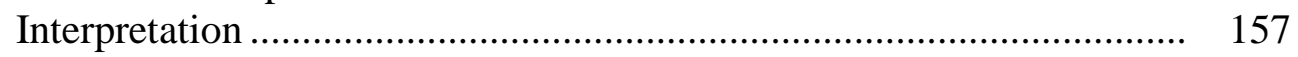

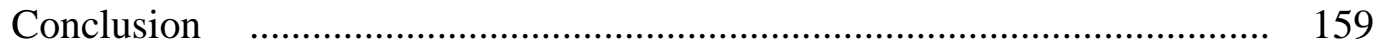

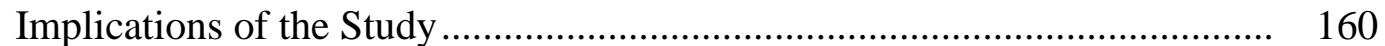

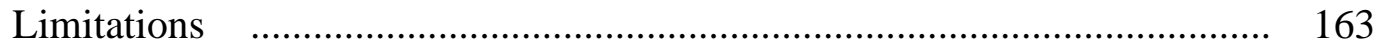

Recommendations for Future Research ..................................................... 164

Appendix

A. Interview Protocol Matrix .................................................................... 166

B. Checklist for Close Reading of Interview Protocol ............................... 171

C. IRB Approval ........................................................................... 172

D. Informed Consent Form ................................................................. 173

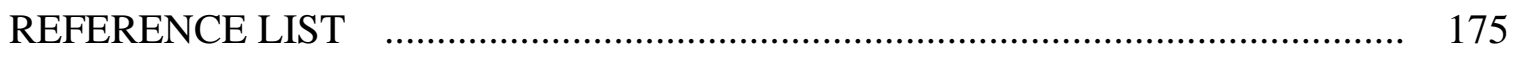

CURRICULUM VITAE ................................................................................. 184 


\section{LIST OF ILLUSTRATIONS}

1. Relationship Between Conceptual Frameworks .............................................. 7

2. The Meaning Of Culture ........................................................................ 127

3. Level of Understanding Multicultural Education ..................................... 151

\section{LIST OF TABLES}

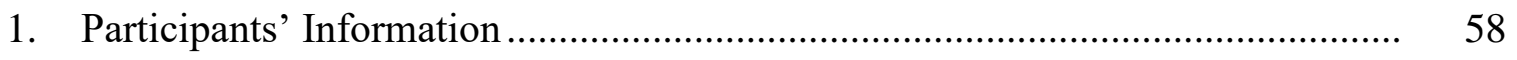




\section{ACKNOWLEDGEMENT}

First, I would like to thank Allah, whom I have always asked to guide me to the right path.

I am enormously grateful to my dissertation committee for their time, expertise, and encouragement. They showed interest in my ideas and inspired me to think deeply about multicultural education. I would like to thank Dr. Larry Burton for his support and encouragement during my time at TLC. I would also like to thank him for being a chair of the committee and for his intellectual engagement and thoughtful feedback. I also would like to thank Dr. Amani Alghamdi - Professor of curriculum and pedagogy at Imam Abdulrahman Bin Faisal University - for being a member of the committee. Her deep understanding of education in Saudi Arabia had a great impact on completing this work in the best way. I also would like to thank Dr. Lori Imasiku for her continued support throughout my courses as an academic advisor and during my dissertation as a committee member. To all the committee members, I appreciate your willingness to be on my committee and appreciate your excellent advice.

I owe a special debt of gratitude to my wife, Maram, for her love and support, and my children, Mayyas, Rakan, and Malak, for their support in creating a great environment to work on this research. My gratitude also goes to my parents, my siblings, and my wife's family for their prayers and support that helped to overcome the difficulties during my academic journey.

I would like to say a special thank you to the proofreaders Dr. Bruce Closser and Pamela Keesler for editing my dissertation and providing valuable feedback. 
I also acknowledge the support of my dear friends Salman and Mohammed, and all other friends in Kalamazoo who provided consultations, sincere advice, and warm greetings. 


\section{CHAPTER 1}

\section{INTRODUCTION}

\section{Background of the Problem}

The world has faced many immigration movements that have participated in demographic change and raised the recognition of diversity among minority groups. The worldwide number of migrants increased during the first decade of the 21 st century to over 200 million people who are living out of their countries of birth and other hundreds of millions who are internal migrants (Migration in an Interconnected World: New Directions for Action, 2005).

Because of globalization, immigration has increased for several reasons (SuárezOrozco \& Suárez-Orozco, 2009). First, immigrants follow capital flows. The combination of production, distribution, and consumption of goods and services stimulates migration to a nation where immigrants can find excellent job opportunities and have a better life. The affordability of mass transportation, moreover, makes immigration an option for many people who were not able to do so earlier. Second, immigrants search for a safe place to live. Conflicts leave behind a lot of destruction, poverty, and economic collapse, which cause the migration of many people, either at the beginning of the conflict in search of a safe place or after the end of the conflict in search of a decent life. The increase in the number of immigrants causes demographical change for many nations, which leads to an inclusive reform in all life aspects. 
Saudi Arabia is one of the most famous destinations for many Muslim immigrants. Its importance arises from the fact that it achieves the main objectives of immigration seekers: a decent life and capital flows. The history of migrations to the Arabian Peninsula began long before the establishment of the Kingdom of Saudi Arabia. The mission of the Prophet Muhammad Peace be Upon Him (PBUH) was a turning point in the region where both Mecca and Medina, the two Holy cities for Muslims, have become a significant destination for many Muslims. These two Holy cities were the starting points of Islam to the world. During the last century, for instance, the two Holy cities have witnessed many immigration movements from central and southeastern Asia and east and central Africa (الثنيعاني, 2011). The immigration movements have changed the demography of the cities and generated a culturally diverse society.

The discovery of oil in the 1930s was a remarkable point in Saudi Arabian history. Oil companies came to the country with much foreign expertise and labor to explore oil reserves. Many other workers came from Middle Eastern and Arab countries, such as Palestine, Egypt, and Syria (Gibney \& Hansen, 2005). The oil crisis in 1973 was another factor for increasing the number of foreign workers. As an oil provider, Saudi Arabia benefited from that crisis to improve infrastructure and development plans, which led to additional workers who came from other Asian countries such as India, Pakistan, Thailand, the Philippines, and South Korea (Gibney \& Hansen, 2005). The vast number of foreign workers participated in increasing cultural diversity and changing the demography in Saudi Arabia. 


\section{Statement of the Problem}

Multicultural education is a school reform approach that was developed to ensure educational equity for all students regardless of their ethnic, cultural, and racial groups (J. Banks, 2009a). The goal of multicultural education is to reform educational institutions, such as schools, colleges, and universities to provide an equitable educational experience for students from different cultural backgrounds. Multicultural education also emphasizes giving students from both genders an equal education experience opportunity to achieve success. In addition, it provides students with educational experiences that enable them to be a viable part of developing their community (J. Banks, 2015). Multicultural education emphasizes diversity between students and aims to ensure equity for all groups. Multicultural education, moreover, is an approach to raise students in this era of globalization to be universal citizens who can be productive parts of their culturally diverse community.

Saudi Arabia is a multicultural country. Cultural diversity has increased in some cities, such as the Holy city of Mecca, which has a large number of Muslim immigrants and millions of visitors throughout the year. It is a universal city that brings all Muslims together from everywhere in the world. This cultural diversity is strongly reflected in schools in the Mecca region. For example, a large number of charter schools existed for non-Saudi students. Many immigrant students did not attend public schools because they did not have legal residency, or they preferred to be with students from the same cultural background. Many of these charter schools were established in low income communities; thus, they had a weak and ineffective learning environment (عطار, 2004, 2007). The Office of the Director of Education in Mecca region initiated two educational reform 
movements - in 1993 and 2014 - to integrate non-Saudi students in public schools to

receive better educational opportunity (الثيعاني, 2011; العربية, 2016). Due to the educational reform that transferred many non-Saudi students to the public schools and the increase of foreign workers who live with their families in Mecca, the move to multicultural education has become necessary for developing an education system that provides equal opportunity for all students to learn and achieve their potential.

Unfortunately, multicultural education in Saudi Arabia does not receive much attention from educators, and only one study found in literature has investigated the status of multicultural education in Mecca (Al Thowaini, 2015). The study had examined the situation of multicultural education before the educational reform that was implemented in Mecca in 2016 to integrate over seventy thousand immigrant students in public schools. Therefore, further research is needed to understand the status of multicultural education in Saudi Arabia in general and in the city of Mecca in particular.

\section{Purpose of the Study}

Multicultural education is a reform movement that provides students from different races, social classes, languages, and cultural backgrounds equal opportunity to achieve their educational potential. In the current study, multicultural education is defined as a teaching philosophy that rejects racism and discrimination regarding the difference in language and nationality and emphasizes educational equity for all students in a classroom.

The primary purpose of this qualitative study is to explore teachers' attitudes toward teaching multicultural classrooms in Saudi Arabia. The second purpose of this study is to examine teachers' understanding of the relationship between culture and 
learning. The third purpose of this study is to explore Saudi teachers' perceptions regarding multiculturalism and multicultural education in Saudi Arabia. Moreover, I want to determine whether teachers' opinions of multiculturalism differ based on cultural diversities in their schools. The current study took place in the Holy city of Mecca, which is considered one of the most culturally diverse cities in Saudi Arabia.

\section{Research Questions}

To examine Saudi educators' attitudes toward multiculturalism and multicultural education in Saudi Arabia, I developed three broad research questions. The first question was, "What are Saudi educators' conceptions of culture and multicultural education?" Related to this question, I explored an answer to the following sub-questions: "How do Saudi educators define multiculturalism and multicultural education? How do educators explain the relationship between culture and learning?" These questions shed light on educators' understanding of the meaning of multiculturalism and multicultural education in Saudi Arabia.

The second research question was, "What practices do educators employ concerning multicultural education?" Regarding this research question, I utilized these sub-questions: "How do Saudi educators perceive non-Saudi students in their classrooms? What kind of teaching strategies do teachers use for teaching culturally diverse classrooms? What is the nature of multicultural activities that teachers use in classroom instruction? How do educators attempt to create a spirit of inclusion in a multicultural classroom?" These questions provided information about how Saudi educators use their knowledge about multicultural education in teaching culturally diverse students. 
The third research question was, "How do educators implement multicultural education for their students at schools with different levels of cultural diversity?" In this regard, I raised these questions: "How does having culturally diverse students in the classroom influence teaching methods in delivering multicultural content? Does having multicultural students in the classroom influence teachers' classroom management?" These questions assisted to clarify Saudi teachers' practices concerning multicultural education.

\section{Conceptual Framework}

The current study aimed to understand how Saudi educators view the relationship between culture and learning and how they implement multicultural education approaches in their classroom. I employed the Islamic worldview, sociocultural theory, and multicultural education as conceptual frameworks for this study, as Figure 1 demonstrates. In the current study, I utilized the Islamic worldview as the epistemological background for the researcher and the population of the study. The sociocultural theory is used as a root for multicultural education, where the theory claims that learning is guided by social and cultural interaction. Multicultural education as a conceptual framework for this study is defined as a teaching philosophy that rejects racism and discrimination regarding the difference in language and nationality and emphasizes educational equity for all students in a classroom. 


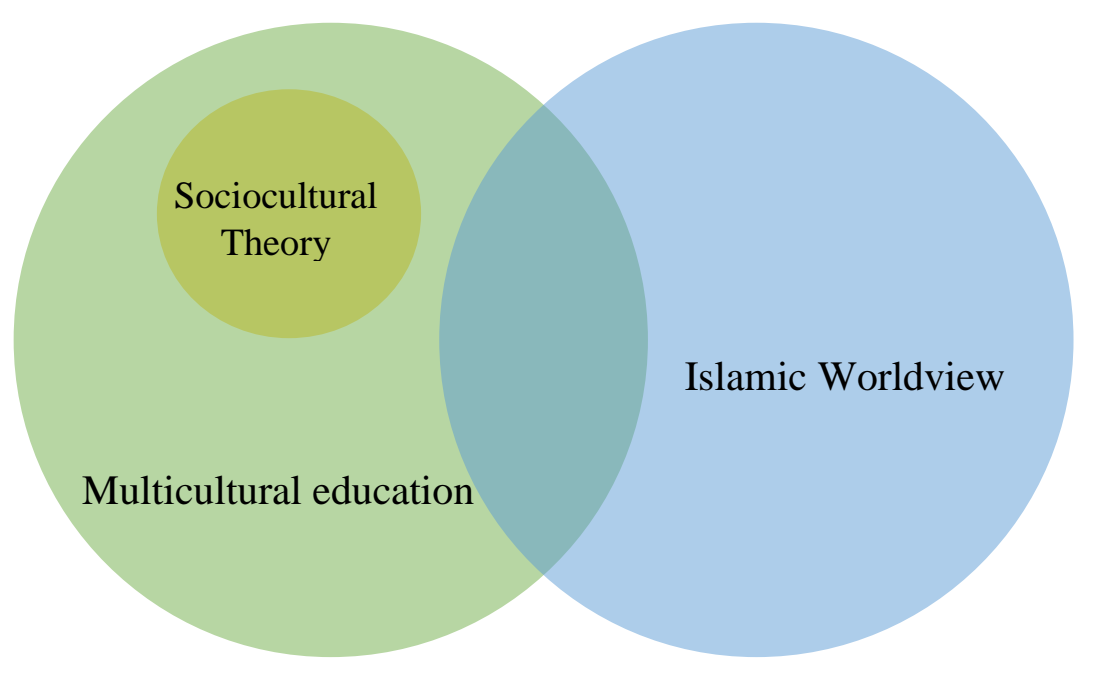

Figure 1. Relationship between conceptual frameworks.

\section{Islamic Worldview}

Islam is considered one of the Abrahamic religions, along with Judaism and Christianity. Islam means voluntary submission and surrender to the will of Allah. Muslims believe that Allah is merciful, mighty, and unparalleled. He has guided humanity through His Prophets, revelation, and natural signs. The primary scriptures of Islam are the Holy Qur'an, which is believed to be the verbatim word of Allah, and the doctrine of Prophet Muhammed (PBUH), who is believed to be the last Prophet sent by Allah. Islamic religious concepts and practices include the five Islamic Pillars testimony 'Shahadah, prayer, charity, fasting, and pilgrimage - which are the compulsory acts of worshiping Allah and following Islamic teaching that affects every aspect of life and society. 
Education in Islam is emphasized as compulsory for every Muslim. The aim of education in Islam is to produce a good human (Yasin \& Jani, 2013). Education from an Islamic point of view aims at the "balanced growth of the total personality of man through the training of man's spirit, intellect, the rational self, feelings and bodily senses" (as cited in Yasin \& Jani, 2013, p. 3). It emphasizes improvement in all life aspects, including spiritual, physical, and intellectual, and integrates all these aspects in a holistic educational system towards perfection to achieve the ultimate goal, which is complete submission to Allah, the Creator.

The concept of education is defined, from an Islamic perspective, in three different dimensions: tarbiyyah which means the process of learning that emphasizes physical and intellectual development; taadib which indicates the educational process of raising good human beings with knowledge of faith and Islamic practice; and talim that is related to the operation of education based on teaching and learning (Yasin \& Jani, 2013). Therefore, the meaning of education in Islam goes beyond the process of teaching and learning; education focuses on all life aspects of individuals and their communities.

Islam profoundly supports multiculturalism. The difference in ethnicity and cultural diversity is not a factor of fragmentation; rather, it is stimulation for individuals to know one another and help each other to live together in peace as Allah says in the Holy Qur'an:

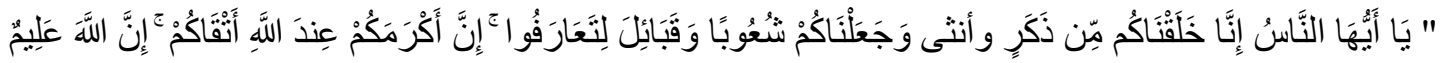

O people! We created you from a male and a female, and made you races and tribes, that you may know one another. The best among you in the sight of God is the most righteous. God is All-Knowing, Well-Experienced (Itani, 2012, p. 271). 
The variety in language, skin colors, ethnicity, and gender does not have any value in consideration of Allah. These varieties should not lead to segregation and discrimination; instead, these should lead people to the nature of temporary assistance and cooperation to carry out and complete the duty of humanity (Omar \& Noh, 2015). Allah, in this regard, requires humans to worship Him by building a strong relationship with Allah as well as by developing relations with other people.

\section{Sociocultural Theory}

To analyze educators' perceptions about learning and culture, I utilized the sociocultural lens as one of the conceptual frameworks for this study. Sociocultural theory states that education is guided by social and cultural interaction (Vygotski1, 1978). The knowledge and experiences of a student, for example, have been shaped by cultural influences before attending school. Language, as a cultural aspect, is learned at an early age of a child and is a primary way of communication that the student uses at school. According to Vygotsky, infants are talented with primary attention, perception, and memory that are developed during the first two years through the connection with the environment and culture. That leads to a growth of language and thinking, which enables children to participate in social dialogues with other people (Berk, 2013).

Sociocultural theory has three key elements, as Berk (2013) stated. The first element is the private speech which is "the process of privatizing speech that higher forms of consciousness arise on the inner plane and in this way our biological capacities are organized into a culturally mediated mind" (Lantolf, 2000, p. 15). Children speak to themselves for self-guidance. They use their voice to help them in thinking out loud 
about their mental activities and behavior. As they age, this way of out loud thinking changes to become internalized.

The second element is the zone of proximal development. According to sociocultural theory, learning is related to the individual's level of development. It takes place within a zone of proximal development, which refers to "a range of tasks that are difficult for the child to do alone but possible to do with the help of adults or more skilled peers" (Berk, 2013, p. 267). The help of adults and peers takes different forms in different cultures. In a comparison between a Southeast Asian family and a CaucasianAmerican family, Berk (2013) stated that while a Southeast Asian family, who values interdependence and child obedience, frequently tells their children what to do, a Caucasian-American family, who values independence and encourages children to think, gives their children opportunities to think and learn from their mistakes. These different ways of helping children are highly reflected in their schools where Caucasian-American children have a lack of self-control and behavior problems, and Southeast Asian children have the ability to follow the rules, do their assignments, and be organized (Berk, 2013).

The third element is make-believe play. Vygotsky argued that make-believe play is an integral part of children's development during the preschool age. Make-believe play helps children to use their skills and achieve cultural abilities by playing the role of adults, which allows them to practice their future actions in the real world. Make-believe play enables children to act against their typical situations and follow the rules of the play. A child, for example, plays the role of a mother in the state of parental behavior with a doll as her child. 
Shaffer (2008) highlighted two main points of sociocultural theory. The first point is that the sociocultural context influences human development. Second, cognitive skills and personal characteristics of a child are developed from the interaction with parents and other people in their community. Vygotsky argued that humans are born with a few elementary mental functions - memory, perception, sensation, and attention - that are ultimately shaped by their culture into new and more advanced mental processes, which he called higher mental functions (Shaffer, 2008). Therefore, culture shapes the way children learn and solve problems. In the learning process, cultural tools are used as a filter to accept, reject, or modify new learning experiences.

\section{Multicultural Education}

To employ multicultural education as a conceptual framework for this study, I used Nieto's (1994) "levels of multicultural understanding" to understand teachers' attitudes toward teaching multicultural classrooms in Saudi Arabia. Nieto claimed that multicultural education is a set of beliefs and philosophy, not a set of programs or courses, and her model "level of multicultural education understanding" can assist in determining school policies and practices that need to change. The model has four levels of multicultural understanding: tolerance, acceptance, respect, and affirmation solidarity and critique.

Tolerance is the first level of understanding of multicultural education. At this level, teachers believe that multicultural education is about being sensitive to students and their cultural background, not reforming the curriculum. Teachers, at the tolerance level, acknowledge diversity in language, race, gender, and social class, but many of them are unable to understand how that can cause differences in students' performances. 
The second level is acceptance. Teachers, at this level, acknowledge the differences between students, but they neither deny nor belittle the importance of these differences. Schools, for example, promote several teachers' professional development programs related to classroom diversity. Signs and announcements in schools are written in major languages spoken by students and their families. The movement toward multicultural education substantially starts from the acceptance level.

The third level in the model of understanding multicultural education is respect. "When differences are respected, they are used as the basis for much of what goes on in schools" (Nieto, 1994, p. 5). This level implies appreciation and high esteem for students' cultural diversity. At this level, teachers create a safe learning environment for all students to talk about issues in the community. Students can share their ideas about historical matters and the role of minority groups in developing their society. Parents are invited to classes to tell stories about their cultures and share life experiences. At this level, students learn to present their stories and learn the story of other minority groups as well, so students will be proud of their culture and respect the culture of others.

The fourth level is affirmation solidarity and critique. At this level, students enroll in respectful dialogue to reflect and critique their own culture and the culture of others to understand the differences of other cultures. This level of understanding multicultural education is based on the assumption that the most potent learning outcome occurs when students cooperate and struggle altogether, even if it is difficult and challenging. It begins with the premise that students' cultural background is accepted as a legitimate vehicle for learning. The conflict between students from diverse cultures, moreover, is what distinguishes this level from the others. Equity and social justice are the big concern for 
multicultural education at this level; therefore, a conflict between students is bound to occur because of the opposed fundamental values of different groups.

Nieto's model "level of multicultural education understanding" will be used to explore the understanding of Saudi teachers regarding multicultural education. Although many other models have been used by other researchers, such as "dimensions of multicultural education" (J. Banks, 2009a), Nieto's model is the best fit in the current study because it examines both teachers' understanding and practices regarding multicultural education.

\section{Importance of the Study}

Despite the fact that there has been significant growth in research in multicultural education, many of these studies do not take into account the Islamic worldview. The belief, history, language, and cultural background of Saudi Arabia differ from other western or eastern countries. This difference emphasizes the need for an in-depth study about multicultural education that takes into account the Islamic and Arab identity.

This study integrates the theoretical aspects of research that have been done in other regions in an effort to explore Saudi educators' perceptions of multicultural education. Because of the importance of using students' cultural backgrounds as a basis for learning new experiences, educators should be able to work effectively with students from various cultural backgrounds. However, Gay (2002) stated that many teachers are not well prepared to teach multicultural classrooms. One of the very few studies that investigated multicultural education in Saudi Arabia was by Al Thowaini (2015), who examined the extent of multicultural education in the Saudi Arabian curriculum by investigating elementary school science textbooks and identifying whether a lack of 
diversity exists in pictorial representation in Saudi textbooks. He also explained the level of awareness for both teachers and curriculum designers about the concept of multicultural education. Al Thowaini (2015) stated that multiculturalism is not represented in textbooks because of the lack of understanding of the meaning of multicultural education from both teachers and textbook developers.

The findings of this current study will promote a better understanding of multiculturalism as it pertains to education in Saudi Arabia. The outcome of this study will assist administrators and teacher-supervisors in Saudi Arabia to understand teachers' perceptions of multicultural education that they can provide professional development opportunities that emphasize the need for multicultural education approach in teaching. The findings of this study, moreover, will contribute to developing a multicultural education approach from Islamic and Arab perspectives that can be applied to other countries in the Arab region.

\section{Nature of the Study}

In the current study, I used a qualitative research approach to explore the perception of Saudi educators regarding multicultural education. Qualitative research, as Saldaña (2011) stated, is a broad concept for various approaches and methods for the study of natural social life. Data collection in qualitative research is nonquantitative in nature - but not exclusively - consisting of verbal materials such as interview transcripts, documents, and field notes, and visual materials such as photographs and video recordings.

The following four characteristics illustrate the nature of qualitative research (Merriam \& Tisdell, 2016): first, the focus in qualitative research is on the process, 
understanding, and meaning. The general purposes of qualitative research are to obtain an understanding of how individuals make sense out of their lives, delineate the process of meaning-making, and clarify how people explain their experience. The second characteristic in qualitative research is that the researcher is the primary instrument for collecting and analyzing data. Since qualitative research aims to develop an understanding, the human instrument is ideal in collecting and analyzing data. The researcher can expand the data collection through verbal and nonverbal communication, clarify and summarize material, and explore unusual or unexpected responses. The researcher, moreover, can identify his biases and observe them, rather than eliminate them, concerning the conceptual framework to express the way of shaping the collection and interpretation of data. The third characteristic is that the process in qualitative research is inductive. Unlike positivists, researchers in qualitative research gather data using multiple ways of data collection to develop concepts, theories, or hypotheses. Therefore, findings in qualitative research are presented in the form of categories, themes, concepts, or theories about certain aspects of social life. The fourth characteristic is that the outcome of the qualitative study is rich in description. The researcher uses words and pictures rather than just numbers to illustrate the understanding of a phenomenon.

The participants in this study were teachers and administrators from two elementary schools. The schools varied in the level of cultural diversity in order to find out how diversity in classrooms influences teachers to implement multicultural education in teaching practice. The participants were engaged in semi-structured, person-to-person interviews with the researcher. The primary purpose of using an interview is to gain a 
particular type of information that could not be obtained by another kind of data collection, such as observation. Interviewing allows the researcher to understand a situation from the participant's perspective because the perspective of other people is meaningful and can be made explicit (Patton, 2015). In order to collect rich data, after the consent from participants, a predetermined set of open-ended questions will be used to elicit participants' responses that can appropriately answer the research questions. All interviews were conducted online via Zoom and recorded for subsequent transcription and analysis.

The conceptual frameworks for the current study are Islamic worldview, sociocultural theory, and multicultural education. The first conceptual framework in the current study is the Islamic worldview, which highlights the beliefs and culture of the community and the population of the study. Islam is the official religion of Saudi Arabia and is embraced by almost all Saudi citizens. Because Islam is a holistic religion, Sharia law or Islamic law - the constitution of Saudi Arabia - which is derived from the Qur'an and the Sunnah of Prophet Muhammed, guides all aspects of people's lives. For Muslims, Islam is not only a religion, but also a culture, a civilization, and a way of life. The long history and spread of the Islamic religion resulted in Islamic culture which has become a culture and a way of life for a large number of people around the world. This variety of using the term Islam - as a religion or a culture - creates confusion when examining social phenomena in a Muslim population. However, in the current study, I considered Islam as a wholistic term that includes both religion and culture that guides the education system and educators' practices in Saudi Arabia. 
This Islamic worldview, as a conceptual framework, matches my belief and cultural background. I, the researcher, am a Muslim who grew up and worked as a teacher in Saudi Arabia. Thus, I am very familiar with Islamic belief, culture, and the education system. According to Merriam and Tisdell (2016), the researcher in qualitative research needs to identify his biases and monitor them in the conceptual framework to clarify the way of collecting and interpreting data. Therefore, this conceptual framework empowers me to acknowledge my beliefs and biases in collecting and analyzing the data rather than eliminate them.

The second conceptual framework emphasizes the importance of cultural background in the learning process. Sociocultural theory, in this study, is used as a primary element of multicultural education because learning develops from interaction with parents and the community before school age. As Vygotsky stated, children are born with elementary mental functions that are later shaped by their culture into higher mental functions (Shaffer, 2008). Culture is a legacy that students inherit from their parents and use as a scaffold to build new learning experiences.

The third conceptual framework in the current study is multicultural education. Multicultural education is a broad concept that advocates achieving education equity and inclusion for all different groups of students. Multicultural education values students' culture and uses it as "a vehicle for learning" (Ladson-Billings, 1995, p. 161). According to Gay (2002), understanding students' cultural elements that are related to teaching and learning is substantial, and many teachers are not well prepared for that. The current study will utilize Nieto's (1994) "levels of multicultural understanding" to find an answer 
to the primary research question, "What are Saudi educators' conceptions of culture and multicultural education?"

\section{Definition of Terms}

- Culture is a combination of three realms: the world of people, the world of objects, and the world of ideas (Bennabi, 2003).

- Multicultural education is defined as a teaching philosophy that rejects racism and discrimination regarding the difference in language and nationality and emphasizes educational equity for all students in a classroom.

- Diverse students are defined as non-Saudi students who are culturally, ethnically, or linguistically different.

\section{Overview of the Remainder Chapters of the Study}

The current study encompasses six chapters, references, and appendices. The second chapter presents an overview of literature related to three main parts: culture, multicultural education, and education in Saudi Arabia. The first section is culture, which includes the meaning of culture and cultural components. The second section explains the purpose and history of multicultural education, theories and research in multicultural education, and implementation of multicultural education in schools. The third section presents an overview of education in Saudi Arabia, the evolvement of culture in Saudi Arabia, and the issue of culture and identity in the Arab world.

The third chapter describes the research methods used in the study. The chapter provides an explanation of the research design, selection of setting and participants, 
method of data collection, and analysis. The chapter includes strategies for issues in qualitative research, such as validity and reliability.

The fourth and fifth chapters provide the answer to the first and second research questions. The fourth chapter presents the case of Central Mecca Elementary school as a school for Saudi students. The next chapter includes the second case of Eastern Mecca Elementary as a school for non-Saudi students. Each of these chapters were analyzed separately based on the participants' responses.

The sixth chapter includes the cross-case analysis for the two cases and the answer to the third research question. The chapter also presents the interpretations of all founded themes. At the end of the chapter, the conclusion, implications, limitations, and recommendations for future studies were included.

The Appendix section was presented at the end of the study, which include the matrix for developing the interview protocols for teachers and administrators, IRB approval, and the consent form. 


\section{CHAPTER 2}

\section{LITERATURE REVIEW}

\section{Introduction}

The main purpose of the literature review is to present an understanding of the existing publications relevant to a research topic. In this literature review, I will analyze and synthesize several publications and research that define and explain the concept of culture and multicultural education. Moreover, this literature review will illustrate the status of education and multiculturalism in Saudi Arabia.

A significant amount of literature has been published regarding multicultural education. The growth of studies in the multicultural education field increased during the last three decades. In reviewing the literature published over a ten year period (19731983), Grant and Sleeter (1986) mentioned that there is an absence of significant research in the field of multicultural education. In a follow-up study, Grant and Tate (1995) found five studies that focused on practicing teaching, and 47 studies for prospective teachers that are related to multicultural education. Grant, Elsbree, and Fondrice (2004) followed up on the research and found 184 studies dealing with multicultural issues in education. Grant and Millar (2017) stated several reasons regarding the lack of quality and quantity of research in multicultural education, such as the unclear manner in presenting the meaning of multicultural education, the limit of financial support, and the demography of 
the majority of higher education faculties which are not conducive to develop research in multicultural education.

Only two studies, written in English, have been found in literature in regard to multicultural education in Saudi Arabia. The first study examined diversity in pictorial representation in school science textbooks in elementary level in Saudi Arabia (Al Thowaini, 2015). The second study focused on understanding the view of international university faculties regarding the cultural background of Saudi students. The study examined the ability of international university teachers to apply culturally relevant pedagogy in Saudi Arabian higher education (Alghamdi, 2014). In addition, there is no study found in literature written in Arabic about multicultural teaching in the Arab region or Saudi Arabia.

In doing this literature review, I used scholarly literature from primary and secondary sources. Peer-reviewed articles, books, dissertations, and further publications that are used in this literature review were found over many databases, including ProQuest Dissertations \& Theses Global, Eric, EBSCOhost, Google Scholar, Saudi Digital Library, and others. The main criteria used in this literature review are multicultural education, education in Saudi Arabia, and cultural diversity in Saudi Arabia. The equivalent meaning of these key terms is also used after being translated into the Arabic language.

In the review of these criteria, several conceptual frameworks have been found, such as culture and education, the issue of culture in the Arabic language, the implication of multicultural education in schools, and cultural diversity in Saudi Arabia. These 
frameworks create a comprehensive picture of the significance of multicultural education and the need for exploring the status of multicultural education in Saudi Arabia.

\section{Culture}

The Meaning of Culture

The meaning of culture has undergone many changes, and publication of Darwin's “On the Origin of Species by Means of Natural Selection” in 1859 is considered a remarkable point in the cultural theory, when it renewed the interest of the origins of human civilization. The 1860s, moreover, witnessed many other works that influenced the idea of culture, such as the work of Charles Lyell "The Antiquity of Man" (Ratnapalan, 2008). A cultural anthropologist, Edward Taylor, who was influenced by the work of Lyell and others, saw culture as a modern concept that exists in modern industrial society. Taylor borrowed the meaning of the word culture from German, where it had been known by an older meaning of cultivation (Kroeber \& Kluckhohn, 1952). He defined culture as a "complex whole which includes knowledge, belief, art, morals, law, custom, and any other capabilities and habits acquired by man as a member of society." (1871,p.1). Later on, however, Taylor's definition was considered as very broad and lacked enough borders (J. Banks, 2015). Another attempt to define culture was made in 1952 by Kroeber and Kluckhohn. In a comprehensive study, they critically reviewed a list of 164 definitions and concepts of culture, and they stated a central idea that is formulated by most social scientists

Culture consists of patterns, explicit and implicit, of and for behavior acquired and transmitted by symbols, constituting the distinctive achievement of human groups, including their embodiments in artifacts; the essential core of culture consists of traditional (i.e., historically derived and selected) ideas and especially 
their attached values; culture systems may, on the one hand, be considered as products of action, on the other as conditioning elements of further action (p.181).

Kroeber and Kluckhohn argued that there is no full theory of culture and this formula will be modified and expanded in the future in regards to the interrelations of cultural forms.

Malik Bennabi, an Algerian Muslim philosopher, provided another definition of the concept of culture and he argued that culture is a combination of three realms: the world of people, the world of objects, and the world of ideas (Bennabi, 2003). The world of people refers to the set of relationships, systems, communications, and laws that rule the lives of persons who make up this society. The world of objects relates to the physical objects that surround the people in their community, such as buildings, streets, and city facilities. It includes tools, natural resources, and instruments needed for the community. The world of ideas is the leading world because humans are distinguished from other creatures by their minds. The world of ideas is all the beliefs and thoughts that one believes in and uses as a guide to lead his behavior (El-Mesawi, 2007). Therefore, the world of ideas has the ability to change the world of people and the world of things. The core of a culture is not the object realm, but how people in society understand and use these objects.

In the last two definitions, Kroeber and Kluckhohn and Bennabi emphasize the aspects of intangible, symbolic, and ideational in the cultural definition. However, other social scientists exclude objects and artifacts from their definition and argue that the essence of culture is the knowledge, rules, and interpretation that are governed by physical objects and not the artifacts themselves (J. Banks, 2015). Hong, for example, states that knowledge is the main dimension of culture and not ethnic and national 
groups; thus he defines culture as networks of knowledge shared by a group of people (2009). Another group of social scientists distinguishes between culture and society. Dimen-Schein, for instance, in her book, The Anthropological Imagination, refers to the word culture for intangible, symbolic, rules, and values that people use to define themselves and the word society for the observable interaction among people (J. Banks, 2015). From the previous explanations of the cultural concept, it appears that the progress in understanding culture is moved from describing culture as objects and norms that govern human behaviors to explaining culture as the knowledge that demonstrates one's behaviors and improved to define culture as an integrated system that encompasses all life aspects.

\section{Cultural Components}

Culture encompasses many elements that shape and influence individuals' cognition and behavior. Teachers, according to Gay (2002), need to understand elements that are related to teaching and learning. For example, educators need to understand diversity between different cultural groups in aspects such as the meaning of life and how that influences their behaviors in classrooms, the interaction between teachers and students in a classroom, and gender roles in different communities for implementing equity in classroom instruction. Banks (2015), moreover, identifies six cultural components that teachers can consider for interpreting the behavior of students in a classroom.

First, values and behavioral styles. The prevailing value is from the main features of culture that differentiate behavior and cognitive thinking for people in different social groups. These values emphasize the beliefs, practices, symbols, norms, and values diffuse 
among people in a society (Schwarts, 2009). People who are sharing the same cultural background have the same prevailing values. In comparing values in two different cultures, Chen, $\mathrm{Du}$, and $\mathrm{Yu},(1991)$ studied the meaning of academic freedom for two different education system groups, China and the United States. In America, they stated, professors have the freedom to lecture about any topic, but that is not the same in China, where professors avoid discussing issues that are not related to their teaching topic.

Students in China show high respect to their professors; stand up and greet professors, raise a hand for permission to ask and answer questions. Professors are the only ones who have the authority to make rules in classrooms. American students, in contrast, "treat college professors as equals" (Chen et al., 1991, p. 32). American students are encouraged to participate in open dialogues and they are free to disagree with their professors and other students. They can answer back to their professors without asking for permission to talk. Although these are different values and behaviors between American and Chinese students, it is not true to generalize these characteristics to describe all the group members.

Second, languages and dialects. Language is a way of thinking and makes meaning in ones' life. Through languages, one can view and make an interpretation of the world. Language, according to Hobbes, “carries our mental discourse (e.g., citizenship) over into verbal discourse, (voting and protest) or the train of our thoughts into a train of words ("I AM A MAN," "I AM A WOMAN," and "Black lives matter")" (as cited in Grant, 2016, p. 3). Through language one becomes aware of himself and the neighborhood and society where he lives. Each cultural group has one or more main languages which the group members use to think and communicate. Deaf cultures, for 
instance, have the language they use to communicate and think. A question was asked in Quoar.com "Does someone who was born with a hearing loss "hear" an inner voice?" A number of deaf people participated in answering this question. Some of them stated that their inner voice is a sign language, pictures, or printed words (Fernyhough, 2014). They use sign language, pictures, and printed words for communication, thinking, and doing mental processes. Therefore, languages have multiple forms; each culture shapes their language in the way they find it valuable to think and communicate and show themselves and their needs.

The third cultural component is nonverbal communication. Nonverbal communication is a way to communicate without words, and it is used mostly to support or modify verbal communication. Nonverbal communication includes body movements, dress, facial expressions, posture, and spatial distance. (Johnson, 1999). Like verbal communication, nonverbal communication has its own grammatical interpretation which explains that it is not uniform in interpretation, but rather a culturally-based way of communication (Sze \& Adetunji, 2012). Eye contact is a nonverbal way of communication that varies between cultures. Looking directly in one's eye, for example, is an indicator of honesty, attentiveness, and interest in some cultures, while it is considered as a way of showing offensive behavior and disrespect in other cultures. Nonverbal language of communication is not universal but culturally based.

Cultural cognitiveness is the fourth component. This component involves the process of knowledge and awareness. It occurs when one recognizes the difference between his own culture and the culture of others. Culture influences how individuals look at the world. In comparing cogitation between eastern and western cultures, studies 
have found that East Asian culture enhances group harmony and contextual understanding, which means that they are holistic thinkers. Western culture, on the other hand, emphasizes personal autonomy and formal logic; thus they are more analytic and pay attention to particular objects and categories (Winerman, 2006). In a study that was done in 2001, Japanese and American students were asked to describe an animated underwater vignette that included focal objects and background objects like rocks, seaweed, and water bubbles. Americans - who focus on personal autonomy - were more likely to start with describing the focal objects, while Japanese - the holistic thinkers were more likely to start with describing things like background objects and the water bubbles (Winerman, 2006).

The fifth component is identification. Cultural identity is a feeling of group belonging. It is a self-conception where an individual sees himself belonging and related to nationality, worldview, or ethnic group. Identity in shaping culture acts as a flag that people stand around. History, religious belief, and nationality are the whole coherent subject that shapes an individual's identity. In earlier history, societies were more stable and identity was not an issue. It was assigned for the whole society by some group members rather than selected or adopted by individuals (J. Howard, 2000). In the current time, many new forms of identities have emerged which make the individual a collection of various identifiers as a result of the change in social structures in which people and their identities are embedded.

The last component is perspective, worldview, and frames of reference. "Cultures are epistemological communities" (J. Banks, 2015, p. 78). That means a specific perspective and view occurs within one culture more than others. Happiness, for 
example, is a goal that each individual seeks to achieve. It is a complex concept that is defined differently based on society's worldview and perspective. In western culture, where people strongly believe in individualism and independence, happiness is defined in terms of personal achievement and is best predicted by self-esteem. In eastern culture, however, where people believe in collectivism and building strong relationships with others, happiness tends to be defined in terms of interpersonal connectedness and is best predicted by the social network that an individual has (Swallow, 2009). Worldviews and perspectives influence an individual's culture which reflects on other cultural components such as cognitiveness and identity.

The relationships between these six elements are very strong. A person's behavior is a reflection of many cultural components and subcultures (J. Banks, 2015). Gender, for example, influences behavior, language, and social class for an individual. All components interact together to impact the behavior of the individual. Moreover, a person belonging to culture does not necessarily have to adopt all the characteristics of that culture; not all Arabs are Muslims and not all Americans are English speakers. Therefore, "we are all multiculturalists now" who are influenced by the subculture of language, belief, gender, and other cultural components.

Issues of Culture and Identity in the Arab World

The issues of culture and identity in the Arab world started early before the collapse of the Ottoman Empire. The weakness and the disintegration of the Ottoman Empire and the separation of some autonomous regions resulted in a conflict in identity and the formation of culture in the Arab region. The division of the Ottoman Empire and the creation of new states in the region were very smooth. After the First World War, the 
Arab region was hit by crises in various fields, including an identity crisis. For a long time, the Arabs were subjected to political marginalization and the denial of the right to represent and manage themselves, which made them divide into two groups: one who saw the necessity of standing with the Ottoman Empire as an Islamic state, and another who saw it a great opportunity to stand with the colonizer against the Ottoman side and then with the independence of their state after that (AL-Tikrity \& AL-Jubouri, 2019). Unfortunately, neither of these options provided a better future for Arabs in the region. The states, which arose from the ruins of the Ottoman Empire, were neither homogeneous nor cohesive. The colonialized carved out the states with little concern over people's demography, geography, or history, which caused a lack of sense of internal cohesion. The Arab states are now struggling between people who believe that they are seeking Islamic identity and others who believe that it should be an Arabic identity. As a result of the failure of these two groups, a third group has emerged and sought a national identity.

The journey of searching for an identity after the Ottoman Empire is also followed by conflict in defining peoples' culture; is it an Islamic culture, Arabic culture, or national culture? Identifying one's culture is faced with many challenges. Culture "Thakafah" is a new concept in the Arabic language. Although the root of this word frequently appears in Arabic literature, the concept culture "Thakafah" does not have a presence until the sixteenth century during the European renaissance, when many literary works were translated into Arabic. Translators were forced to use this term "Thakafah" to express the meaning of culture, as Bennabi (2003) stated. He argued that the difficulty in defining the word culture "Thakafah" in Arabic is that because the word was translated 
from a European language, it should be understood from a Western perspective because the word has real meaning European society which is missing in the Arabic language. Bennabi (2003) stated that the missing meaning in Arabic language is what makes many writers follow the word "Thakafah" by a non-Arabic word such as "culture" to strengthen and clarify the meaning.

\section{Multicultural Education}

Multiculturalism and multicultural education are concepts that were influenced by the United States during the Civil Rights Movement in the 1960s, where eliminating discrimination in education was one of the objectives (J. A. Banks \& Banks, 2010). The goal of multicultural education is to reform educational institutions such as schools, colleges, and universities to provide an equal educational experience for students from different racial, ethical and cultural groups. Multicultural education also emphasizes giving students from different genders an equal education opportunity to achieve success. It provides students with educational experiences that enable them to be an effective part of developing their community (J. Banks, 2015). Multicultural education emphasizes diversity between students and aims to assure equity for all the different groups.

The goal of multicultural education has three dimensions: the individual, the school, and the community. From the individual dimension, multicultural education aims to utilize students' cultural background to impart identity and attitudes in order to empower them intellectually, socially, emotionally, and politically (Ladson-Billings, 2013). It gives students an opportunity to express themselves and show their abilities and excellence. "Education happens elsewhere" (Morris, 2015, p. 174) and the school is not the only place students can learn from. Therefore, teachers are encouraged to use 
students' culture and cultural knowledge as a scaffold to build new educational experiences. Multicultural education, moreover, changes the role of students in a classroom from only receiving to producing knowledge. Students participate in presenting their culture by sharing objects, artifacts, literature, and music to others in their classrooms. Not only the student but also the teacher gains advantage of multicultural education. Teachers in a multicultural education classroom are continuously learning; they learn more about students and their cultural background.

From the school's viewpoint, multicultural education aims to reform educational institutions to actualize educational equality for students from different ethnic, cultural, and linguistic groups. A significant academic achievement gap existed, according to Banks (2009), between group minority, such as Mexican Americans and African Americans in the United States, and other White American students. That gap influenced minority groups to demand educational reform that reflects their cultural identities and background in order to increase their academic achievement. The change and development in multicultural education, moreover, includes the total school environment and is not limited to teachers or textbooks. Educators should consider the school as a social system that has many variables that interact with each other such as school policy and politics, school culture, and hidden curriculum and teaching style and strategies. The improvement of any one of the social system variables, as Banks (2010) states, is not sufficient, but all the variables should be improved simultaneously.

Multicultural education from the community perspective is influenced by the social reconstructionist ideology of educators such as Paul Freire, who argued that students should participate in developing their community (2000). Multicultural 
education is intended to prepare students to be effective citizens by providing them with educational experiences that enable them to preserve commitments to their cultural community (J. Banks, 2009a). Promoting democracy is another goal of multicultural education. Ladson-Billings (1995), for instance, stated that academic success is not a goal by itself for teaching culturally diverse students, but it is a way to give a voice for all students to participate actively in a democracy. Multicultural education aims to promote equity and social justice between students in school and encourages them to promote that in their communities.

A great number of researchers define multicultural education. Gay (1994) analyzed the most frequently used definition of multicultural education over two decades (1973-1992), and she stated several common points that was included in multicultural education; ethnic identities, cultural pluralism, the distribution of resources and opportunities, and sociopolitical issues regarding long histories of oppression. She argued that multicultural education "means different things to different people" $(1994$, p. 5). Nieto (2010), for instance, stated that multicultural education is a philosophy and a way to look at the world but not a course, activities, or simple program that is taught to students in a certain period of the school year. Nieto provides a comprehensive definition of multicultural education in a sociopolitical context;

... a process of comprehensive school reform and basic education for all students. It challenges and rejects racism and other forms of discrimination in schools and society and accepts and affirms the pluralism (ethnic, racial, linguistic, religious, economic, and gender, among others) that students, their communities, and teachers reflect. Multicultural education permeates the schools' curriculum and instructional strategies as well as the interactions among teachers, students, and families, and the very way that schools conceptualize the nature of teaching and learning. Because it uses critical pedagogy as its underlying philosophy and focuses on knowledge, reflection, and action (praxis) as the basis 
for social change, multicultural education promotes democratic principles of social justice (p. 68).

This definition has several characteristics for multicultural education, as Nieto states. "Multicultural education is an antiracist education." Understanding antiracism enlightens educators to critique their perception and the school policies and practices showing favoritism toward some students over others and making the school curriculum appropriate for them. The multicultural approach is basic education. Multicultural education must be seen as basic in the education field. The need for multicultural education is the need for teaching other subjects such as reading, writing, and mathematics. Considering multicultural education as the core curriculum gives it the attention of teachers, students, and parents.

Multicultural education is for all students. The widespread misunderstanding is that multicultural education is only for students of color, students with disabilities, students at risk, or students in any minority groups. Multicultural education is "inclusive" for all students from all cultural groups to empower them to be proud of their culture and respect the culture of others. Multicultural education, moreover, is pervasive. It is an approach that permeates every section of the school curriculum. It appears in the school climate and physical environment. It is reflected in the relationship between teachers, students, and their parents. The multicultural education approach is apparent in every lesson, curriculum guide, and letter that is sent home.

Multicultural education is an education for social justice. The phrase "social justice" has been widely used in the field of education as an educational reform movement and as a conceptual framework for approaches such as multicultural education. Social justice in education is defined as a goal and process (Hackman, 2005). 
The goal is to provide educational equity for all groups of society to meet their needs. The process for achieving the goal of social justice is by participating in democracy and empowering students to work collaboratively in developing their community. Education for social justice does not merely emphasize diversity and cultural difference but it focuses on the way of distributing educational resources that empower students.

Other multicultural education specialists such as Grant and Banks define multicultural education in a broad meaning. In defining the concept, Grant (2016), for example, argued that "it is fluid and continually undergoes modification to meet the needs and demands of an ever-changing society" (p.4). Banks (2009a), moreover, states that it is an approach to school reform that aims to actualize educational equity for students from different cultural, ethnic, and linguistic groups. The broadness of the scope of multicultural education to include diversity in all groups such as gender, disability, and social class among other social and cultural differences diminishes the main purpose of multicultural education, which is to prevent discrimination and racism among marginalized students, lose its importance (Gay, 2010).

\section{The History of Multicultural Education}

The first introduced of the term "Multicultural education" was in the field of adult education by Horace Kallen in 1915, and the term expanded on by Alain Locke in 1925 (Johnson-Bailey \& Drake-Clark, 2010). The civil rights movements were the motivations of multicultural education reform. Seeking equity and social justice, and the emergence of the school desegregation movement during the 1960s and 1970s raised a multicultural education reform and the development of multiple theories and teaching practices that focus on culturally and ethnically diverse classrooms (Aronson \& Laughter, 2016). 
Multicultural education emerged as a reform during the Civil Rights movement in the 1960s, where eliminating discrimination in public education was among the major goal of that movement (J. Banks, 2010). Educators and schools, initially, responded to this movement by developing elective courses and programs that were primarily taken by students from certain groups to achieve the needs and demands of these various groups (Banks, 2010). To track and understand the history of multicultural education, Banks $(1993,2015)$ illustrates four phases that show the development of the concept in the school curriculum.

Monoethnic courses are the first phase. During the civil rights movement, schools and educators responded to the needs and demands of minority groups. This response translated as courses that were established to teach history, culture, music, and literature of the minority groups. Courses were mainly taught by a member of a group who emphasized the role of White people in oppressing other ethnic groups.

The second phase in the history of multicultural education is multiethnic studies courses. The increase in the number of courses that were taught by different ethnic groups, including White ethnic groups such as Polish American, led educational institutions such as colleges and schools to find multiethnic studies courses that focused on several ethnic groups. Students were studying the history of minorities, cultures, and music from comparative perspectives (Banks, 2015).

Multiethnic education is the third phase. The spread of the ethnic studies in many educational institutions and the increase in the number of educators who recognized that it was not sufficient to develop an educational reform were factors to the emergence of the third phase. Educators recognized that the ethnic and multiethnic studies courses were 
not able to make progress in the achievement of students from minority groups compared with the achievement of White students. The aim of multiethnic education was to improve and increase the educational system equity (J. Banks, 1993). Therefore, educators began to call for another educational reform that focused on the school environment as a unit of changing the community (Banks, 2015).

The fourth phase is multicultural education. This phase takes the multicultural education concept to a new level. It emerged when other cultural groups such as women, people with disabilities, religious groups, and different social class groups viewed themselves as victims of society. The demand for these groups was to present their cultures, histories, and voice in the school curriculum as well as multi-ethnic groups (Banks, 1993, 2015). This shift of the concept made the multicultural education movement very broad and universal and made issues such as racism and educational segregation, which are the main focus of multicultural education, might become lost or deemphasized (Gay, 2010).

The current status of the multicultural education movement is not limited to the last phase. When a new phase emerged, the previous phases continued, but in a modified and limited way (Banks, 1993, 2015). The first phase, for example, became more conceptualized by the time the second phase appeared. The last phase, however, tends to be more distinguished than the earlier ones, in both the theory and practice. Theories such as culturally responsive teaching (Gay, 2010), culturally relevant pedagogy (LadsonBillings, 2013), and multicultural education (J. Banks, 2015) have generated lists of characteristics about multicultural education to assist educators to understand and shape 
students' strengths in their schools (J. Banks, 2013). These theories take advantage of students' cultural and prior knowledge and use it as a bridge to students' minds.

\section{Theories and Research in Multicultural Education}

Multicultural education has influenced many theories and research in the field of education which lead to substantial growth in that area for the last two decades. Sources such as Handbook of research on multicultural education (J. Banks \& Banks, 2004) and Research and multicultural education: from the margins to the mainstream (Grant, 2017) present research, concepts, theories, and practices in the context of multicultural education. The Routledge international companion to multicultural education (J. Banks, 2009b), moreover, is another source that presents a global experience for the implementation of multicultural education.

Theories that focus on ethnic identity development significantly influence research and practice on multicultural education. Students experience their racial identity in multiple stages; personal experiences, social contacts, and sociopolitical realities influence areas such as teacher education and intergroup relation (Nieto, 2009). Theories on learning style, in addition, have influenced multicultural education. Many theories related to learning style emphasize that culture has an impact on how people learn (Nieto, 2009). The $21^{\text {st }}$ century had a great shift in multicultural education. The massive global immigration and demographical change in many areas meant that the simple definition of multicultural education that emphasizes race, gender, and social class was no longer sufficient. Therefore, new fields were added to multicultural education such as postmodernism, postcolonialism, feminism, and critical race theory (Nieto, 2009). 
The globalization of the field of education is another significant factor that influenced multicultural education. Many scholars in multicultural education in the United States recognized the importance of international connections in the development of the field. For example, Banks (2009b) has done significant work in that by publishing the book, The Routledge international companion to multicultural education, that provides international experience for implementation of multicultural education.

Teachers' preparation programs were shifted to emphasize the need for equity and social justice in many international educational institutions. Examples for that can be seen in the work of Alghamdi (2014) when she examined diversity in higher education in Saudi Arabia. She concluded that international professors face difficulties in understanding students' language and cultural background and she recommended that Saudi universities should develop training programs that enable international professors to understand students' culture and language. Another study was done by Lim, Tan, and Saito (2019) who interviewed and observed five teachers in order to examine the experience of Singapore teachers in developing an education system that takes into account cultural diversity in classrooms. Alnawar (2015), moreover, explored teachers in the United States to find out attitudes toward students from Middle-Eastern countries. These studies and many others are emphasizing that multicultural education is within the main educational objectives in many countries.

\section{Implementation of Multicultural Education}

There is general agreement among educators that for a successful implementation of multicultural education, the education reform should include a change in a school curriculum: teaching and learning styles and teaching materials. It also should include a 
change in teachers' and administrators' attitudes and perceptions; the goals and culture of schools (J. Banks, 2015). Viewing multicultural education only from ethnic and cultural groups' differences negatively affects teachers' perception in implementing multicultural education. Multicultural education is a concept, education reform, and process (J. Banks, 2010) that includes all the curriculum elements.

In his book, We can't teach what we don't know, Howard (2006) examines the reasons underlying the cultural mismatch between students of color in urban schools and their White teachers. Teachers' knowledge and understanding of students' culture is important to achieve the pedagogical needs. Danielson (2007), for example, stated that knowing students and their background is important to prepare and design instruction. Because culture is a very complex concept, teachers need to understand elements that are related to teaching and learning in classrooms. For example, educators need to understand diversity between different cultural groups in the meaning of life and how that influences their behaviors in classrooms, the interaction between teachers and students in a classroom, and the role of both genders in their community (Gay, 2002). Understanding students' cultural background will strengthen the relationship between students and their teachers and facilities to make a classroom a safe learning environment.

Multicultural education is an educational reform movement that emphasizes equity and social justice in education. The goal of multicultural education is to ensure that all students - regardless of their culture, gender, belief, and social class - will have an equal educational opportunity. To fulfill the gap between theory and practice in multicultural education, Grant and Sleeter (2010) state five different approaches that a teacher can use to implement multicultural education and ensure educational equity in a 
classroom. These five approaches take into consideration teachers' perspectives and beliefs about the aim of education and the relationship between schools and communities.

The first approach is teaching of the exceptional and the culturally different. It is an approach that is used often with low-performance students. This approach aims to provide students with information, concepts, cognitive skills, language, and values that enable them to have a good job and be effective in their social institutions in communities. Teachers using this approach believe that one of their responsibilities is to empower all students to fit into the school and community (Grant \& Sleeter, 2010). Using this approach requires teachers to determine students' performance levels and use it as a starting point to build new knowledge.

The second approach that Grant and Sleeter (2010) state is the human relations approach. The goal of this approach is to encourage students to promote tolerance and acceptance between each other. Teachers who follow this approach believe that the school should aim to teach students how to live together peacefully in a culturally diverse community. Using this approach enables educators to build a strong relationship between teachers and their students and between students themselves. It creates a positive feeling among students in a diverse classroom which will enable students to be proud of their culture and respect other cultures.

Single-group study is the third approach. This approach aims to increase the social status of a particular group of people by providing historical information about the group and how it has been oppressed (Grant \& Sleeter, 2010). Teachers who use this approach argue that knowledge taught in schools reinforces the power and the control of the white men over every other ethnic group. In this approach, teachers work with their 
students to study in-depth an oppressed group in order to empower, develop a sense of consciousness and pride, and offer historical information about the oppressed group. The single-group study approach improves students' ability in developing and making an appropriate decision on issues regarding culture, language, belief, and race in their community (J. Banks, 2008). Single-group study has also been used as an approach in designing school curriculum by including units about history and culture in order to present the power and pride of multiple oppressed group members.

The fourth approach is multicultural education. Unlike the three previous approaches, the multicultural education approach advocates total school reform and makes the school reflect the real diverse world in the community. The goal of this approach, according to Grant and Sleeter (2010), is "to reduce discrimination against oppressed groups and to work toward equal opportunity and social justice for all groups" (p.67).

The last approach is the multicultural social justice education. This approach is rooted in social reconstruction ideology. Educators who follow that ideology, such as Freire (2000), argue that students should be effective participants in developing their community. Teachers who believe in this approach claim that the purpose of the school is to prepare future citizens who are able to improve their society and solve its problems (Schiro, 2012). The multicultural social justice education approach aims to prepare students to be good citizens who are able to spread respect and equity for all community members.

These five approaches presented by Grant and Sleeter (2010) show different perspectives for implementing multicultural education in a school and classroom. These 
approaches vary based on the purpose of education that reflects teachers' beliefs and the level of application. The fourth approach, for example, is a school reform that requires all school members to participate effectively to make it successful, while the other approaches are mainly focusing on the classroom level.

\section{Education in Saudi Arabia}

The Arab peninsula had not received much attention during the Ottoman Empire. At the time before the foundation of the Kingdom of Saudi Arabia, education was founded in mosques and Qur'anic institutions, where the curriculum was limited to teach students how to read and write to have a better understanding of the Holy Qur'an. In addition to public education, the private sector had played an important role in developing education in the region by founding many schools in the main cities such as Mecca, Jeddah, and Madinah (Mani \& Sbit, 1981). In 1925, the education system had a big development in the founding of the Directorate of Education. The main principle of the Directorate of Education was to provide free education to everyone by establishing new schools and education offices across the kingdom (Mani \& Sbit, 1981).

December 1953 witnessed a big jump in the development of education when the Saudi government established the Ministry of Education as a way of transferring to modern education. The role of the Ministry of Education is to found schools, train teachers and develop the school curriculum. The need for the foundation of this Ministry was to make progress in the number of schools around the country which was a big challenge in front of the Directorate of Education to carry out. This increase in the number of schools through the country made the Ministry of Education realize the necessity of finding the Office of the Director of Education in each city in order to be 
responsible for schools in its cities (Ministry of Education, 2008). The role of the Ministry of Education also was to take responsibility for the country's progress in many other ways by investigating the future needs of the country.

Education in Saudi Arabia is based on the Islamic religion and the Arabic culture. One of the key goals of education is to raise Muslim students who have a comprehensive understanding of Islam. Mani and Sabìt emphasize that the purpose of education in Saudi Arabia is to help students to have "the correct understanding of Islam and the inculcation and dissemination of the Islamic creed; the imbuing of the student with Islamic values, doctrines and ideals; the imparting of the various types of knowledge and skills; the social, economic and cultural development of society; and the preparation of the individual to be a useful participant in the building of his society." (1981, p. 14). This goal of education reflects in Saudi citizens' life to make Islam the main religion, and almost all Saudis are Muslims.

In 2016, the Saudi government established an ambitious plan to improve the country in all areas. This plan is known as "Saudi Vision 2030". Education has an important part of this new vision and the government has identified the educational goals to empower the transformation from total dependence on oil to rely on human power. In order to achieve this goal, the school curriculum will emphasize the skills that are needed for a modern economy, which include vocational, technical, and higher education (Kahn, 2016).

The new education system aims to reduce the differences between the higher education outcomes and the needs of the labor market by having students participate in effective training programs that improve their fundamental skills (Saudi vision 2030, 
2016). Baqadir (2013) argues that there is a big gap between education outcomes and the labor market needs in both the public and the private sectors in Saudi Arabia. This gap is because of the low quality of the learning outcomes as well as other social-cultural, and economic issues. The Saudi government aims to decrease the gap between education outcomes and the labor market by developing the higher education system and increasing the income of the employee in the private sector.

\section{Issues of Education in Saudi Arabia}

Since the beginning of public education in Saudi Arabia in the 1960s, the traditional education approach has been the backbone of the school curriculum. The teacher is the transmitter of the information and the student is the ineffective receiver. Alisa, (العيسى, 2009), the education minister between 2018-2015, stated the situation of Saudi Arabian education in his book written in Arabic, Education Reform in Saudi Arabia. The education system in Saudi Arabia is sufficient for preparing employees who are doing what they have been asked to do and not for preparing thinkers, scholars, and influencers. Those thinkers, scholars, and influencers are exceptions, who have their own way to educate themselves by self-learning or studying abroad.

Alghamdi (2014) and Hamdan (2014), moreover, argue that the Saudi Arabian school curriculum demonstrates many aspects of what Freire (2000) called "the banking concept of education". In this banking system, "instead of communicating, the teacher issues communiqués and makes deposits which the students patiently receive, memorize, and repeat." (p.72). Freire criticized this banking system approach and emphasized the importance of establishing an open-ended dialogue and engaging students in a peaceful classroom environment. Teachers in Saudi Arabia, in accordance with Freire's pedagogy, 
are not keen to engage students in an open-ended dialogue during the education process, but instead, they transmit knowledge that is predominantly immaterial to learners (Hamdan, 2014). Many of them are following what Schiro (2012) calls a "scholar academic" teaching approach, where the communication in the classroom takes one way from the teacher to students. That does not give the teacher the opportunity to listen and learn from students. The teacher does not know much about students; their cultural background, their learning style, and their prior knowledge.

\section{Evolvement of Culture in Saudi Arabia}

The number of diverse ethnic groups in Saudi Arabia has increased rapidly over the last years. Statistics released by the General Authority for Statistics in Saudi Arabia show that the percentage of the non-Saudi population was 31 percent in 2010, and this percentage increased to 37.8 in 2019 (2019a). The three main sources of the non-Saudi population are foreign workers who perform specific jobs, Muslims immigrants who left their homes and moved to the western region of the Arab peninsula before and after the establishment of the Kingdom of Saudi Arabia, and Muslim visitors and pilgrims, who visit the sacred sites in the Holy city of Mecca in certain times of the year.

Foreign workers are the first and foremost source of the non-Saudi population. History shows that Saudi Arabia was one of the poorest countries in the middle east before oil was discovered in the late 1930s (El-Ghonemy, 2001). Oil production, in the beginning, required foreign expertise and labor to exploit the vast oil reserves in the country. Some of the workers came with foreign oil companies, and the majority came from other Middle Eastern countries such as Palestine, Egypt, and Syria (Gibney \& Hansen, 2005). The great increase in the number of foreign workers followed the 1973 oil 
crisis which supported the country, as oil providers, to improve infrastructure and development plans. This improvement led to an influx of workers from Arabic countries and other Asian countries such as India, Pakistan, Thailand, Philippines, and South Korea (Gibney \& Hansen, 2005). The number of foreign workers is still large today where their estimated number was over nine and a half million during the second quarter of the year of 2019, according to the General Authority for Statistics in Saudi Arabia (General Authority for Statistics, 2019b).

The Mecca region contains the second-highest number of foreign workers after the capital of the country, Riyadh, with approximately a million and a half workers (General Authority for Statistics, 2019b). Many of those workers moved with their family to live together in Saudi Arabia, which increases the number of non-Saudi population. The population of non-Saudis in the region of Mecca is about three million and the workers are only half of this number. The number of students who attend schools and universities was about 558,351 students, in the year of 2019, with a percentage of 39.6 from the total of students in the region (General Authority for Statistics, 2019b).

Muslim immigrants are also an important source of foreign people in Saudi Arabia. Since the mission of Prophet Muhammad PBUH, Muslims began moving to the Holy cities of Mecca and Medina, which made them highly diverse cities that include a large number of Muslims from different ethnic and cultural backgrounds. During the last century, after the establishment of the Saudi state, the migration of many Muslims from some conflict areas to Mecca and Medina continued. The two Holy cities have witnessed

many immigration movements from southeastern Asia and eastern Africa (الثيعاني, 2011). A large number of those immigrants were able to obtain Saudi citizenship, but there are 
still others who could not obtain it and be granted permanent residence in Saudi Arabia. Statistics from 2010 indicate that the number of non-Saudis in the city of Mecca amounted to approximately three million people, which accounts for over a third of the total population in this city, according to the General Authority for Statistics in Saudi Arabia (2019a).

The Muslim-Myanmar community is the largest immigrant community in the country. Throughout four great immigrant movements between 1948 and 1971 (الثيعاني, 2011), their population is over a half-million people whose majority are living in Mecca (السويهري, 2013). The Muslim-African community is another large group of immigrants who select the Holy city of Mecca to start a new phase of their life. The immigration movement from Africa started very early, before the unification of the Kingdom of Saudi Arabia (الثيعاني, 2011). Many Muslim immigrants prefer Mecca to be their new residence where they have the freedom to practice their Islamic religion in peace.

Many immigrant groups established their own charter schools to teach their children. Charter schools in Mecca began to spread long before the unification of Saudi Arabia. These charter schools are funded by parents and people from the community and later on by the Office of the Director of Education in Mecca. This spread, however, began to lead to a lack of organization, which led to the loss of many students as a result of the unsuitable environment for education (الثيعاني, 2011). عطار (2004, 2007) has explored 57 charter schools for Myanmar and African charter students and he stated that the school buildings for many of these charter schools do not have sufficient school equipment such as whiteboards, air-conditioners, and teachers' rooms. Many students who attended these 
charter schools were living in poverty, thus they were in need of school supplies and free breakfast and lunch. Teachers, moreover, at these schools were not well prepared and some of them did not have a college degree.

The Office of the Director of Education in Mecca has instituted two educational reforms to ensure educational quality at these charter schools. The first educational reform was in 1993 which aimed to decrease the number of charter schools by transferring students who have legal residency to the nearest public schools. The remaining charter schools will be provided with curriculum and well-prepared Saudi teachers and school principals (الثيعاني, 2011). The second reform began in 2014 with the establishment of the office of education and supervision of charitable communities' schools under the Office of the Director of Education in the Mecca region. This movement targeted over seventy thousand students by establishing 121 new schools under the watchful eye of the Office of the Director of Education in Mecca (العربية, 2016). These reform movements increased the level of schools' diversity in the Holy city of Mecca by closing many charter schools and transferred a big number of non-Saudi students to the public schools to study along with other students which emphasize the need for multicultural education practice in classrooms.

The third group is Muslim pilgrims and visitors. Throughout the year, the city of Mecca receives large numbers of pilgrims and visitors who come from around the globe to visit the Holy Mosque and other sacred places on the city. The number of pilgrims, for example, in the year of 2019 was approximately two million and three hundred thousand, over one and a half million were coming out of the country, according to the General Authority for Statistics in Saudi Arabia (2019a). On the other hand, the number of 
vوصول "، (visitors who came outside the pilgrimage season was over six million visitors (أكثر من 6.9 مليون معتمر إلى الملكة وإصدار أكثر من 7.4 مليون تأثيرة عمرة," This huge number of people who visit the Holy city from all around the world emphasizes the need for multicultural education in schools. Students who live in this global city should be educated to be "cosmopolitan citizens" (J. Banks, 2009a, p. 10) who are able to communicate and understand visitors from various cultural perspectives.

Multicultural education is a reform movement that provides students from different racial, social classes, languages, and cultural backgrounds equal opportunity to achieve their educational potential. In this regard, this study will take place in the Holy city of Mecca, where teaching in public schools is limited for Saudi citizens, to investigate how Saudi teachers implement multicultural education with their students in classes. 


\section{CHAPTER 3}

\section{METHODOLOGY}

\section{Introduction}

In modern history, cultural diversity in Saudi Arabia was increased by the discovery of oil in the 1930s, where many forging workers from Middle Eastern countries came along with oil companies and their foreign expertise (Gibney \& Hansen, 2005). Another factor of the rapid increase of cultural diversity was the migration of many Muslims from several parts of the world to the Holy cities of Mecca and Madinah (الثيعاني, 2011). These two factors accelerate the cultural diversity and demographic change in the country.

The current study is designed to develop an understanding of the beliefs and practices of educators in Saudi Arabia with respect to multicultural education. The study has three primary research questions that explore and examine educators' attitudes and practices in culturally diverse schools.

1. What are Saudi educators' conceptions of culture and multicultural education?

2. What practices do educators employ concerning multicultural education?

3. How do educators implement multicultural education for their students at schools with different levels of cultural diversity? 


\section{Qualitative Research Design}

In the current study, I used the qualitative inquiry approach to explore how educators in Saudi Arabia interact with students from different cultural backgrounds. Qualitative research has multiple definitions that reflect the complexity of the term. Saldaña (2011), for example, defines qualitative research as a wide concept for various approaches and methods for the study of natural social life. Another old definition for qualitative research was in 1979 by Van Maanen; qualitative research is "an umbrella term covering an array of interpretive techniques which seek to describe, decode, translate, and otherwise come to terms with the meaning, not the frequency, of certain more or less naturally occurring phenomena in the social world" (as cited in Merriam \& Tisdell, 2016, p. 15). The interest of qualitative research, therefore, is to understand the meaning people constructed; how people cope in their real-world settings (Merriam \& Tisdell, 2016; Yin, 2016).

There are several reasons for choosing qualitative inquiry; the first reason for using qualitative research is to develop an understanding of the status of multicultural education in Saudi Arabia. The primary purpose of qualitative research is to develop an understanding of how individuals make sense of their lives and interpret what they learn (Merriam \& Tisdell, 2016; Yin, 2016). The second reason for using a qualitative research method is that it enables the researcher to identify his own biases and worldview and observe them concerning the conceptual framework. Creating a relationship between the researcher's worldview and the conceptual framework of a study clarifies the way of collecting and interpreting the data (Merriam \& Tisdell, 2016). The third reason is that qualitative research allows a researcher to explore an issue or a phenomenon. The 
exploration in the current study is needed because educators believe and practice regarding multicultural education cannot be understood by using instrument like survey. The exploration is also needed because there is no sufficient literature or result from other studies the current study can rely on.

In the current study, I conducted a qualitative case study research design. Qualitative research is based on the belief that human knowledge is constructed by engaging in activity, experience, or phenomenon. A qualitative case study design is defended as investigating a real-life contemporary bounded system in an in-depth data collection that involves multiple sources of data to report a case description and themes (Creswell \& Poth, 2018).

Merriam and Tisdell (2016), moreover, stated that the case study can be comparative studies, multisite case study, to involve collecting and analyzing data from multiple cases. In the qualitative case study design, the data are collected through observation, interview, or document analysis. The analysis of the data is about identifying patterns or themes that characterize the collected data. The overall interpretation will be an understanding of the studied phenomenon.

\section{Researcher as an Instrument}

I was born and raised in Mecca from a Muslim family. My birth and upbringing in Mecca had a major impact on shaping my Islamic identity. Mecca is the Holy city for all Muslims around the world, as it is visited every year by millions of Muslims for visiting and pilgrimage. Like many people who grew up in Mecca, I started my educational life, early before enrolling at the public school, by joining the Qur'anic schools. The Qur'anic schools are evening schools that took place in mosques and they existed in each 
neighborhood. The primary purpose of the Qur'anic schools was to teach the Holy Qur'an and Islamic education.

My formal education began at school like any other child. The goal of the school curriculum was not very different from that of the Qur'anic schools. The school curriculum was based on the Islamic educational theory, which "aims at the balanced growth of the total personality of man through the training of man's spirit, intellect, the rational self, feelings and bodily senses." (cited in Yasin \& Jani, 2013, p. 3). There was a great harmony between the public schools and the Qur'anic schools in the society, where many Qur'anic schools were led and supported by public school teachers. This integration between the public schools and the Qur'anic schools created a Muslim community that worships Allah and loves to help each other.

My interest in multiculturalism and multicultural education was a result of two important stages in my life. First, being raised in Mecca which I consider being the beginning of recognition and interest in cultural diversity. From an early age, my parents used to take me to the Holy Mosque which introduced me to the cultural diversity among many Muslims in that place. Despite the differences in language, race, and social classes, there was no distinction from one to the other, as all gathered in one place at the same time.

The second stage was my journey to study in one of the most diverse universities in the United States. Studying at Andrews University gave me an opportunity to know people from many cultures and philosophical worldviews that are different than what I had experienced in Mecca. I would never forget what a professor said about his course objectives. "The goal is to be a good Muslim." It was a course that had a significant 
change in my life and helped me to think about the world from a different perspective that I have not thought about before. The course was philosophical foundations for professionals, which helped me to look at myself as a Muslim and be proud of that, while at the same time look at others and respect their point of view and way of thinking because they are looking at the world from a different worldview. I consider these two stages, arise in Mecca and study at Andrews University, as the motivation behind my interest in multiculturalism and multicultural education.

\section{Ethical Protection of Participants}

Ethical issues arise during several stages of the research process, and these issues expand in a domain as a researcher becomes aware of the participants' needs. "A common misconception is that these issues only surface during data collection" (Creswell $\&$ Poth, 2018, p. 53). In examining the ethical issues, I conducted Creswell \& Poth (2018) strategy to examine ethical issues as they apply to different stages of the research process.

The first stage is prior to conducting the study. At this stage, I applied for IRB approval from the institutional review board at Andrews University for conducting this

study (Appendix C). IRB approval depends on three principles: respect for persons, beneficence, and justice (Andrews University: Institutional Review Board Handbook, 2007). Respect for persons encompasses that participants in the study should be treated as independent agents which require informed, voluntary agreement to participate in the research and that participants are entitled to protection. Beneficence involves researchers to ensure the safety of the participants. Justice means that participants should be treated fairly in the distribution of the benefits and risks related to the study. 
At the beginning of conducting the study. Participants were aware of the purpose of the study and had the right to stop participating at any time during the study (Appendix D). As a researcher, I showed respect to the participants' norms and characteristics, where I agreed with some participants to turn off their camera during the online interview. During the data collection, the participants had acknowledged the purpose and the use of the study data. In the research question, I avoided include leading questions, disclose sensitive information, and withhold sharing personal impressions.

During analyzing and reporting the data, I introduced schools and participants by assumed names to respect the teachers' privacy. I avoided being on a side with one participant by reporting multiple perspectives for the phenomenon study.

\section{Sample and Data Collection}

Data collection in the qualitative study involves much more than the procedures for gathering data. Data collection involves gaining permissions for data collection, conducting a qualitative sampling strategy, developing means for recording information, and storing the data securely (Creswell \& Poth, 2018). In the process of collecting data

for this study, I introduced the environment of the study, the large population, strategy for selecting sampling, and method for gathering data from participants.

\section{Selection of Settings and Participants}

The study was conducted at the Holy city of Mecca in Saudi Arabia, which is one of the most highly diverse cities in the whole country. The Office of the Director of Education in the Mecca region includes 1,603 schools, of which 706 schools are for boys and 897 schools are for girls. Approximately 15,927 male teachers teach on the boys' 
schools and 15,279 female teachers work in girls' schools. The number of students in schools in the region of Mecca is 409,780 students. Statistics of the Office of the Director of Education in Mecca indicate that the percentage of Saudi students out of the total number of students is $63.7 \%$ and more than one-third of the students are non-Saudis; their percentage is $36.3 \%$.

I selected schools in the Mecca region for several reasons. First, I was born and grew up in the city of Mecca and I studied all my education levels in it. Later on, I became a teacher in the same city where I grew up. I am familiar with the cultural diversity in many school districts and now I wonder how teachers deal with this diversity in their classrooms. The second reason is that the Mecca region occupies the largest percentage among other regions in the country in terms of the number of non-Saudi population, where the number of non-Saudi population from all age groups is approximately 2.8 million people and the number of the Saudi population is about 4.1million people. Another reason is that Mecca is the Holy city of all Muslims, that has the Holy Mosque and the sacred sites, which are visited annually by more than 10 million Muslim visitors from around the world. Therefore, multicultural education in a global city like Mecca enlightens students to accept and respect visitors from different ethnic and cultural groups.

\section{Sampling Strategy}

For the sample selection, I used a purposeful sampling strategy. The purposeful sampling strategy enables the researcher to select a sample that provides rich information to develop an in-depth understanding of specific phenomena (Patton, 2015). It is based on 
the assumption that the researcher wants to select a sample from which he can learn more, that he can discover and understand the phenomenon. In this case study, it is necessary to have two levels of sampling (Merriam \& Tisdell, 2016). The study primarily focuses on identifying cases in which schools have different level of cultural diversity. To identify these cases, four criteria were developed to guide the selection of the schools. The first-level sampling criteria were (1) elementary school, (2) in the region of Mecca, (3) boys' school, and (4) high percentage of non-Saudi students. For the second case I used the following criteria; (1) elementary school, (2) in the region of Mecca, (3) boys' school, and (4) high percentage of Saudi students. For each case, I purposefully selected a school with a total of two schools.

The second-level sampling criteria require the selection of two groups of participants: teachers and administrators. Teachers were selected to explore their teaching perceptions and pedagogy related to multicultural education. From each school, I selected two teachers with a total of four teachers from both schools. Administrators, moreover, were selected to explore the perception, the process of school enrollment, the relationship between parents and schools, and the role of schools in developing their communities. 
Table 1

Participants' information

\begin{tabular}{|c|c|c|c|c|}
\hline Name & Teaching subject & Level of Education & $\begin{array}{c}\text { Years of } \\
\text { Experience }\end{array}$ & School \\
\hline Fayez & Vice school principal & $\begin{array}{l}\text { Ph.D. in Islamic } \\
\text { Education }\end{array}$ & 19 & 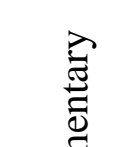 \\
\hline Bandar & First-grade & $\begin{array}{l}\text { Bachelor's degree } \\
\text { in Dawah and } \\
\text { Fundamentals of } \\
\text { Islamic Religion }\end{array}$ & 23 & 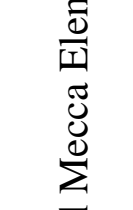 \\
\hline Mosh & Mathematics & $\begin{array}{c}\text { Bachelor's degree } \\
\text { in Teaching } \\
\text { Mathematics }\end{array}$ & 12 & 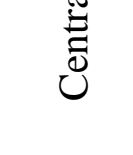 \\
\hline Saeed & School principal & $\begin{array}{c}\text { Bachelor's degree } \\
\text { in Islamic } \\
\text { Civilization }\end{array}$ & 27 & 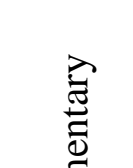 \\
\hline Khaled & Mathematics & $\begin{array}{c}\text { Bachelor's degree } \\
\text { in Teaching } \\
\text { Mathematics }\end{array}$ & 16 & $\begin{array}{l}\frac{0}{1 I} \\
\frac{\pi}{0} \\
\int_{\Sigma}^{e}\end{array}$ \\
\hline Yasser & Third-grade & $\begin{array}{c}\text { Ph.D. in Arabic } \\
\text { Language }\end{array}$ & 17 & $\begin{array}{l}\tilde{\tilde{n}} \\
\tilde{I}\end{array}$ \\
\hline
\end{tabular}

\section{Data Collection Method}

Literature has shown a new form of data collection that emerges, but all forms can be grouped into four main types; interviews, observations, document analysis, and audiovisual materials (Creswell \& Poth, 2018; Merriam \& Tisdell, 2016; Yin, 2016). In the current study, I utilized interviews as a method for collecting data. According to 
Saldaña (2011), an interview is a method that many qualitative researchers have used to gather data from participants because it is an effective way to document participants' perspectives, feelings, beliefs, opinions, and attitudes regarding their personal experiences. The research interview is defined as "a process in which a researcher and participant engage in a conversation focused on questions related to a research study" (deMarrais, 2004, p. 54). These interview questions usually focus on beliefs, opinions, perspectives, or descriptions of individuals' experiences to develop an understanding of a certain social phenomenon.

In the current study, I conducted semi-structured interviews for teachers and administrators to understand Saudi educators' attitudes and perceptions regarding multicultural education. A semi-structured interview is recommended to be used when the researcher does not have a chance to interview participants more than one time (Bernard, 2006). It determines that the researcher has control of the interview but leaves the researcher free to ask prompt questions and follow new paths. A semi-structured interview gives the impression that the researcher is well prepared for the interview and not trying to use excessive control.

The interviews primarily aim to understand Saudi educators' conceptions of culture and multicultural education. In this regard, I developed two sets of questions; the first set is asking demographical questions that help to understand the background of teachers and administrators and their schools. The second set of questions is designed to explore how Saudi educators define culture and multicultural education and how they see the need for multicultural education in Saudi Arabia. The secondary purpose of the interview varies between teachers and school administrators. In the teachers' interview, I 
asked questions related to their teaching practices and how they adjust their instruction to include students from different cultural backgrounds. For that purpose, I asked Questions such as how do you engage all students in learning activities, and what is your strategy to make the classroom a safe place for all students to participate and share their thought? In the administrators' interview, moreover, I asked questions regarding the interaction between the school and the community which included questions related to the process of school enrollment for both Saudi and non-Saudi students, the way of communication between the school and students' parents, and professional practices in the school community.

In the current study, I conducted a synchronous online interview to meet with participants and collect data for the study. Utilizing an online interview for this study has several advantages for both the researcher and the participants. Conducting an online interview is a way to overcome the physical separation between the researcher and the participants. As I stated before, the samples of the study were teachers and administrators in the Office of the Director of Education in the Mecca region, and I am in the state of Michigan, and there was no chance to meet the participants physically. Conducting an online interview, moreover, allows the researcher to video record the interview session. In a face-to-face interview, many researchers are voice-recording the interview session because using a camera to make a video recording might not be comfortable for many participants. An online meeting reduces the fear of the camera and makes the participants more comfortable for video recording which will allow the researcher to see the body language and facial impressions. An online interview, furthermore, authorizes the participants and the researcher to find their favorite place to do the interview. By doing 
an online interview, the participants do not need to leave their comfortable place and meet with the researcher in a pre-prepared site for the interview. These three advantages encouraged me to do a synchronous online interview as a strategy for collecting data for this study. For that purpose, I used Zoom (https://zoom.us) to meet with participants and video record the meeting sessions.

The interview was done in the Arabic language which is the main language of the researcher and the participants. The data was translated into the English language after the analysis process. Suh, Kagan, and Strumpf (2009) recommend that translation after the process of analyzing data will ensure capturing the meaning and cultural expression and concept.

\section{Strategy for Developing an Interview Protocol}

Interview questions are different from the research questions. Maxwell (2013) stated that the research questions formulate what the researcher wants to understand, but the interview questions are what the researcher asks participants to gain that understanding. Therefore, rather than asking participants direct research questions, the researcher should ask questions that help to understand the phenomenon and find an answer to the research question. In developing an interview protocol, I utilized the interview protocol refinement (IPR) developed by Castillo-Montoya (2016). IPR is a framework that is designed mostly for structured or semi-structured interviews to strengthen the reliability and increase the quality of data obtained from the interview. The IPR framework has a four-phase process:

Phase 1: Ensuring interview questions align with research questions. This phase focuses on the alignment between the research questions and interview questions. The 
alignment between the interview questions and the research questions guides the participants to organize their stories one layer at a time to be compatible with the purpose of the study (Castillo-Montoya, 2016). The root of the interview is not to get a direct answer to the research questions; however, it is to understand "the lived experience of other people and the meaning they make of that experience.'(Seidman, 2006, p. 9). To ensure the alignment of questions, I created a matrix for mapping interview questions into research questions. Appendix A shows the matrix for the first and second research questions. In creating the matrix for mapping questions, the researcher can easily find if any gap exists in interview questions or if too many questions are related to one research question.

Phase 2: Constructing an inquiry-based conversation. An interview is an instrument of inquiry-asking questions related to the research question as well as an instrument for a conversation about the participants' live experiences (Castillo-Montoya, 2016). In developing an interview protocol, the researcher should write interview questions that are different from the research questions, organize the questions to follow the rules of an ordinary conversation, and develop a script with prompts and follow-up questions. In this regard, I developed four types of interview questions; Introductory questions, questions that ask participants general information and background about themselves and their teaching in the school. Transition questions: questions that move the conversation toward the main interview questions. Key questions: they are the main questions the researcher asks to find answers to the research questions. Closing questions: they are open-ended questions that are asked at the end of an interview or an interview 
section to share additional information or add reflection about previous interview questions.

Phase 3: Receiving feedback on interview protocols. The aim of this phase is to enhance the reliability of the interview questions as a research instrument (CastilloMontoya, 2016). At this phase, the interview protocol is conducted to a close reading from a colleague, research team member, or others from the population of the study to examine its structure, writing style, length, and comprehension. Castillo-Montoya (2016) developed a checklist for close reading that I used to receive feedback on interview protocol (Appendix B). The checklist entails four main aspects; interview protocol structure, writing of interview questions and statements, length of the interview protocol, and comprehension. To receive feedback, I shared the interview protocol and the checklist with colleagues and committee members. After that, I translated the interview protocol and the checklist to the Arabic language and shared them with Arabic speaker colleagues and teachers from the population of the study.

Phase 4: Piloting the interview protocol. A pilot study is defined as a small study that applies to test the research protocol, sample selection strategy, instrument for data collection, and prepare the researcher for a larger study (Hassan et al., 2006). Pilot studies are generally connected with quantitative research; however, they are expanded to the qualitative inquiry where its main purpose is the preparation for the major study (Abdul Majid et al., 2017). Merriam and Tisdell (2016), furthermore, stated that a pilot interview protocol is crucial to practice interviewing and explore strengths and weaknesses interview questions. To pilot my interview protocol, I conducted the Arabic 
version of my interview protocol to interview one teacher from the population of the study.

For the purpose of the current study, I developed two interview protocols. The first interview protocol was to understand the teachers' perceptions and practices of multicultural education in their classroom. This protocol has questions related to the relationship between teachers and students in the classroom and teaching strategies for the culturally diverse classroom. The second interview protocol was to understand the administrators' perceptions and attitudes toward multicultural education in their schools. Administrators were asked questions related to the school culture, the relationship between the school and students' families, and the school enrollment for students from different nationalities.

\section{Data Analysis}

The process of analyzing data goes further than analyzing the participants' responses. Creswell and Poth (2018) mention that analyzing the data "involves organizing the data, conducting a preliminary read-through of the database, coding and organizing themes, representing the data, and forming an interpretation of them" (p.181). In this study, I analyzed the data collected from interviewing participants. It was a video recording and note-taking during the interview to gain data such as emotions and body language that cannot be obtained from audio recordings.

To begin analyzing the data, I engaged in a process of moving into analytic circles like a spiral rather than a fixed linear approach (Creswell \& Poth, 2018). Managing and organizing the data was the first loop of the spiral. By using MAXQDA I wrote the interview's transcript and organized it into two types of data collected for the research; 
Central Mecca Elementary and Eastern Mecca Elementary. In the second step of analyzing the data, I started reading the transcript several times in order to get the sense of the interview as a whole before breaking it into multiple parts. While reading the transcript, I wrote notes and memos to helped me in coding and categorizing the data.

The third step in the spiral is to move from reading and memoing to describing, classifying, and interpreting the data (Creswell \& Poth, 2018). This step is the heart of analyzing the qualitative data where the researcher starts to format the codes and themes. For this study, I analyzed data using two-cycle coding. In the first cycle, I used open coding by using the Arabic language to name codes. In that stage, I analyzed data using codes such as In Vivo, attribute, and descriptive coding methods. The reason for using open coding in the Arabic language was to be close to the data and not have a language barrier. In the second cycle coding, I used the descriptive coding method to develop major themes from the data and to examine the relationship between educators and students and between students themselves. The descriptive coding was done in the English language to facilitate develop themes and interpretations of the data in English.

The fourth step is developing interpretations of the data. In qualitative research, interpretation "involves abstracting out beyond the codes and themes to the larger meaning of the data" (Creswell \& Poth, 2018, p. 195). To guide my interpretation, I was asking myself questions like: What is the surprising information that I did not expect? What information is interesting or unique? What are the dominant interpretations and what are the alternate notions? (Creswell \& Poth, 2018). The last step in the spiral is representing and visualizing the data. In this step, I looked at the data in a different way 
to have a different angle to understand the data. I created figures that summarize the data analysis in a meaningful way.

\section{Strategies for Validating Findings}

In order to obtain an accurate translation and verify the reliability of the data after the translation, I did the following: I collected the data using the participant's native language, which is Arabic, as a source language, then disseminate the data in English after the analysis. Because the participant and I are speaking the same language, cultural and language challenges were limited. Van Nes, Abma, Jonsson, \& Deeg argue that "With participants and the main researcher speaking the same language, no language differences are present in data gathering, transcription and during the first analysis, because usually the first coding phase stays closely to the data" (2010, p.314). Thus, in order to not lose the meaning and present the full idea to the audience, I analyzed the original data collected in the participant's native language. I analyzed the Arabic transcript in Arabic then translated the themes into English.

Qualitative researchers are encouraged to engage at least two validation strategies (Miles et al., 2014). In this qualitative study, the data was validated from the researcher's and the participant's lenses. As a researcher, I tried to be neutral and not biased toward any direction when analyzing data. After collecting and analyzing the data, I presented the data to some of the participants to verify it again and provide feedback if needed.

Triangulation is another strategy that was used to ensure validity (Miles et al., 2014). Triangulation strengthens a study by combining multiple methods of data collection, maximizing the variation of participants, and the use of multiple theory and philosophical perspectives to analyze the dataset. The triangulation is based on the 
premise that "no single method ever adequately solves the problem of rival causal factors. Because each method reveals different aspects of empirical reality, multiple methods of observations must be employed." (as cited in Patton, 2015, p. 478). In the current study, I applied the triangulation strategy by using multiple sources of data collection: interview and video recording, to understand the participants' perspective as well as to capture their emotion and implicit meaning. I also maximized the variation between participants in many ways: the position of the participants in the school varied between teachers and school administrators, the academic background differed between participants, the education degree was not the same for all participants, the level of school diversity was different between a school for Saudi students and the other for non-Saudi students.

\section{Summary}

This chapter discussed the methodology that used to explore Saudi educators' attitudes toward teaching multicultural classrooms. The study took place in Mecca, which is one of the most highly diverse cities in the country. From two elementary schools that differ in the level of cultural diversity, six elementary educators participated voluntarily in the study. A qualitative comparative multi-case study method guided the data collection and analysis of the study. An online semi-structured interview was the way of data collection. Participants asked questions related to their understanding of the meaning of culture, multiculturalism, and multicultural education as well as questions related to their practice as teachers or administrators. The data were analyzed according to spiral procedures based on first and second cycle coding. In the initial coding cycle, I used the open coding method in the Arabic language. In the second cycle coding, I used descriptive coding to develop themes and examine relationships between educators and 
students and between students themselves. The validity of this study was ensured by several strategies. First, the data were validated form the researcher and the participants' perspectives. Second, the data were collected from multiple sources. Third, the participants of the study were selected from different school environments and different school positions. This variation in the participants and data sources helped to ensure the validation of the study and data collection. 


\section{CHAPTER 4}

\section{CENTRAL MECCA ELEMENTARY SCHOOL}

\section{Introduction}

This chapter presented the first case on the current study. It is the case of Central Mecca Elementary school as a school for Saudi students only. At this chapter, I presented the case of two teachers and the school vice-principal to understand their perceptions and attitudes about multicultural education and multiculturalism in Saudi Arabia. The first section of the chapter introduced the school and the participated teachers. The second section of the chapter presented the participants' responses regarding the first research question, which was divided into three themes; definition of culture, culture and education, and multiculturalism in Saudi Arabia. The third section explained the answer for the second research question, and it was divided into three themes; culturally diverse classroom, education for all, and professional development.

\section{Central Mecca Elementary School}

The first school to join the study was given the pseudonym Central Mecca Elementary. Originally, the school was in a building that was not intended to be a school, but rather was designed to be a residential building that contained many apartments. Because of the school needs in the neighborhood, the Office of the Director of Education in Mecca had rented that building to be an elementary school. It had a school population 
of approximately 300 students, over 100 of them were non-Saudi students from countries such as Syria, Yemen, Egypt, and Pakistan.

As a response to the government project to establish school buildings with suitable educational environments, Central Mecca Elementary was merged with several other schools that were in inappropriate school facilities in the same neighborhood and moved to an old renovated building that was designed to be a school. The large number of students from the schools that were included in the reform project caused the Office of the Director of Education to take advantage of the appropriate school buildings to operate in two shifts: morning and evening. The students were divided into these two shifts, with Saudi students in the morning school that was named Central Mecca Elementary, and the non-Saudi students in the afternoon school that was given a different school name. The schooling time for Central Mecca Elementary is started from seven o'clock in the early morning until twelve o'clock in the afternoon. The vice principal of Central Mecca Elementary stated his opposition to the merging of two schools in the same building. He said that Central Mecca Elementary always suffered from electrical issues, needing to arrange chairs and tables again in the early morning in each classroom, and losing teachers' and students' belongings. He also mentioned that a school building that was attended by nearly a thousand students between morning and evening was hard to keep clean all day.

Central Mecca Elementary is a school in a multicultural community, like many other neighborhoods in Mecca, which has inhabitants from multiple regions of the world. Central Mecca Elementary is a school in a middle-class multicultural neighborhood. One of the teachers described the school neighborhood as having a strong interconnectedness, 
because of the role of mosques in Muslim communities, which increases the community gathering and acquaintance with each other. Central Mecca Elementary, moreover, has a significant role in the neighborhood. The school has entered into community partnerships with the neighborhood center, neighborhood clinics, and the police department to offer courses and workshops at the school for the students and the community. Another path of the community development is what the school faculties offer to the community members. The school gathers parents in parents' councils and conducts workshops about topics such as how to deal with children's aggressive behavior and the role of parents in the formative assessment. According to the vice principal, Central Mecca Elementary teachers believe that the impact of the school should not be limited to students, but it should reach the community out of the school border.

\section{Bandar}

I first met with Bandar, who is a first-grade teacher at Central Mecca Elementary. Bandar has his bachelor's degree from the Faculty of Dawah and Fundamentals of Religion $^{1}$ at Umm Al-Qura University in Mecca. His academic training is highly reflected in his behavior, as he has memorized the Holy Qur'an and has regularly attended some scientific seminars specializing in Islamic studies. Bandar grew up in a Muslim family, where his parents were keen on his Islamic upbringing. They encouraged him to be an active element in their small community by promoting him to perform prayers in the mosque, join other children in the Qur'an memorization groups, and participate in summer activities, which all contributed to shaping his Islamic identity and culture.

\footnotetext{
${ }^{1}$ A faculty concerned in teaching the fundamentals of Islamic religion.
} 
By virtue of his upbringing in Mecca, Bandar describes himself as belonging to the culture of the Meccan society, which is primarily derived from Islamic teachings. The Meccan culture, as Bandar describes, is an open and receptive culture, unlike many other cultures in Saudi Arabia. It is a dynamic culture influenced by many different cultures of Islamic societies that come periodically for Hajj. As an example of the diversity and acceptance of the other cultures in the Meccan community, Bandar argues that there is more than one Islamic jurisprudence school in Mecca, which one cannot see in many other regions in Saudi Arabia. Mecca is a cosmopolitan city, as it receives Muslims from all parts of the earth, and its society is receptive to the other regardless of their languages, color, and race because this is what the Islamic religion urges.

Bandar has been teaching more than twenty-three years, during which time he moved between elementary, intermediate, and high school teaching. During his teaching journey, Bandar had the opportunity to teach in multiple regions in Saudi Arabia - which is the case for many Saudi teachers - that gave him the chance to meet students from different backgrounds and learn about their cultures. Bandar has been teaching first-grade for a long time. At the beginning of each school year, many parents come to the school demanding their children be in Bandar's classroom, which makes his class jammed with students and embarrasses him with many parents who do not get their request.

Bandar believes teaching is not a profession; it is a mission. In this context, Bandar described the role of teachers when I asked him about his duties towards his students. He stated that the impact of the family on children has decreased significantly in recent years. That is due to the spread of social media, which has reduced verbal communication among members of the same family and made many children feel 
isolated inside their the home. Therefore, the teacher's role is no longer confined to transferring information but must go beyond that to fortify students and preserve their Islamic identity from change.

Fayez

Fayez was the vice-principal of the Central Mecca Elementary and has spent more than eighteen years in this field. He has a Ph.D. in Islamic Education from Umm Al-Qura University and is also a collaborating professor at the same University. Fayez has some research published in Arabic journals and his research interest is on social control and intellectual deviations among Muslim youth. Fayez has many contributions to the school community, as he has provided many training workshops for students' parents on many topics such as adolescent coping skills and role integration between home and school. "My culture is the culture emanating from the Book of Allah Almighty and the Sunnah the Prophet Muhammad (PBUH) and accepts every new and codified thing." (تقافتي هي الثقافة المنبنقة من كتاب الله عز و جل و سنه النبي صلي الله عليه و سلم و استقبال كل ما هو جديد مقنن) (Fayez). With these words, Fayez defines his culture, as a dynamic culture that is open to all new things provided; it is compatible with his interpretation of Islamic doctrine. Despite his origins in Mecca, Fayez does not see that the culture of the Meccan society represents him, and he argues that the culture of the Meccan community does not always coincide with Islamic teachings. Therefore, Islamic culture is the only culture to which he belongs.

Fayez divides teachers in Saudi Arabia into two categories. First is those who believe that teaching is a profession. This group of the teachers implements the traditional teaching strategy where the teacher is an information transformer and the students are an 
inactive recipient. This teacher wants to do everything by himself and the student is only required to do the homework at the end of the day.

The second group of teachers is those who believe teaching is a mission. This group of teachers has a good relationship with their students. They use modern teaching methods such as active learning, where the student and the teacher work simultaneously to achieve the learning objectives. However, Fayez argues that a mix of these two teaching strategies is the best for students. The traditional way of teaching needs a teacher who is very good at his teaching subject, but the modern way needs a teacher who is good at building a relationship with students.

Mosh

Mosh was another teacher in Central Mecca Elementary that I interviewed. Mosh has a bachelor's degree in teaching mathematics from the teacher preparation college in Mecca. Before moving to Mecca, his teaching journey began in Riyadh, in the central region of the country, where he stayed for seven years teaching mathematics for middle school students. Mosh has been teaching mathematics at Central Mecca Elementary for three years for the first and fourth grade students.

Mosh describes his culture as one of the people of Najd. Although he did not mention much about the culture of Najd, it has its dialect and heritage that distinguishes it from some other regions. It also has other cultural elements that it shares with many other areas in Saudi Arabia, such as the predominant Bedouin customs and traditions that maximize the tribe's affairs and tend to prevail in the interest of the group versus the individual. 
Mosh believes that the teacher should be positive when dealing with students. If the teacher is positive when entering the classroom, this will be reflected in his students, and they will be positive too. However, the issue is that when an inspired teacher comes to a classroom after a negatively thinking teacher, it is challenging to spread positivity among students after such teacher. In addition, Mosh criticizes many students for not being keen on learning and performing their homework. He argues that the main reason for this is that many parents did not proceed with their duties towards their children and they leave them free to use technology throughout the day without assigning a specific time for schoolwork.

\section{Conceptions of Culture and Multicultural Education}

The first question is, "What are Saudi educators' conceptions of culture and multicultural education?" This research question focused primarily on determining how Saudi educators define culture, multiculturalism, and multicultural education. The question also aimed to determine how educators in Saudi Arabia explain the relationship between culture and learning. This question contributes to developing an understanding of educators' perceptions about the meaning of multiculturalism and multicultural education in Saudi Arabia.

\section{The Definitions of Culture}

I first asked participants to explain what comes to their minds when they hear the word "culture" and then I asked them to develop a definition of that concept. Not all participants were able to create a definition, but all answered the first part of the question, "what comes to your mind when you hear the word culture?" Based on the participants' 
understanding, the definitions of culture were categorized into two themes:(1) knowledge and (2) an integrated system.

Both Bandar and Mosh agreed that culture is a concept related to knowledge and gaining information in diverse fields. They thought of the word in its adjective form when describing a 'cultured' person as one who enjoys reading, educating himself, and updating his/her knowledge in many fields, such as in art and literatures. Bandar believed that what one inherits from his parent is basically knowledge and it is part of ones' culture. For example, he was raised in a Muslim family and he was taught the Islamic traditions and manners like many other people in the country. Mosh had a different perspective regarding customs and traditions, and he argued that they are not part of one's culture because they are behaviors one can learn and not knowledge that one can gain. Thus, Mosh highly emphasized that culture is knowledge that is found in books such as literature and art and not traditions and manners that are learned from the community.

Fayez understood the word culture in a very different way. He mentioned that culture is an integrated system that encompasses all life aspects, "الموروث الثقافي و العادات و التقاليد و الدين كلها جز ع من الثقافة. الثقافة منظومة متكاملة ليست مقصورة على جانب معين مثل ما سيتقيه الطالب "من المدرسة ("cultural heritage, customs, traditions and religion are all part of the culture. Culture is an integrated system that is not limited to a specific aspect, such as what a student will learn from school"). Fayez argued that the word culture in Arabic language means improving and developing a thing and everyone is cultured in his field of work. For example, the engineer is cultured in his area. The carpenter, the blacksmith, and every craft people are cultured because they produce and develop products. Fayez 
criticized limiting the meaning of culture to knowledge and information. He said it is an issue in the Arab world that:

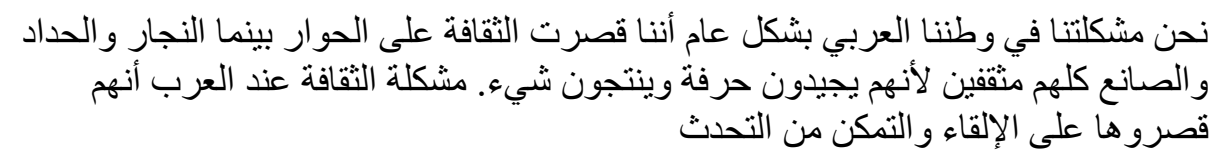

("Our problem in the Arab world is that we limit the meaning of culture to dialogue and discussion. However, the carpenter, the blacksmith, and the maker are all cultured because they are proficient in craft and produce something. It is a problem of culture among the Arabs that they have limited it to speech.").

Fayez believed that because the Arabs were at a high level of linguistic eloquence, they consider that culture is limited to what is said and not what is made. Thus, the cultured person is one who has information and can manipulate words and not someone good at his craft. This way of understanding the meaning of culture, according to Fayez, is preventing Arabs from building a stable civilization in modern history because they underestimate workers who use their hands to develop products and overrate those who use their minds to promote ideas.

Fayez stated that he is highly influenced by the work of Malik Bennabi and that is clearly reflected in his understanding of culture from an Arabic perspective. Bennabi defined culture as a holistic system which is a combination of three realms: the world of ideas, the world of things, and the world of people. Bennabi added that the world of things has not yet matured in the Arab and Islamic countries; thus, they only have a world of ideas that seek to build their culture and shape their identity (Bennabi, 2003).

\section{Culture and Education}

The relationship between culture and education is another essential part of the first research question. After asking participants to define culture, I asked them if they see a correlation between culture and education. There is an agreement between participants 
about the role of students' culture in the learning process. Students' culture is a guide that teachers utilize to achieve learning objects.

Bandar stated that students' cultural backgrounds influence the way they think and see the world. Students come to the classroom with their culture and use it as a basis to think and solve problems. During his teaching journey in some regions of the country, he found that some cultural traditions were not compatible with Islamic teaching. As an Islamic studies teacher, Bandar found it difficult to persuade some students that what their parents did was not consistent with Islamic education because Muslims have to follow what has been said in the Qur'an and Sunnah. Many times, Bandar had to meet with students' parents to educate them about the Islamic teaching and that they have the role to teach their children. Bandar concluded that students could not accept new things from the teacher if they see the opposite at home.

Mosh had a different perspective on the relationship between culture and education. Since he argued that culture is only knowledge and it relates to what an individual learns, he stated that the level of education of the parents reflected on their students' behaviors. When dividing students into groups, Mosh mentioned how the way of naming the groups differs between students. While some students prefer to name their groups after their favorite kind of pets, others select the name of predators. Mosh added that the variety in selecting the group's name was related to the level of parents' education. Students who prefer to name their group after predators were mostly from families with lower levels of education and those who favor naming their group after their pets were from highly educated families. Mosh concluded that naming the students' group in the classroom is not a serious thing for many students; however, it causes 
conflict between some students. Therefore, if a teacher is not aware of students' cultural diversity, the classroom environment will not be safe for all students to participate and share their idea.

Fayez distinguished between two types of culture: innate and acquired. The innate culture is what students bring from home and the acquired is what they learn at school. When talking about the relationship between culture and education, Fayez focused on the acquired culture that students learn from school, and how the school principal could build an inclusive learning environment that accepts and include all students from different backgrounds. However, the school principal cannot apply his plan without having an approval from the Office of the Director of Education, which may take a long time. Fayez criticized the education system in Saudi Arabia as being too centralized with all its decisions made from one central authority, which is the Ministry of Education. He said that this centralization in decision-making is an obstacle that would confront school administrators because developing a school culture is framed by education policy, and we cannot change these policies.

\section{Multiculturalism in Saudi Arabia}

Understanding teachers' perceptions of multiculturalism in Saudi Arabia is a primary goal of the current research. Cultural diversity in this study is limited to national differences, although Saudi Arabia is a vast country that includes people from multiple cultural backgrounds. I first asked participants about the status of multiculturalism in Saudi Arabia and they all agreed that Saudi Arabia is a culturally diverse country. Then I asked them about their perceptions about multiculturalism in Saudi Arabia. The 
participants' responses are categorized into two themes: (1) multiculturalism strengthens the Saudi community and (2) multiculturalism weakens the Saudi community.

Participants agreed, in slightly different ways, that Saudi Arabia is a multicultural country and the city of Mecca is a highly diverse city. Bandar, for example, claimed that Mecca is the most highly diverse city in the country and the Meccan culture is a dynamic culture that has been influenced by many other Islamic cultures that were carried by Muslims who came to the city from all over the world. In his life in Mecca, Bandar added that "Iانا عشت هذا التنوع كثير. التتوع الثقافي موجود عندنا في مكة من قديم الأزل"I experienced this diversity. The cultural diversity in Mecca exists from ancient times").

Mosh agreed with Bandar and stated that Saudi Arabia is a multicultural country, and Mecca has the largest share in this diversity as it contains a large number of the Muslim community that settled in it a long time ago. Fayez saw the cultural diversity in Mecca from a different perspective. He did not see Saudi Arabia as a multicultural country. He stated that there is only one primary culture in Saudi Arabia, which is the Islamic culture, and the others are sub-cultures that have emerged from the same root, which is the Qur'an and Sunnah.

The participants' perceptions regarding multiculturalism in Saudi Arabia divided into one group who believes that multiculturalism is participating in developing the community, and another believes that multiculturalism is a way of harming and losing the cultural identity. Fayez, who argued that all cultures in Saudi Arabia have emerged from the Islamic culture, is the only participant who believed that multiculturalism played an essential role in improving the perception of Saudi citizens. Saudi Arabia is a highly diverse country that includes other people from different cultures, and Saudi peoples 
became open-minded to accept other people and their cultures. He concluded his answer about multiculturalism in Saudi Arabia by "فin the end, our country is embracing everyone").

The other participants, Bandar and Mosh, agreed that Saudi Arabia is a multicultural country. However, this cultural diversity negatively impacts the community and participates in the loss of the Islamic and Arabic identity. Bandar defined multiculturism as a coexistence, where people from the same neighborhood of different cultures could live together peacefully. However, multiculturalism is a way for an individual to influence others' cultures and change their cultural identity. According to Bandar, technology has accelerated multiculturism in Saudi Arabia. It has removed physical boundaries between humans and enabled people to communicate with others whom they have never seen before. Therefore, it is the teachers' responsibility to protect students from extremist ideas such as terrorism and atheism that might be transferred by social media.

Mosh, along the line of Bandar, criticized multiculturalism in Saudi Arabia, and he mentioned that it negatively affected Saudi society by participating in the loss of the old customs and traditions. The new Meccan generation, according to Mosh, has been influenced by many foreign cultures that were carried by Muslim immigrants to the country. For example, many Saudi students are using words from some African languages in their daily talk - African society represents a large proportion of the community outside of school - which Mosh saw as a strong indication that multiculturalism may affect the Arabic language and identity. 
The difference between participants regarding their attitudes of multiculturalism in Saudi Arabia is related to their understanding of the concept. Fayez, who stated that multiculturalism contributes to developing the perception and the way of thinking in Saudi people, saw that all cultures in Saudi Arabia have emerged from the same original Islamic culture. Thus, multiculturalism will not affect the main cultural principles that are related to the Islamic religion but will only affect the traditions and manners that distinguished between cultures, as he stated that in other words, multiculturalism will only affect the branches and not the root of the Saudi culture. On the other hand, Bandar and Mosh, who both agreed that cultural diversity in Saudi Arabia harms the community, defined a multicultural society as a coexistence where people from different cultures live together peacefully. From this perspective, people in a multicultural community will communicate and learn from each other, and that is a way of losing Islamic culture and identity if a Muslim is not prepared to live in a culturally diverse community.

\section{Multicultural Education Practices}

The second research question is, "What practices do educators employ concerning multicultural education?" This question focused on practices and attitudes that Saudi teachers employ in their classrooms with respect to multicultural education. Teachers agree that Saudi Arabia is a highly diverse country, and this diversity influences their school. To understand Saudi teachers' perceptions and practices regarding teaching culturally diverse classrooms, I asked participants about the current status of multicultural education in Saudi Arabia and what practices they employ with respect to multicultural education. I generated three themes from their responses, (1) culturally diverse classroom, (2) education for all, and (3) professional development. 


\section{Culturally Diverse Classroom}

There is an agreement between all participants from Central Mecca Elementary that Mecca is a multicultural city, and this diversity is highly reflected in the school's demographics. Bandar, for example, explained the school diversity in Mecca and he said

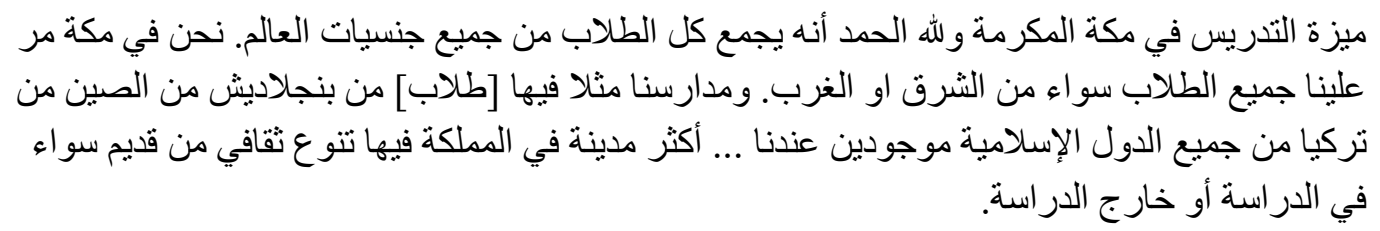

The advantage of teaching in Mecca, by the blessing of Allah, is that the school brings together students from all nationalities. We in Mecca have met students from all regions, whether from the East or West. Our schools, for example, have [students] from Bangladesh, China, Turkey, and all other Islamic countries... Mecca is the most culturally diverse city in the state, whether in school or out of school.

However, the reform movement being carried out by the Office of the Director of Education in Mecca, which aims to provide the best learning environment for all students, has brought about a significant shift in the demographics of the classroom. The segregation between Saudi and non-Saudi students in schools has no justification and has caused some adverse effects that have been reflected in the students' achievement.

\section{Students' Performance}

In a multicultural classroom, students perform better compared to a monocultural class, according to the participants from Central Mecca Elementary. Bandar, for instance, showed how cultural diversity in a school participates in developing students' thinking and academic performance. Although he was against multiculturalism in Saudi Arabia, Bandar stated that one of his remarkable classes was a culturally diverse classroom that had twenty non-Saudi students out of thirty from countries such as Egypt, Syria, China, 
and Malaysia. The students were very active and varied in their way of thinking and sharing their ideas. Mosh, moreover, tried to be neutral in evaluating multicultural education in Saudi Arabia, but in the end, he stated that it has many positive impacts on Saudi education. The multicultural classroom is very energetic and the students' performance is very high. Bandar and Mosh concluded by criticizing the separation between Saudi and non-Saudi students in the schooling time and claimed that this segregation has negatively affected Saudi students in their academic performance and cognitive skills.

Fayez argued that cultural diversity in a classroom is not only developing students' achievement but also it plays a part in improving teacher's performance as well. He saw multiculturalism in education as a step forward to internationalizing the curriculum when an international student shared with the teacher the teaching strategies that are used in his home country

$$
\text { وكيانا يكون طالب درس في بلده أربع إلى خمس سنوات ويأتيك يكمل در استه عندك وينقل للك ثقافة بلده }
$$

A student might have studied in his home country for four or five years and comes to Saudi Arabia to complete his education. He will transmit his culture and how he was studying there. There is no doubt that the diversity of ideas and multiculturalism has a significant role in education.

Fayez considers multicultural education as a way of professional development where the teacher will learn from international students a new culture, way of thinking, and a new teaching strategy. 


\section{Teaching Practices}

Teaching strategies in a multicultural classroom are different from those in a monocultural class. Fayez distinguished between what he called traditional and modern teaching strategies. The traditional teaching strategy is the most common among Saudi teachers, according to Fayez. In this strategy of teaching, the teacher has the responsibility to set the learning objectives and develop the classroom activities, and students are inactive receivers. The other teaching method is that when a teacher works with his students to develop the lesson objectives and activities that Fayez described as modern teaching. However, Fayez implied that each teaching strategy has its strengths and teachers should take advantage of them. The traditional method shows the teacher's capability of mastering the teaching subject because he is the only source of knowledge in the classroom and students highly respect teachers who are well versed in their teaching subject. The modern way of teaching shows the teacher's creativity and ability in managing and organizing the classroom and developing classroom activities.

Bandar is an example of a modern teacher who considers students' ability and cultural background when developing the learning objectives. According to Bandar, the role of the teacher in the current time goes beyond passing knowledge to the students. It is a teacher's responsibility to educate students and fulfill the emotional gap that many students have because of the isolation between children and their parents at home. Bandar added that some students feel alienated at their home and they find in social media people who will give them attention and listen to them. Thus, it is the school's duty to improve students' high order thinking and protect them from dangerous influences that can lead to the destruction of their beliefs. 
When planning for a lesson, Bandar considers all students with respect to their cultural background and learning ability. Non-Saudi students, for example, might miss prior knowledge because they had learned in a different country; thus, the teacher should know the students' abilities and set up multiple learning objectives that for all students. Therefore, students should speak and express themselves and participate with teachers in developing their learning goals.

Mosh highlighted a challenge that faces many teachers in a multicultural قابلت طلاب لديهم " classroom, which is the understanding of a spoken language. He said that ("I have met students with language "مشاكل في اللغة. كان لا يستو عب ايش اقول ولا افهم عليه ايش ييغي problems. They were unable to understand what I said, and I did not understand what they wanted"). Some of the non-Arabic students have difficulty understanding the Arabic language, especially those who are newcomers to the country. This major problem did not get attention from the Ministry of Education, the only body in the country that determines educational policies. Therefore, no decisions were made to design Arabic language programs for non-Arabic speakers. Moreover, some Arab students have difficulty in understanding the Saudi dialect, which makes the teacher repeat the idea more than once in different ways to ensure the understanding of all students. However, the problem of students not understanding the Saudi dialect does not last for long. They can master the Saudi accent in a short period.

Building a healthy relationship between students is a primary goal for teachers in Central Mecca Elementary. The school started a required program for high-grade students $-4^{\text {th }}$, 5th, and 6th - about the impact of bullying in students' lives. In that course, students learn about the risk of bullying, and what is the correct behavior if they are exposed to it. 
Another remarkable act to build a relationship between students is providing equal learning opportunities for all. Bandar claimed that teachers in the school do not distinguish between students on the basis of nationality when selecting students for participating in activities, whether in or out of school. Parents, according to Mosh, have their role in building the relationship between students. Some parents play a significant part in spreading friendship in a classroom by sharing cake and candy with students.

The participants' responses regarding this theme, culturally diverse classroom, is concluded that teachers' and students' performance vary in a multicultural classroom. Although Central Mecca Elementary is a school for Saudi students, the responses of the participants were from their experience from the teaching in multicultural classrooms during the previous years.

\section{Education for all}

Education is one of the basic needs that the Saudi government guarantees to provide at no cost for all students. Since the unification of the country, interest in education has been one of the cornerstones of the country's constitution. The government has expanded building schools in cities and villages to deliver free education to all residents. Saudi Arabia, moreover, participated in developing the Sustainable Development Goals (SDGs) and the Education 2030 Framework for Action (UNESCO, 2018). SDG 4 aims for equal educational opportunities for all population groups.

All the participants agreed that free education is the right for every student and there is no differentiation between Saudi and non-Saudi students in providing educational opportunities. Fayez, for example, claimed that “ من حق الإنسان أي إنسان موجود في أي أرض "it is a right of every human being who lives in any country to 
have health care, food, and free education"). The general objectives of education policy in Saudi Arabia affirm that free education is a right for all and it is the first goal after Allah's monotheism.

Bandar agreed with Fayez and he stated that free education is a right for every individual who lives in Saudi Arabia. The equity in education is not limited to opportunities in schools but also it goes beyond that to participation in educational competition on a country and global level. Bandar added that

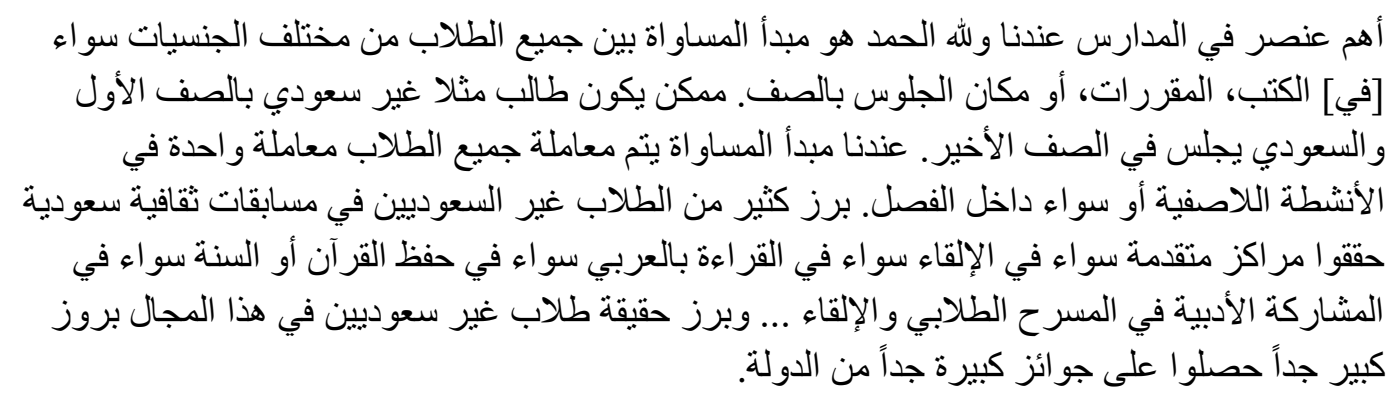

(The most critical element in our education is the principle of equity between all students of different nationalities, whether [in] giving school text books, registering in courses, or where to sit in the classroom. A non-Saudi student, for example, may be sitting in the first row of the classroom and a Saudi student seated in the last row. We have the principle of equality. In the non-classroom activities, for example, all students are treated equally as well as classroom activities. Many non-Saudi students have achieved advanced positions in Saudi cultural competitions, whether in Arabic reading, in memorizing the Qur'an or Sunnah, or in literature such as in theater and recitation ... The fact is that nonSaudi students in this field have emerged and gained massive prizes from the country).

The only difference between Saudi and non-Saudi students, according to Fayez, is that international students do not have the right for free university, as do Saudi students. The lack of opportunity for free higher education negatively affects the academic performance of some of these students, because they believe that their educational journey will end after high school. 
When I asked the participants about how they can describe their relationship with لمعلمين السعوديين يتعاطفون مع الطلاب الغير سعوديين “ non-Saudi students Bandar mentioned that يعني تعاطف كبير جدا وخصوصا من يعاني مثلا من ضائقة مالية أو الأسرة تكون لا تستطيع توفير مصاريف "'أبنائهم. "Saudi teachers sympathize with non-Saudi students, especially those who suffer from financial hardship, or if a family is unable to provide their children's expenses"). Mosh, moreover, stated that there is no difference between Saudi and non-Saudi students in the classroom, and he has great non-Saudi students who taught him new words from their language.

In the present time, non-Saudi students are transferred to evening schools, and the morning schools are for Saudi students only. All participants agreed that this is only an organizational matter to avoid overcrowding of students in classrooms, and will not last for long. Fayez stated that student registration in schools is automated, and the principal does not have the authority to accept or reject any students. When a student reaches school age, he is registered through a unified website under the administration of the Ministry of Education. The parents provide their home address and their children will be placed in schools near their home. If they are Saudi students, they will be provided with the morning schools and the non-Saudi students with the evening schools.

When I asked Mosh about excluding non-Saudi students from Central Mecca Elementary, he said that three years ago, the school was allocated to be a school for Saudi students only. Mosh did not see this as detracting the education right for non-Saudi students because, like other morning schools, the schools are funded by the Ministry of Education, taught by professional Saudi teachers, and used in the same morning school facilities. Still, the only difference is that their school day starts in the evening. The 
segregation between Saudi and non-Saudi students is only for organizational purposes as

a result of the overcrowding of students in the classroom after closing many inappropriate school facilities that were not intended to be school buildings. Mosh concluded his response by saying that he would not be happy if his son is transferred to study in evening schools.

In conclusion, all three participants agreed that free education is a right for all students from all different nationalities. Non-Saudi students, like other Saudi students, have the full right to attend schools, participate in activities, and receive educational supports. In addition, the relationship between Saudi teachers and their students does not vary based on the students' cultural backgrounds. Teachers deal with all students based on their needs and desires and not based on their cultural backgrounds. All the participants agreed that the separation between Saudi and non-Saudi students was in a matter of school organization to avoid students overcrowded in the classroom. Participants were not able to explain how that segregation was because a matter of organization and they concluded their answer by "it will not take a long time".

\section{Professional Development}

Believing in the importance of on-service training, the Ministry of Education in Saudi Arabia has established a unit for educational training in every Office of the Director of Education. The role of the Educational Training Department is to develop the knowledge, skills, and attitudes of the trainees to keep pace with the educational and technical development, and improving the teaching and learning processes. The Educational Training Department has a variety of workshops and training courses, and 
many of these programs are week-long, and require physical attendance in the morning time.

Fayez, the vice school principal, stated that many teachers in Central Mecca Elementary are keen on professional development, and they regularly register for training programs. He emphasized that teachers in a culturally diverse school are dealing with students from different cultural and ethnic backgrounds and it is essential for them to have discussion skills and be open to students' ideas and ways of thought. The Educational Training Department offers several training programs about critical thinking, developing discussion skills, and accepting students' ways of thought, which are what teachers need in a multicultural school environment.

Bandar and Mosh claimed that despite the variety of programs offered by the Educational Training Department, multicultural education does not have a spot on these programs. Bandar, for instance, said that he is very interested to participate in training programs offered by the Educational Training Department, and he has not found topics related to multiculturalism. Saudi people are now witnessing a new historical stage. Whereas formerly Saudi tourism was limited to Muslim visitors who come to the sacred spots in Mecca and Madinah, the country has recently seen a significant expansion in the tourism sector, receiving tourists from various parts of the world. This growth in tourism confirms the importance of training programs on multiculturalism. According to Mosh, teachers in Central Mecca Elementary do not need training programs related to multiculturalism in the current time, because it is a monocultural school.

As a response to the quality of training programs provided by the Educational Training Department, participants agreed that educational trainers do not have a high 
level of preparation and that many of them did not show enthusiasm during training, which made the attendees got bored. Bandar, for example, said that he attended many of these programs where the trainers only share their presentation slides and read a script for the participants. Mosh and Bandar agreed that it would be more beneficial if the trainers send the teachers their slides via email; thus, the teachers do not need to leave their classrooms. Fayez added that we need high-quality training programs, and what has been done does not meet the teachers' desires or needs. He suggested developing a training center in each school; hence, teachers do not need to leave their school and miss their classes to attend training programs.

In conclusion, all the teachers agreed about the importance of the professional development for teachers, and low quality of training programs provided by the Educational Training Department in Mecca. The responses regarding the need for professional development programs about multicultural education varied between the three teachers: Bandar emphasized the need for training programs related to multicultural education to keep abreast of Saudi plans for the future. Fayez stated that training programs about critical thinking reach the same goal as multicultural education. Mosh said that since Central Mecca Elementary is a school for Saudi students, there is no need for multicultural education programs. 


\section{CHAPTER 5}

\section{EASTERN MECCA ELEMENTARY SCHOOL}

\section{Introduction}

This chapter presented the second case on the current study. It is the case of Eastern Mecca Elementary school as a school for non-Saudi students only. The chapter presented the case of two teachers and the school principal to understand their perceptions and attitudes about multicultural education and multiculturalism in Saudi Arabia. The following chapter was divided in three sections: the first section introduced the school and teachers who participated on the study. The second section highlighted the responses for the first research question, which was divided into three themes; definition of culture, culture and education, and multiculturalism in Saudi Arabia. The third section explained the answer for the second research question, and it was divided into four themes; evening school, multicultural education, education for all, and professional development.

\section{Eastern Mecca Elementary School}

Saudi Arabia is a multicultural country, and the Holy city of Mecca is considered one of the most diverse cities in the country. The cultural diversity in Mecca strongly influences the education field by establishing a significant number of charter schools for students from immigrant families. In 1993, the number of charter schools reached one hundred thirty schools and served over ten thousand students. The Office of the Director 
of Education in Mecca assigned a committee to study the needs of these charter schools and develop a plan to help students gain better learning (الثيعاني, 2011). In two waves of education reform, the Office of the Director of Education in Mecca closed the ineffective schools and transferred the immigrant students to study along with other students in public schools. The first reform movement was in 1994, and it reduced the number of charter schools to fifty schools and established the Office of Education and Supervision of Charitable Communities' Schools under the Office of the Director of Education in Mecca to be the direct supervisor of these schools.

The second wave of education reform started in 2014, and it aimed to transfer over twenty-one thousand non-Saudi students to public schools. Simultaneously with the second wave of the charitable schools' project, the Office of the Director of Education in Mecca had issued another project that aimed to improve the school environment by eliminating all the inadequate school buildings, that were designed to be a residential facility, and transferring students to the nearest public schools. The implementation of these two projects simultaneously doubled the number of students in public schools, which led the Office of the Director of Education to issue a decision to use many school buildings and facilities for two schools in two different shifts, one in the morning and the other in the evening. The morning schools are designated for Saudi students and evening schools for non-Saudi students of all different nationalities.

The second case of the current study was investigating multicultural education in a school given the pseudonym Eastern Mecca Elementary. It is one of many other schools that were directly affected by the project that aimed to improve the learning environment for students. It is a school that was in an inadequate building and transferred to another 
public-school building in the evening shift for non-Saudi students only. The schooling time for Eastern Mecca Elementary is started from 12:30 in the afternoon until 6:30 in the evening. Eastern Mecca Elementary relocated to the new school building in 2016, and it is a building that has all the essential facilities for a school such as equipped classrooms, laboratories, gyms, and school theater. The number of students at the school was 450 students, with an average of 25 students in a classroom. The majority of students were from Yemen and Myanmar, with other students from countries such as Sudan, Bangladesh, and Afghanistan.

Eastern Mecca Elementary is a school in a culturally diverse neighborhood that has a mix of Saudi and non-Saudi people. Many families in that neighborhood suffer from poverty, as many parents are not highly educated and work in simple occupations that are not sufficient to meet their essential financial needs. Many non-Saudi parents are unable to pay the annual residency fees for themselves and their children, which leads the Office of the Director of Education in Mecca to condone the validation of the residency and allow all students to continue studying regardless of the validity of their visa. To address the problem of poverty, teachers at Eastern Mecca Elementary cooperated to make an excellent effort to help students to provide their essential school needs. One of the teachers declared that it would be helpful if the Office of the Director of Education offered financial support for those students, that will let them focus more on their study and not need to work with their parents after the school day. 
Khaled

Khaled was the first teacher I met in Eastern Mecca Elementary school. He has a bachelor's degree in teaching mathematics from the Teacher Preparation College in Mecca and started this journey as a mathematics teacher for an elementary school level in 2004. Like many teachers in Saudi Arabia, Khaled was assigned to teach in many regions in the country before he was moved to Mecca nine years ago. Khaled taught in several schools in Mecca. During the last few years, he was asked to move from Eastern Mecca Elementary to another school than he went back to his main school after a year.

Khaled described his culture as a Meccan culture that is generated from the Islamic religion that loves good for all. It is an open culture that welcomes everyone, where the people of Mecca receive millions of visitors throughout the year and try hard to leave a good feeling for these visitors to remember them well when they return to their homes. Khaled added that the Holy Mosque is the heart of Mecca and is the basis for the emergence of the Meccan culture and multiculturalism in Mecca, as it is the point that unites the people of Mecca with visitors who come from abroad.

Khaled criticized the conduct of the Office of the Director of Education in Mecca as they did not study the needs of teachers and students before transferring them to an evening school. He stated that a week before the beginning of the school year, Eastern Mecca Elementary was assigned to merge with two other schools and transfer to a new school building in the evening shift. Teachers met with students from many non-Saudi nationalities and the majority of the non-Arab students who faced issues in the Arabic language. Khaled argued that it would be better if teachers enrolled in a training program during the summer to prepare them to deal with students from multiple cultures properly. 
Khaled concluded by saying these students, even if they are non-Saudi, have been entrusted to us, so we must do our work as teachers to the fullest, and we should not perform less than when we were in a morning school.

\section{Saeed}

Saeed was the Eastern Mecca Elementary school principal. He has a bachelor's degree in Islamic Civilization from Umm Al-Qura University in Mecca and started his career as a teacher in 1993. He was upgraded to a school vice principal until he became a school principal and now has over 14 years of experience in this field. However, when I met Saeed, it was his first year as principal of the school, and he showed his lack of knowledge of many things in the school, such as teachers' performance, community outside of the school, and teachers' perceptions about teaching in an evening school.

Saeed stressed that the evening school is a temporary solution at the current stage, and it aims to correct the situation of many schools and get rid of inadequate school buildings. Saeed appreciates the efforts of the Office of the Director of Education in Mecca in dealing with their school as an evening school and said that there are ongoing efforts to transform their school into a morning school. Unlike many teachers in the school, Saeed did not see any difference between being a morning or evening school, as they both use the same school facilities and have well-prepared teachers and allocate their budgets equally.

Saeed believed that he is at the right level of education and that he is passionate about his academic studies - Islamic Civilization - and he is continuously aware of all new trends in this field. Tribal customs and traditions are considered the cultural heritage to which Saeed belongs. He is the son of the tribe and grew up respecting its customs, as 
is the case with many Saudi citizens. Despite this, Saeed believes that all other cultures should be respected, no matter how different. Every society believes that their culture is the best, and they have the right to do so, but that should not undervalue other cultures.

\section{Yasser}

Yasser was my last interviewee. He is a specialist in Arabic language studies; he earned his bachelor's degree in teaching the Arabic language from the Teacher Preparation College in Mecca. He earned both his master and doctoral degrees in the Arabic language from the Islamic University of Madinah. In 2008, Yasser started his career as a second-grade teacher in a small town in the middle region of the country before he moved to Mecca. Since 2016, Yasser has been a third-grade teacher in Eastern Mecca Elementary, and it will be his last year as a teacher in public school. He will start his new career as a faculty member in the Arabic Language Department at Taif University.

Yasser described his culture as a Saudi Islamic culture, like many other Saudi people. He criticized what other people call Meccan culture because all cultures in Saudi Arabia emerged from the same root, which is the Saudi Islamic culture. There is not much difference between the people of Mecca and other regions of the country in their culture. The difference in culture, however, might appear in some families who migrated and settled near Mecca a long time ago. Because “ “ الاقران و الأصحاب لهم دور كبير في [تشكيل] "الثقافة" ("peer and companions play a major role in [shaping] culture") (Yasser), some people of Mecca acquired the customs and traditions of these immigrants from outside the Arabian Peninsula. 
Yasser clarified his opinion regarding transferring their school to the evening time, and he stated that the Office of the Director of Education in Mecca was not prepared for that step. Students and teachers of Eastern Mecca Elementary were unwelcome guests in the new school building. According to Yasser, the administrators of the morning school, who were mainly in charge of the school building, were deliberately locking laboratories, teachers' lounge rooms, and some administration offices. The Office of the Director of Education failed to develop a way of communication between the morning and the evening schools, which made the school principals moved to this building anxious to reach an agreement that determines the responsibilities of each of them.

\section{Conceptions of Culture and Multicultural Education}

The first question is, "What are Saudi educators' conceptions of culture and multicultural education?" This research question focused primarily on understanding how educators in Saudi Arabia define the meaning of culture, multiculturalism, and multicultural education. The question also aimed to determine how educators in Saudi Arabia explain the relationship between culture and learning. The question participates in developing an understanding of educators' perceptions about the meaning of multiculturalism and multicultural education in Saudi Arabia.

\section{The Definitions of Culture}

I asked the three participants to define the concept "culture" and to express their definition by explaining what comes to their minds when they hear the word culture. All of the three participants define the term culture differently. Thus, I categorized their 
response into three themes: (1) customs and traditions, (2) knowledge, and (3) integrated system.

The first participant was Khaled, who defined culture as behavior that represents customs and traditions that an individual has inherited from the older generation. Khaled believed that an individual first learns culture from the family who shapes the main cultural frame by giving their language and faith to the next generations. Because he was born and raised in Mecca, Khaled inherited the culture of the Meccan people, which considers the Islamic religion and Arabic language to be two of its main pillars.

Saeed stated that culture is the umbrella word for all kinds of knowledge that a person receives from various types of learning resources. Although many people argued that culture is the inherited tradition, Saeed emphasized that culture and inherited traditions are two different things. We cannot consider traditions and customs as part of human culture because it is not knowledge one can learn, but rather a behavior upon which a person was brought up. Based on his understanding of the meaning of culture, Saeed described himself as a cultured person because he has the right amount of knowledge in his field of study, which is Islamic civilization. Still, it is the community that has the right to classify a member, whether he is educated or not.

Yasser was another teacher at Eastern Mecca Elementary, who believed that culture is a way of life. It is a behavior that a person learns from the surrounding community, starting with the family, which is the fundamental nucleus of forming culture, then later from to the companions at schools and in neighborhoods. Yasser argued that what an individual learns from the community is considered out of the ordinary if it does not correspond with the belief of the family. Therefore, peers have a 
significant impact on shaping culture, and the family has an essential role in knowing about those peers and their cultural backgrounds. Since Yasser regarded culture as a way of life, he defined his culture as a Saudi Islamic culture that includes all aspects of life. It is an Islamic culture in its origin that draws all its teachings from the Holy Qur'an and the Sunnah of the Prophet Muhammad (PBUH), and it is a Saudi culture in its branches such as customs, traditions, and dialects of speaking.

Khaled and Yasser agreed that culture is dynamic and is undergoing change. Khaled stated that the culture of the Meccan society had acquired many characteristics that distinguished it from other regions of Saudi Arabia due to the frequent occurrence of Muslim visitors from different parts of the world. The culture of the people of Mecca was influenced by visitors and immigrants, as many Meccans imitated visitors in their clothing and the way they spoke, which became a prominent feature of the Meccan society, distinguishing them from other Saudi people. Yasser, moreover, stated that building one's culture is not complete at a certain age; instead, it continues with the individual throughout his life. The family comes first in shaping the culture, then the school, then the peers in the neighborhood, and the circle of influence expands with age.

\section{Culture and Education}

An examination of the understanding of participants about the relationship between culture and education is another fundamental element of the first research question. I asked participants to explain the relationship between culture and education and how cultural background influences students' learning. Culture and education are very related, according to participants from Eastern Mecca Elementary. 
Khaled stated that cultural background plays a significant role in the learning process. Understanding student culture helps teachers to develop a teaching strategy that reaches learners' minds. For example, if the technology is a prevailing culture to society, this will help the teacher in introducing technology into the teaching. On the contrary, if the use of technology is not part of the culture, this would be an obstacle for the teacher to use technology in the classroom.

Saeed stated that culture and schooling are very related. The higher the culture, the better the learning outcomes. Because he understood culture as a level of knowledge, Saeed stated that the culture of the family is what explains differences in learning between students. A child who is raised in an educated family will be eager to learn. Saeed did not believe that the cultural background impacts students in the classroom; instead, it is crucial in building a relationship between home and school. If the family, for example, is at a high level of education and appreciates the importance of education, it will be keen to cooperate with the school in improving the learning process for their child. On the other hand, the family that does not appreciate education will not work with the school and might not provide a suitable learning environment for students at home.

Yasser stated that there is a relationship between culture and education. He agreed with Saeed that the level of knowledge of the family is what plays a significant role in the classroom and not the cultural background of the students. Because Yasser defined culture as a way of life, and all Saudis are sharing the same Saudi Islamic culture, he did not see a cultural gap between himself and his students. Although Eastern Mecca Elementary is an evening school and all of its students are non-Saudis, Yasser believed that there is no cultural gap between him and his students. They share the Islamic culture, 
and many of them grew up in Mecca, so their cultural allegiance is more to the Saudi culture than the family culture.

\section{Multiculturalism in Saudi Arabia}

Another core goal of the current study was to understand teachers' perceptions of multiculturalism in Saudi Arabia. To understand their attitudes, I asked them to explain the status of multiculturalism in Saudi Arabia and how that influence Saudi communities. All participants agreed that multiculturalism had become a necessity, and it participates in empowering Saudi society.

Teachers from Eastern Mecca Elementary agreed that multiculturalism is imperative in this era and that Mecca is one of the highest cities in cultural diversity in Saudi Arabia, as it receives many Muslims from all over the world. Khaled, for instance, defined multiculturalism as “ التعددية الثقافية هي مجمو عة وثقافات مرتبطة ببعضها البعض تكوّن مجتمع "قوي ("a gathering of a people from diverse cultures that linked together forming a strong society"). He narrated that

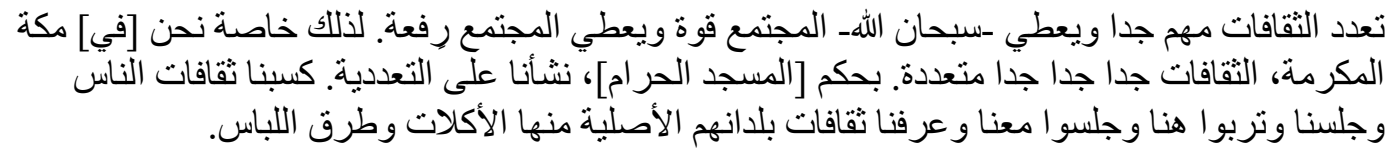

Multiculturalism is critical and gives - Glory be to Allah - society strength and gives society a pride. So especially we [in] Mecca are very, very, very multicultural. By virtue of the Holy Mosque, we grew up on multiculturalism. We gained the cultures of the people who lived and grew up here, and we learned the cultures of their origin countries, including food and dress.

Khaled believes that multiculturalism contributes to the development of thought and the growth of society. Monocultural societies cannot develop because they only benefit from their experiences and do not take the experiences of others. 
Saeed and Yasser agreed on the importance of multiculturalism and that it is one of the vital means of intellectual growth. Multiculturalism in society allows individuals to learn about different cultures and experience many things that would not be available in less culturally diverse communities. Yasser, moreover, experienced cultural diversity from an Islamic perspective. He said “ بسبب] المكانة الدينية ووجود المقسات لابد من تعدد الثقافات في] " ("السعودية (Because of] the religious standing and the presence of Holy places, there must be multiculturalism in Saudi Arabia"). The country receives many Muslim visitors from different regions of the world who all gathered in one city.

\section{Multicultural Education Practices}

The second research question is, "What practices do educators employ concerning multicultural education?" The second research question examined classroom practices and Saudi teachers' attitudes regarding multicultural education. As the first question shows, all teachers agreed that Saudi Arabia is a multicultural country, and the city of Mecca is one of the great culturally diverse cities in the country. To answer the second research question, I asked participants to explain their thoughts about the current status of multicultural education in Saudi Arabia and how they perform in their school concerning multicultural education. As a response for that, I generated four themes (1) evening school, (2) multicultural education, (3) education for all, and (4) professional development.

\section{Evening Schools}

In 2016, the Office of the Director of Education in Mecca started a project that aimed to provide a suitable learning environment by eliminating a great number of school 
buildings that were originally designed to be residential and not school buildings. This project followed another project that aimed to correct the status of many charter schools and transfer many immigrant students to public schools. Employing these two projects at the same time increased the number of students in the remaining schools. Thus, the Office of the Director of Education had made an urgent and temporary solution to this problem by making the school buildings work in the morning and evening periods. The morning period is dedicated to Saudi students and the evening for non-Saudi students from various nationalities.

In 2016, two elementary schools were merged under Eastern Mecca Elementary and assigned to be an evening school. Teachers and faculties claimed that they did not know about that change until a week before the beginning of the school year, and they had no choice but to move to evening schools. The teachers' opinions regarding being in an evening school varied between those who were willing to work in an evening school and those who were not. The teachers who accepted the decision to transfer to an evening school were the minority and many of them had other jobs besides teaching. Khaled stated that working in a morning school was an impediment to many teachers in carrying out their own business. Switching to an evening school allowed them the freedom to work in their business during the morning without affecting their work as teachers.

The other group of teachers who were opposed to moving to an evening school was rejecting that for either the schooling time or the students' types. Working in an evening school impacts the teachers and their families as well. It changes their daily routine and creates a gap between the teachers and their children at home. By the time children return from the morning school, the teacher leaves the house to begin the 
workday without having time to see their children. The situation could be worse if both parents work in evening schools and their children study in morning schools. However, the Office of the Director of Education excluded some Saudi students and allowed them to attend evening schools where their parents teach.

Another issue regarding school time was mentioned by Khaled, who explained how the weather affects their school day. The evening school day is about six hours that start from 12:30 P.M., where the temperature is the highest during the day, until 6 O'clock evening. The climate in Mecca is generally hot, with temperatures reaching $45^{\circ} \mathrm{C}$ $\left(113^{\circ} \mathrm{F}\right)$ in the summer, which makes the situation in evening schools very difficult. Although all classrooms and laboratories have an excellent air-conditioning system, the schoolyard is not. The schoolyard is used for physical education classes, the school queue, a gathering point to perform the prayer during the school day, and all students must meet at this place in that high temperatures. Khaled concluded by saying, "لك أن "تتخيل كيف مكة المكرمة في الصيف ("You can imagine this in Mecca during the summer”).

The type of students was another reason for rejecting the evening schools. Yasser mentioned that before transferring to an evening shift, his students were a mixture of Arab origin, Saudis and non-Saudis, as well as many of South Asian and African students. As for now, there are no Saudis in the evening school except for a small percent who were children of the school faculty. The major issues for non-Saudi students can be categorized into two types; low economic status and lack of Arabic language. The financial status of most students is low. Many parents had low levels of education and worked in simple occupations that do not meet their actual expenses. Students were not able to afford their education supplies, and therefore could not do their homework, which 
negatively affected their education performance. Teachers at Eastern Mecca Elementary started a donation program to provide free lunch for those low-income students. Khaled was hoping that the Office of the Director of Education would give financial support to these students so that they could obtain their school supplies.

Students' mastery of the Arabic language was another issue that teachers faced in Eastern Mecca Elementary school, and it was limited to non-Arab students. Khaled and Saeed agreed that many students have difficulty in understanding the Arabic language. Khaled explained that many teachers complained that some students lack many language skills, and they were not at the required level of understanding the Arabic language. To communicate with these students in the classroom, teachers asked other students who are fluent in Arabic to be an interpreter to transfer what the teacher wants to say.

Yasser had a different opinion about the problem of students' mastering the Arabic language. He argued that he did not notice that there was a weakness in understanding the Arabic language among his third-grade students, and there was no difference in the language aspect between their previous morning school and the current evening school. The school neighborhood is a mixture of different Arab and non-Arab nationalities, and Arabic is the only language for communication between members of the community. Therefore, the school is not the only place for practicing Arabic for nonArab students, and many of them have good relations with members of society and are in constant contact.

Despite the problem of school time and mastery of the Arabic language, the school principal was optimistic and emphasized that the teachers were able to overcome these problems. The Office of the Director of Education in Mecca, moreover, was trying 
hard to find a solution to get rid of the evening schools and bring them back to work in the morning, as Saeed believed, and the problem would not last long.

\section{Multicultural Education}

Teachers have different opinions about multicultural education; there are those who see it as positive and that is contributes to improving student performance and those who see it as a tool for the demolition of Islamic values and traditions. Both Saeed and Khaled agree that multicultural education has many positive aspects. Saeed explained that it is preferred that students be familiar with the cultures of other people, especially those who live within the same neighborhood. The school is the ideal place to know about other people's cultures, and the multicultural classroom is intellectually diverse.

Khaled claimed that multicultural education benefits both the teacher and the students. For many Saudi teachers, multiculturalism in education started with the beginning of the teaching journey, as many teachers are appointed to teach outside of their hometown, and this allows them to learn more about the cultures of different regions of Saudi Arabia. As students learn from their teacher, the teacher should learn from the students, Khaled stated. He learned a lot from his students, and he - a mathematics teacher - has mastered counting in different languages that he could not know if he did not see his students as a source of inspiration.

Students are the primary target of multicultural education. According to Khaled, multicultural education contributes to building an informed generation familiar with the cultures of others, and that students in a multicultural classroom perform better compared to students in a monocultural classroom. Therefore, Khaled believes that " الطلاب السعوديين "خسروا من هذه [التعددية الثقافية] ("Saudi students missed this multiculturalism”) after 
separating them from morning schools. Especially in some neighborhoods inhabited by non-Saudis who are highly educated, Saudi students have lost the opportunity to learn in a multicultural environment. Saudi students learn from non-Saudis habits, traditions and new ways of thinking and solving problems that they would not have known in a classroom with only Saudi students.

Yasser stood against multiculturalism in education in Saudi Arabia. Although he believed that cultural diversities in Saudi Arabia are only on the branches and that the origin is the Islamic culture, he argued that it is the demographics of society that determines whether multicultural education will have a negative or a positive effect on students. It could be said that students benefit from each other and learn about different cultures and learn new methods of solving problems if they are all from educated families. As for the low income and uneducated communities, where crime rates are high, it cannot be said that it is a suitable environment for multicultural education. Yasser added that multiculturalism in their current school participates in reducing the quality of education in Saudi Arabia because students were from uneducated backgrounds and many of them do not think that education may improve their lives. However, when I asked him about multiculturalism in education in their previous school before moving to evening time, he stated that the situation varied due to the difference in the economic status of students. During the last school, there were large numbers of Saudi students from the middle class and educated families. On the other hand, there were several other non-Saudis aware of the importance of learning in changing an individual's life, but as a result of the economic reforms undertaken by the country since 2016 , many of them returned to their country and left behind a gap in multicultural classrooms. The Saudi 
government increased the fees for renewing residence permits for families and individuals, which made some of them have to leave the country and search for another place to live. According to Yasser, this economic reform negatively affected students' performance in multicultural classrooms, because many of the students who left the country were from highly educated families.

Both Khaled and Yasser, according to their interviews, did not consider cultural diversity in their teaching. Khaled - mathematics teacher - stated that some school subjects are based on tangible skills and that the difference in cultures and language is not considered an obstacle for the student to master these subjects such as mathematics, physical, and art education. In his classroom, Khaled used two main teaching strategies; using tangible objects and cooperative learning. He used touchable objects to explain mathematics to students, such as using cubes to count, add, and subtract. Collaborative learning aims to allow students to learn from each other, and it removes many of the barriers resulting from the Arabic language proficiency, as some students use their mother tongue to communicate with their peers in the group. Moreover, Yasser - thirdgrade teacher - did not see the importance of taking into account cultural diversity in the classroom for two reasons: all students and teachers belong to Islamic culture, and students in the class do not face any linguistic difficulties. Therefore, Yasser did not think that it is necessary to take cultural diversity among students into account when preparing for teaching.

Khaled and Yasser, like all other teachers in the Eastern Mecca Elementary school, are implementing a program called $(5 \times 10)$ that aims to develop students' skills in reading and writing. The idea of the program is that at the beginning of each class for ten 
minutes, the teacher asks his students to read and spell ten sentences or words associated with the teaching lesson. $(5 \times 10)$ is an initiative launched by the Ministry of Education and circulated to all schools, but it did not receive the approval of some school principals, which made them not keen to implement it. However, Khaled and Yasser believed that the program reflected positively on the students' performance in reading and writing. As many of students were non-Arabia speakers and facing difficulties in Arabic language, $(5 \times 10)$ was considered as an intensive Arabic learning for non-Arabic speakers.

When I asked the participants to explore the relationship between students and the role of school faculty in building this relationship, they all agreed that students have a strong friendship with each other, and this relation extends out of the school. Students in the elementary stage love making new friends, and they do not yet understand the meaning of racism; they do not differentiate between each other based on race and color. Therefore, Yasser argued that the school does not have a significant role in strengthening the relationship between students, but rather it is an innate thing " الأطفال في السن هذا طبيعتهم الود (“children at this age are naturally friendly”). Another significant point mentioned by some participants was that students at the evening school are well behaved in general. They are keen to follow the school rule and not become involved in any problem with other students for fear that the punishment will be harsh, and they cannot bear its consequences.

\section{Education for all}

Since the establishment of the Kingdom, providing free education has been one of the foundations that witnessed a rapid growth movement across the country. The government focused on education and building schools in cities and villages to deliver 
education for all. Saudi Arabia, with other UN member states, involved in developing the Sustainable Development Goals (SDGs) and the Education 2030 Framework for Action that aim to ensure equal educational opportunities for all population groups.(UNESCO, 2018).

Participants for Eastern Mecca Elementary agreed that free education is a right for every individual who lives in the country, and that the Ministry of Education does not distinguish that between Saudi and non-Saudi students. They all have equal education opportunities by attending the same schools and sharing the same school facilities. Saeed - the school principal - stated that in Saudi Arabia there is no differentiation between students based on their cultural background, "في المدرسة كلهم سو اسية"in school, they are all equal"). Non-Saudi students, just like other Saudi students, participate in all school activities and take advantage of all school facilities.

Khaled mentioned that in the first year in an evening school, he felt the distinction between the morning and the evening schools. The reason for this distinction, according to Khaled, was because of the lack of organization for relocating many evening schools in the same school year. However, in the current year, there are no differences between morning and evening schools. Students at both schools study the same course, taught by competent Saudi teachers, and use the same school facilities, but the difference is only in the timing of the study, which is a matter of time and will be resolved. Unlike Khaled, Yasser stated that transferring non-Saudi students to study in the evening period deprives their right to freedom of education. He criticized the segregation between Saudi and nonSaudi students and explained that it is possible to improve the school environment without this segregation based on students' nationalities. 
Saeed claimed that teachers at Eastern Mecca Elementary perform very well when I asked him about the performance of the teachers after moving them to an evening school. The school had many distinguished teachers, many of whom are accustomed to the working time and have made great efforts in teaching non-Saudi students. On the other hand, Khaled and Yasser argued that the performance of some teachers differed after moving to the evening period, and the grumbling became the character of many of them. The teachers complain about school time and the type of students. Some of the teachers believed that they were wronged when they were transferred to work in the evening. According to Yasser, not all teachers in the evening school were passionate about teaching and realize their responsibility towards their students. Some students may be subject to contempt and criticism by some teachers. Some teachers repeat phrases such as "What will these students become when they grow up", "They will not change the world" as a way to show that there is no need to exert more effort with some students. This contempt is not because students are non-Saudi, but rather it presents in many schools in low-income societies regardless of the ethnicity of students.

The enrollment in the Eastern Mecca Elementary school is not different from the rest of the schools in Saudi Arabia, as it is through a unified platform managed by the Ministry of Education. The school enrollment requires a valid legal residency for nonSaudi students. However, some nationalities are excused from the valid residency due to the difficult circumstances in which they live. Students from countries such as Yemen can enroll in public schools by their visitor visa, but they have to do a placement test to determine the appropriate school level if they do not have an academic record. The other side of the non-Saudi students are those whose residency permits expire, and they are not 
able to renew them, the school allows them to study, and they are not deprived of their rights to education. Khaled stated that there was a third of the students in their school whose residency permits expired, but they have to come to school on a daily basis, so the school "ما يتركو هم في الشارع" (“cannot leave them on the street”). The public schools in Mecca encompasses all students and provide them with equal educational opportunities and do not require valid legal residency as a condition for enrollment in the school for all students.

\section{Professional Development}

The Ministry of Education has established an Educational Training Department in each Office of the Director of Education that aims to develop the knowledge, skills, and attitudes of the teachers to keep pace with the academic and technical development, and improving the teaching and learning processes. At the beginning of each school year, the Educational Training Department publishes a list of training programs during the year where teachers can know and register for the programs they desire.

Teachers at Eastern Mecca Elementary criticized the role of the Office of the Director of Education in preparing them for teaching in an evening school. Khaled believed that it is necessary to found training programs for teachers who work in evening schools since many students were not fluent in Arabic, which hinders the communication between the students and the teacher. A tremendous amount of class time is wasted because of a gap in communication between students. Thus, teachers should be trained to communicate with those students by learning common words in their languages, such as open the book, read, and write. Yasser mentioned that he is always aware of the courses offered by the Educational Training Department and that he has never seen any training 
program on multicultural education or any program intended for evening school teachers. يشتكون من أن اللغة حائلا بينه وبين الطالب مع هذا ما “ During the training programs, many teachers (complain that the language is a barrier between them "في أي مبادرة من مكتب التدريب التربوي. and their [non-Arabic speakers] students, though there is no initiative from the Educational Training Department”) to offer training programs for the evening teachers.

The performance of the Educational Training Department is not satisfactory to many teachers. The repetition and lack of variety is the dominant characteristic of the offered programs. Yasser believed that many of the trainers are not at a high level of professionalism, as the role of many of them is limited to reading some papers and slides for the audience, which disappointed teachers and discouraged their interest in registering for future programs. Yasser blamed the Office of the Director of Education for the low quality of training programs, and he stated that teachers' supervisors are responsible for preparing the training programs in addition to their usual duties of monitoring and developing teachers' performance in the classroom and many office tasks. Although many supervisors do not want to provide training programs because they believe they are not qualified for that, the Office of the Director of Education does not exclude any of them from doing that. He suggested that the Educational Training Department should have full-time coaches who are responsible for presenting courses for the teachers, and not ask the help of the supervisors for that. 


\section{CHAPTER 6}

\section{CROSS-CASE ANALYSIS, INTERPRETATION, AND CONCLUSION}

\section{Introduction}

This study aimed to present an understanding of Saudi teachers regarding multiculturalism and multicultural education in Saudi Arabia. The previous two chapters presented two cases from schools that varied in their level of cultural diversity. First, Central Mecca Elementary. It was a morning school where the time for schooling started from early morning till noon and it was restricted only to Saudi students. Second, Eastern Mecca Elementary. It was an evening school where their time for schooling starts in the afternoon (12:30 p.m.) until evening (6:00 p.m.) and it was for students from all nationalities but Saudi Arabia.

This chapter has two purposes. The first is the presentation of the cross-case analysis for the first and second research questions "What are Saudi educators' conceptions of culture and multicultural education?" and "What practices do educators employ with respect to multicultural education?". The cross-case analysis reported in this chapter is built upon the themes and categories presented in the two cases: Central Mecca Elementary and Eastern Mecca Elementary. Moreover, the cross-case analysis in this study aimed to display and summarize the data and draw conclusions.

The second purpose of this chapter is to answer the third research question, "How do educators implement multicultural education for their students at schools with different levels of cultural diversity?" After finishing analyzing the data of the two 
schools separately, I identified in this chapter the similarities and uniqueness resulting from the differences in the school environment and the levels of cultural diversity.

\section{Comparison of Schools}

The education reform movement carried out by the Office of the Director of Education in Mecca has affected all students in the city. The closing of many charter and public schools that had an inadequate school environment led to an increase in the number of students in the remaining schools. Therefore, the Office of the Director of Education in Mecca has taken temporary steps to solve this problem. One of the most important was to increase the working hours in some school buildings and use them in several shifts. This decision affected many schools; the year 2016 was different for many students, as they had to attend schools in the evening time and in a new school environment that had not been previously experienced. One of the most critical organizational procedures for this decision was to segregate between Saudi and nonSaudi students by allocating the morning schools for Saudi students and the evening schools for non-Saudi students of various nationalities.

Both Central Mecca Elementary and Eastern Mecca Elementary were affected by the reform movement but in different ways. Central Mecca Elementary was merged with two other elementary schools and moved to a renovated school building in the morning time. At the same time, Eastern Mecca Elementary was also combined with other schools and moved to a new school building, but in the evening time. Moreover, the students' demography in both schools tremendously changed from demography that reflected the cultural diversity of the city of Mecca to demography that did not represent the neighborhood around the school. In a culturally diverse city like Mecca, Central Mecca 
Elementary became a monocultural school that was only for Saudi students, and Eastern Mecca Elementary was a school that for students from different cultural backgrounds but excluded Saudi students.

The communication between morning and evening schools was an issue mentioned by many teachers from the two schools. Both Central Mecca Elementary and Eastern Mecca Elementary shared the school building with other schools. The morning school was mainly responsible for the school building. In contrast, the evening school was temporary and awaits moving to a separate building in the morning time whenever it will be available. According to Fayez, there was no coordination or joint plans between morning and evening schools, as each of them has its separate school plans. The lack of coordination between the two schools that share the same school building disrupted the educational process in the schools through the difficulty of accessing some school facilities such as laboratories, the school library, and teacher rooms. The evening school was the worst affected by the schools merging as it was the temporary school in the building. Yasser - a teacher at Eastern Mecca Elementary - stated that because of the lack of coordination, some school facilities were purposefully locked by the administrators of the morning schools. The Office of the Director of Education did not develop a communication strategy between the morning and the evening schools to coordinate with each other.

The neighborhoods of the two schools differ in the economic status and level of education. Central Mecca Elementary was a school in a middle-class community. Bandar described the community around the school as an interconnected Muslim society due to the role of mosques in peoples' life. The school, moreover, significantly participated in 
educating people in the neighborhood. It had partnerships with many community organizations such as the neighborhood center, neighborhood clinics, and the police department to offer courses and workshops at the school for the students and the community members. However, Eastern Mecca Elementary was a school in a lower-class community. Khaled explained the economic status of the students as many of their families were not highly educated and they live in poverty. The majority of parents were working in simple occupations whose pay is not sufficient to meet their essential financial needs, such as carpentry, construction, and car maintenance.

The Eastern Mecca Elementary had no activities and partnerships with the community outside the school. Saeed - the school principal - stated that the schooling time is an obstacle to building community partnerships and providing training programs for the school neighborhood. The negative effect of the schooling time also affects teachers and students at the evening school. The school day began in an afternoon time when the temperature reaches $45^{\circ} \mathrm{C}\left(113^{\circ} \mathrm{F}\right)$ on some days. Students were exposed to high temperatures when they leave the house heading to school and during the performance of some school activities such as physical education classes and the school queue. Khaled mentioned that the cooling system in classrooms and laboratories is excellent, but students cannot do any activities outside of their classrooms.

\section{The Meaning of Culture}

The meaning of culture varied between participants. When I asked participants to define culture, their answers came in three different themes: (1) three participants defined culture as knowledge, (2) one participant described culture as customs and traditions, and (3) two participants believed that culture is an integrated system. 


\section{Culture as Knowledge}

Mosh, Saeed, and Bandar agreed upon defining culture as knowledge. They stated that culture is a word that encompasses all kinds of information an individual receives from various sources of learning. The word culture is mostly used in its adjective form to describe a knowledgeable person as a 'cultured' who enjoys reading in multiple fields of knowledge. Although many people use the word culture to refer to traditions and family background, there is a significant deferent between the two meanings, according to Mosh, Saeed, and Bandar. Mosh and Saeed, for example, clarified that customs and traditions are manners and behaviors that one learns from the surrounding community and is not information one seeks in books. Bandar had a different perspective in explaining why culture is knowledge. He stated that what an individual inherited from the previous generation is the knowledge that contributes to shaping behaviors and manners.

Therefore, the three participants agreed that culture is knowledge, but they did not agree with the source of cultural information and how it influences human behaviors.

Although they defined culture as knowledge gleaned from books and literature, Mosh and Saeed described themselves as belonging to the culture of their tribes, which appreciates the customs and traditions inherited from previous generations. The conflict between their definitions of the culture and the culture they belong to implies that they agreed with Bandar in understanding how inherited culture shapes behaviors. Bandar, on the other hand, believed that his culture belongs to the society where he lives and is not inherited from his tribe. As a person who grew up in Mecca and was affected by its cultural diversity, Bandar mentioned that he belongs to the culture of the Meccan society, 
which is greatly influenced by the millions of Muslims who visit the Holy Mosque every year.

\section{Culture as Customs and Tradition}

Khaled was the only participant who believed that culture relates to customs and traditions. Culture is the outcome of what individuals learn from the older generations and the surrounding community to shape behaviors such as language and faith. Khaled, moreover, mentioned that culture is dynamic and is experiencing change. The Meccan culture, for example, differs from the culture of many other regions in Saudi Arabia. It is a culture influenced by many Muslim visitors from different parts of the world.

Khaled defined himself as a person who belongs to the Meccan culture and is influenced by the multicultural society. As a person who grew up in Mecca, he was influenced by the customs and traditions of its people. Since their childhood, people of Mecca have dealt with millions of visitors from different cultures. Thus, the Meccan people are more open to other cultures than people from many other regions in the country, according to Khaled.

\section{Culture as a Relationship to People vs. Place}

Although Bandar and Khaled explained culture in different ways, they both stated that they belong to the Meccan culture. The difference between Khaled and Bandar is that Bandar, who believed culture is knowledge, saw his relationship with the Meccan culture as a relation to people of Mecca. The culture of Mecca is an Islamic culture that people learn and practice. The people of Mecca and their enthusiasm to teach their children the Islamic education, such as praying in mosques, attending Islamic scientific lessons, and 
performing good deed with neighbors all are dominant parts of the Islamic religion, which is the root of the Meccan culture.

Khaled, on the other hand, saw his relationship with the Meccan culture as a relation to a place. The Meccan culture is a dynamic culture that is influenced by many Muslim visitors. The presence of the Holy Mosque has made Mecca the excellent destination for Muslims since the early era of Islam. Many Muslims have come to Mecca from several regions, such as India, East Asia, and Africa, all of whom participate in forming part of the Meccan culture.

Bandar and Khaled are both belong to the Meccan culture, but their belonging was seen from different perspectives. Bandar believed that he belongs to the culture of the people of Mecca who are the bases of the Meccan culture. Khaled, on the other side, claimed that he belongs to the culture of the city of Mecca that has a high value for all Muslims.

\section{Culture as an Integrated System: Two Perspectives}

Fayez and Yasser defined culture as a broad term that includes all aspects of life. It is a framework that guides the behaviors of an individual and society. Although Fayez and Yasser defined culture as an integrated system, they understood it from two different perspectives. Fayez argued that culture is a framework for society. Culture is the framework for interaction with and communication between members of the community. For example, one characteristic of the Arabic culture is that it distinguishes between people based on their public speaking skills, where they appreciate the poet, writer, and skilled speaker more than anyone who works with his hands. 
Yasser, however, believed that culture is a framework for an individual. Culture is the context that determines how a person deals with matters surrounding him. Because Yasser belonged to the Saudi Islamic culture, Islamic teachings are the basis that guides his life in dealing with the people around him, even with people from a different culture.

Both Fayez and Yasser explained their culture as a Saudi Islamic culture, which they shared with all Saudi citizens. Although they belonged to the Meccan community, they refused to define their culture as a Meccan culture. Unlike Khaled and Bander, Fayez and Yasser stated that the people of Mecca do not have a distinct culture that distinguishes them from the other Saudis. If there is a difference in culture, it is limited to some Saudi families of non-Arab origin who settled in Mecca a long time ago.

\section{Interpretation}

In relation to the finding of the meaning of the cultural concept, similar to those involved in the review of the literature, participants did not agree on one definition of culture. They each developed a definition that describes their understanding of the word culture based on their lives and their surrounding communities. Participants' definition of the word culture can be categorized into three groups. The first group includes three participants who defined culture as the knowledge that is gained from various sources. The second group is only one participant who defined culture as customs and traditions that are learned from the older generations and the surrounding community. The last group contains two participants who defined culture as an integrated system that encompasses all life aspects.

The three categories were found in the literature. In many studies, culture was defined as a network of knowledge, thought and behaviors that passed through 
generations, or complex whole that includes all aspects of an individual's life. However, the definition presented by Bennabi included all the three categories that found in the current study. Bennabi defined culture as a combination of three realms: the world of people, the world of objects, and the world of ideas (2003). The world of people is the relationships, systems, and communications that govern the lives of individuals. The world of objects is the materials and physical items that surround the people in their community. The world of ideas is the thought, knowledge, and beliefs that guide the behaviors. Participants' understanding of the word culture perfectly fits in one or more of the three cultural realms that are mentioned by Bennabi.

Defining culture as knowledge was consistent with many works of literature, including what was mentioned in the review of the literature. Culture has been defined by Saeed, Bandar, and Mosh as knowledge an individual receives from various external sources. This definition agreed with what Bennabi called the world of the idea that refers to the thoughts, knowledge, and beliefs that shape behavior. Hong (2009), moreover, provides another explanation of the reason for defining culture as knowledge. Hong stated that culture "as networks of knowledge, consisting of learned routines of thinking, feeling, and interacting with other people, as well as a corpus of substantive assertions and ideas about aspects of the world" (2009, p. 4). Hong mentioned that the main dimension of the culture is not the ethnic and national groups, but knowledge. Defining culture as networks of shared knowledge helps to create a deeper understanding of culture and differentiates between culture and the people who carry it. Based on this definition, racial, ethnic, and national groups are agents who are carrying this knowledge between generations. 
Bandar, who defined culture as knowledge, stated that he belonged to the people of Mecca, and he described his own culture as a Meccan culture. His relationship with the Meccan culture is a relation to the people of Mecca. His understanding of the cultural concept is related to the world of people that was stated by Bennabi (2003). The world of people in Meccan culture is governed by Islamic teaching that set the relationships, communications, and laws that rule their lives. Bandar mentioned that, during his childhood, he learned many things from his parents as well as other older people in the neighborhood. The relationship between Bandar and other people of Mecca shaped his Meccan culture.

Khaled was the only participant who defined culture as customs and traditions that an individual learns from the surrounding community and the older generations. Defining culture as inherited behaviors and thoughts was also mentioned by Carter, who explains culture as "learned patterns of thought and behavior that are passed from one generation to another and are experienced as distinct to a particular group" (as cited in Hollins, 2008, p. 18). Although traditions include everything from the prior generations, even the small things such as saying 'Hi', in his definition Khaled limited the traditions to physical matters such as the food and the costumes.

Khaled stated that he belonged to the Meccan culture. Unlike Bandar, he explained his relationship with the Meccan culture as a relation to a place. The existence of the Muslims' sacred places in Mecca was the primary impetus behind creation of the Meccan culture. This relation to a place is related to what Bennabi (2003) called the world of objects that understand the culture as a form of physical items such as buildings 
and landforms. Khaled mentioned that Mecca is a city that receives Muslim visitors from several regions, and all of them participate in forming part of the Meccan culture.

Defining culture as an integrated system was the statement of the third group of participants. In this definition, participants agreed that culture is a whole life system for an individual and society. This definition corresponds to much of what was mentioned in the literature. For example, Edward Taylor, who was among the first who utilized the word culture, defined it as a "complex whole which includes knowledge, belief, art, morals, law, custom, and any other capabilities and habits acquired by man as a member of society." (1871,p.1). Another statement that explained culture was by Kroeber and Kluckhohn (1952) who reviewed and analyzed a list of cultural definitions and stated that Culture consists of patterns, explicit and implicit, of and for behavior acquired and transmitted by symbols, constituting the distinctive achievement of human groups, including their embodiments in artifacts; the essential core of culture consists of traditional (i.e., historically derived and selected) ideas and especially their attached values; culture systems may, on the one hand, be considered as products of action, on the other as conditioning elements of further action (p.181).

Although they stated their definition, they mentioned that there is no full theory of culture, and this formula will be modified and expanded in the future in regards to the interrelations of cultural forms. Another well-known definition in the Arab world and quoted by one of the participants is the definition stated by Bennabi (2003). Defining culture as an integrated system encompasses all the three realms mentioned in Bennabi's statement. It includes the world of people, the world of objects, and the world of ideas to cover all the life aspects of individuals and society. 


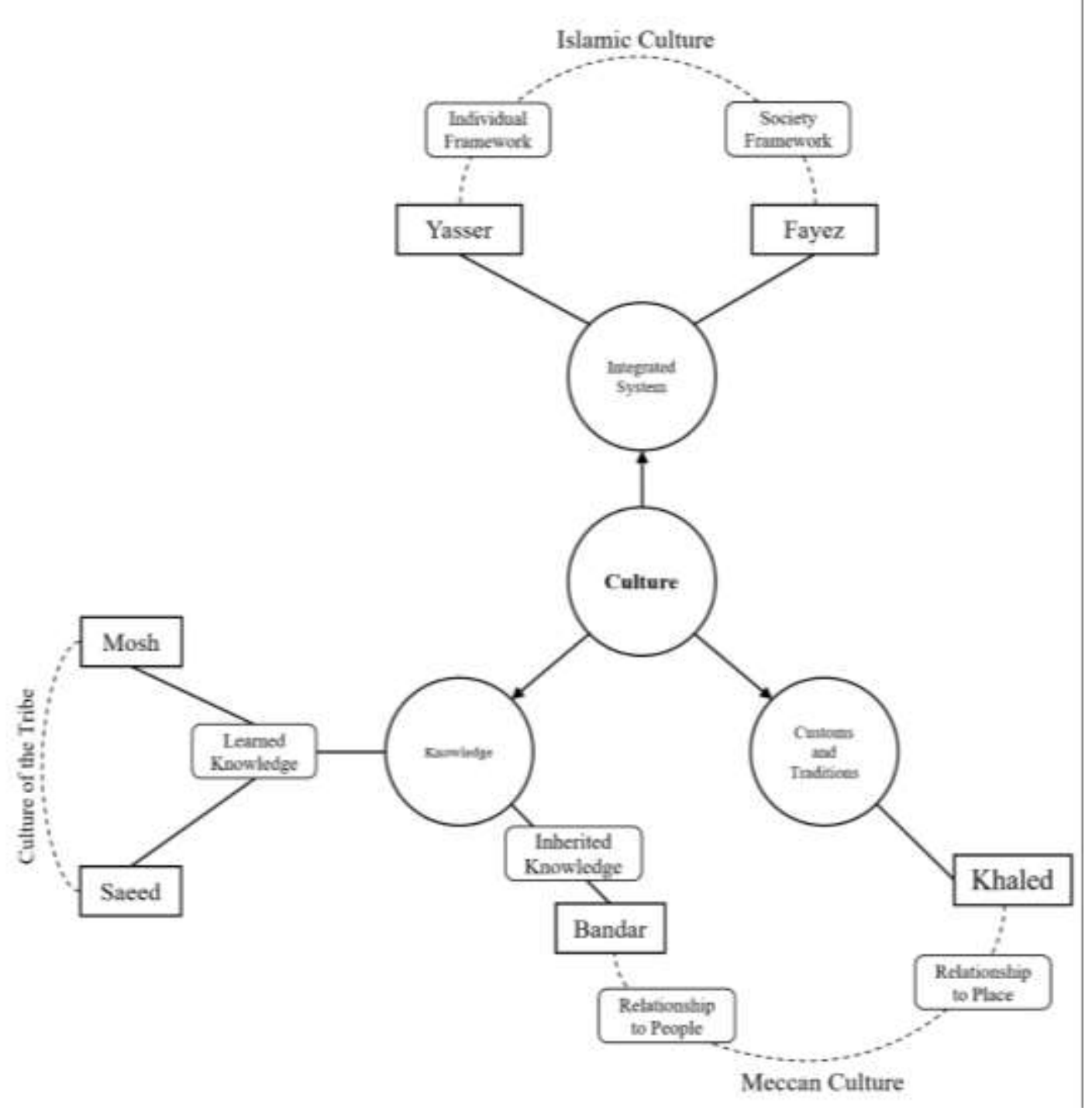

Figure 2. The meaning of culture ${ }^{2}$

2 (C) 2020 Mohammed Alharbi 


\section{Culture and Education}

The existence of a strong relationship between culture and education was agreed among all participants, but from various perspectives. When I asked participants about the relationship between culture and education, there responses came in three different themes: (1) there were teachers who believed that students' cultural background influences their learning at school, (2) another group of teachers stated that what influenced students' learning is not the culture but rather the family's background, and (3) the other group distinguished between the home's culture and the school's culture and argued that the teachers only could control the school's culture.

\section{Culture Shapes Ways of Thinking and Participating}

Bandar and Khaled agreed that students' cultural backgrounds influence their way of thinking and participating in a classroom. The essential part of the student's culture is shaped at home at an early age before attending school. Students can only realize what is compatible with what they learned from their parents. Bandar, for instance, mentioned that some Saudi students followed their cultural traditions, which might not be consistent with Islamic teaching. Bandar had to educate students' parents about Islamic teaching so that the students can follow what their parents learned and not the cultural tradition. Khaled, moreover, claimed that understanding students' culture assists the teacher in developing a teaching strategy in a multicultural classroom.

In his classroom, where some students were not fluent in the Arabic language, Khaled implemented a collaborative teaching strategy and divided students into groups based on their language abilities to ensure that each group has students from a different 
level in understanding the Arabic language. Because some students who were not fluent in Arabic feel embarrassed by participating and presenting their ideas in front of all classmates, collaborative teaching strategy creates a safe learning environment that enables non-Arabic speaker students to engage in an open dialogue with a small number of students who share the same language.

\section{Parent's Background and Student Performance}

Participants who stated that culture is knowledge, believed that the relationship between culture and education is the correlation between the parents' level of education and students' performance. An educated family plays a significant role in improving a child's performance in school. Saeed, for example, mentioned that the education of the family is what explains differences in school performance between students. Therefore, Saeed argued that in order for the school to help students in developing their academic performance, it is essential to build a way of communication between school and home rather than understand how students live at home. Yasser agreed with Saeed about the importance of the role of the family in improving academic performance. Although he defined culture as a way of life, Yasser did not see a cultural gap between teachers and students in his school. He argued that many non-Saudi students in his school were born and raised in Mecca and acquired Saudi culture from the society in which they live. Because he believed that all Saudis share the Saudi Islamic culture and there are no cultural differences between members of Saudi society, there is no cultural gap between students and teachers in Eastern Mecca Elementary as they share the same Saudi Islamic culture. Therefore, the difference between students' achievement in school is not related to the culture; instead, it associated with the education of the family. 


\section{School Culture}

Fayez distinguished between what he called innate and acquired cultures. The innate culture is what students learn from home, and the acquired is what they learn at school. As a school administrator, Fayez was concerned about the school culture in creating an inclusive school environment for all students from diverse cultural backgrounds. The school culture encompasses the school regulations and communication between teachers, administrators, students, and parents. Fayez mentioned that the influence of the school administrators is limited to the school culture; therefore, they must work with what they can control, not with what students live in their homes.

The sudden change in students' demography requires an urgent modernization of the school culture, which Fayez emphasized. The change that made Central Mecca Elementary a school for Saudi students requires an update in the school culture.

However, that urgent update needs approval from the decision-makers in the Office of the Director of Education. Fayez, nevertheless, argued that the Office of the Director of Education in Mecca is the decision-maker for school projects, and he considered this an obstacle that caused delays in implementing many educational programs. He concluded that school administrators face difficulties in updating school culture based on the need of their students. They develop a year plan and share it with the Office of the Director of Education to get approve. Updating the school plan based on the students' needs during the school year needs another approval form the Office of the Director of Education and that might take a long time. 


\section{Interpretation}

The finding of this section, culture and education, shows that all participants agreed about the strong relationship between culture and education. Their understanding of this relationship can be categorized into three themes; students' culture shapes their way of thinking, parents' background and students' performance, and school culture. All three themes appeared in literature as significant elements in improving students' performance at school.

The first theme, students' culture shapes their way of thinking, reflects the role of the cultural background in classroom activities. The role of students' cultural backgrounds in their learning is highly emphasized in many theories, such as culturally responsive teaching (Gay, 2010), culturally relevant pedagogy (Ladson-Billings, 2014), and multicultural education (J. Banks, 2010; Bennett, 2018). It is through the cultural elements that knowledge is acquired. As it was mentioned in the literature review, there are six cultural elements, according to Banks (2015), that influenced students' learning and behaviors in classrooms such as cultural values, language, nonverbal communication, cognitiveness, identification, and worldview. Therefore, teachers should use the students' cultural background as a vehicle for learning. "When academic knowledge and skills are situated within the lived experiences and frames of reference of students, they are more personally meaningful, have higher interest appeal, and are learned more easily and thoroughly" (Gay, 2002, p. 106).

The second theme is the parents' background and children's performance. Several studies were found in the literature that investigated the relationship between family background and children's educational achievement. Coleman (1988) illustrated that 
family background is separable into three elements: financial capital, human capital, and social capital, all of which contribute to students' achievements. Financial capital is the family's income and wealth, and it relates to providing the resources that aid school achievement. Human capital is the parents' education and providing a supportive learning environment at home. Social capital is the relations between family members. Coleman (1988) and Li and Qiu (2018) found that the family's background influences the academic performance where the high social-economic status parents participate in their children's learning activities, communicate with teachers, and manage their children's behaviors at school. Li and Qiu (2018), however, added that the impact of the socialeconomic status on students' academic performance is not direct, and there is great room for the families and schools to take action in improving students' achievements.

The last theme in the category of culture and education is the school culture. The school culture is unwritten rules, traditions, customs, and expectations. In his book 'The Sociology of Teaching' Waller (2014) explained that when analyzing different schools, it was found that each school has its specific population, norms and traditions, networks of social relationships, and culture that is definitely their own. These unwritten and unofficial cultural patterns permeate all school aspects such as the school regulations, the relationship between teachers and students, how students and teachers dress, and school and family relationships (Deal \& Peterson, 2016).

Multiple studies showed significant correlations between school culture and students' achievement. The finding of this section is supported by correlational studies that investigated the relationship between school culture and students' academic achievement (Herndon, 2007; Quin et al., 2015; Waters et al., 2004). In a meta-analysis 
study that investigated 5,000 researches on school leadership and students' achievement, Waters, Marzano, and McNulty (2004) found a strong correlation between school culture and students' academic performance. Herndon (2007), moreover, found a significant positive correlation between a school culture factor of "learning partnership" and students' performance in mathematics. Furthermore, Quin, Deris, Bischoff, and Johnson (2015) conceptualized school culture in six factors; collaborative leadership, teacher collaboration, professional development, collegial support, unity of purpose, and learning partnership. They found a significant correlation between school culture and student achievement and recommend the school leaders to improve their cultural practices, especially the learning partnership, in order to increase students' academic performance.

\section{Multiculturalism}

The number of diverse ethnic groups in Saudi Arabia has increased rapidly over

the last decades. Statistics released by the General Authority for Statistics in Saudi Arabia show that the percentage of the non-Saudi population was 31 percent in 2010, and this percentage increased to 37.8 in 2019 (2019a), which made Saudi Arabia one of the most diverse countries in the world. The population of non-Saudis in the region of Mecca is about three million, making Mecca the second-most diverse city in Saudi Arabia after the capital Riyadh. The number of non-Saudi students who attend schools and universities in Mecca was 558,351 students in the year of 2019, with a percentage of 39.6 from the total of students in the region (General Authority for Statistics, 2019b). 


\section{Multicultural vs. Monocultural}

Teachers' perceptions regarding multiculturalism in Saudi Arabia varied between a group of teachers who believed that Saudi Arabia is a multicultural country and the other group of teachers who denied the existence of multiculturalism in the country. Participants' understanding of the concept of culture highly influenced their perceptions regarding multiculturalism.

Participants who believed that culture is knowledge and culture is a customs and traditions stated that multiculturalism is an existed phenomenon in Saudi Arabia. For example, Bandar - who believed that culture is knowledge - stated that Saudi Arabia is a multicultural country and the city of Mecca is a culturally diverse city. The culture of the city of Mecca is a dynamic culture that has been influenced by other Islamic cultures because of the millions of Muslims who visit the city each year. As a person who was born and raised in Mecca, Bandar said: “ انا عثت هذا التنوع كثير. التنوع الثقافي موجود عندنا في مكة "من قديم الأزل "I experienced this diversity. The cultural diversity in Mecca exists from ancient times").

Khaled was another participant who believed that Saudi Arabia is a multicultural country. Khaled defined culture as customs and traditions. This understanding of the concept of culture enabled him to observe the cultural diversity in the city of Mecca. According to Khaled, because of the existence of the Holy Mosque that gathered Muslims from different cultural backgrounds in the city of Mecca, the city has become multicultural and this distinguishes it from many regions of the country.

Yasser was one participant who stated that culture is an integrated system that governs the individual's life. He argued that there are no cultural differences between 
Saudi people, and all Saudis are sharing the same culture, which he called Saudi Islamic culture. However, multiculturism is an existed phenomenon in Saudi Arabia. The presence of this phenomenon is because of the foreign people who live in the country. For example, multiculturalism in Mecca is because of the sacred places for Muslims, where the city received millions of people from over the world. “ "بسبب] المكانة الدينية ووجود

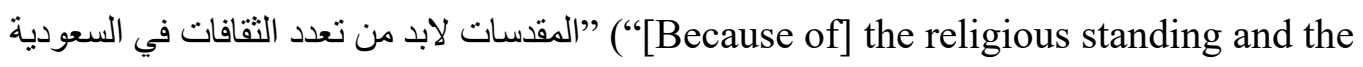
presence of Holy places, there must be multiculturalism in Saudi Arabia”).

Fayez was the other participant who defined culture as an integrated life system. He was the only participant who denied the existence of multiculturalism in Saudi Arabia. Fayez argued that there is only one primary Islamic culture, and the difference between cultures in Saudi Arabia and other regions in the Islamic world does not amount to be multiculturalism; instead, they all Islamic culture. The differences in things like dress, food, language, and traditions are minor that generate subcultures that had emerged from the same origin, which is the Qur'an and Sunnah.

\section{Perceptions Toward Multiculturalism}

The perceptions about the importance of multiculturalism in Saudi Arabia varied between the teachers who believed that it contributes to the community development and the others who argued that multiculturalism in Saudi Arabia contributes to losing the Islamic and Arabic cultural identity.

Teachers such as Fayez, Saeed, and Khaled agreed that multiculturism contributes to developing a community. Fayez, who argued that people in Saudi Arabia have only one major Islamic culture and many other subcultures, stated that this subcultural diversity contributes to improving the perception of the public. Because of the cultural 
diversity, Saudis became open to new cultures, and "our country is embracing everyone". Khaled, moreover, mentioned that monoculturalism contributes to decreasing the level of improvement in a community, but cultural diversity strengthens the community and broadens their perceptions because the members of the community would be open to new ideas and benefit from the experiences of others. Saeed, furthermore, claimed that a culturally diverse society allows people to learn about various cultures and experience new things that would not be available in less culturally diverse communities.

The other group of teachers, such as Bandar, Yasser, and Mosh, agreed that multiculturalism has a negative impact on Saudi society. All three teachers examined the advantage of cultural diversity in the school community, and they argued that children are vulnerable to new things and do not have a high level of critical thinking in order to distinguish between what is appropriate in their community and what is not. For example, Mosh stated that because of the cultural diversity, Saudi students in Mecca were influenced by many foreign cultures. Students at Central Mecca Elementary are using many non-Arabic words to express their emotions and feeling, which Mosh believed is a strong indication regarding losing the Arabic language and identity. Bandar, besides, explained that it is a beautiful thing for a society to be culturally diverse, but this requires raising the religious awareness of everyone by getting to know what contradicts the Islam teachings. Yasser added that children at the elementary school age do not have that awareness to distinguish between the good and the bad deed. It is the teachers' responsibility to protect students from extremist ideas and contribute to improving their critical thinking. Therefore, the three teachers, Bandar, Yasser, and Mosh, appreciate 
multiculturalism in the community but not in the school because the children are easily affected by every new idea.

\section{Interpretation}

The disagreement between the participants' responses about the existence of multiculturalism in Saudi Arabia is related to their understanding of the location of religion within the culture. Religion and culture are strongly related as a religion is a cultural expression (Beyers, 2017). The first group of participants who argued that Saudi Arabia is a multicultural country were able to distinguish between their culture and religion. Although they were all Muslims and many of them explained the role of Islamic society in shaping their culture, they differentiated between following Islamic teaching and practicing their traditions and habits. Ramadan (2010) proposed that the essence of Islam is religious, therefore, it should not be viewed as a culture. Islamic religion respects cultural diversity and it always been inclusive regarding social affairs. Muslims in Asia or Africa, for instance, have kept their traditions and habits that did not contradict any principle of Islam. "Thus, there is one religion, one Islam, with various interoperations and several cultures" (Ramadan, 2010, p. 42). Participants of the first group were able to follow the Islamic teaching and classify their personal culture and the culture of others in the country.

The second group of participants, who could not separate between culture and religion, viewed the culture from a religious perspective. Fayez was the only participant who argued that there is no separation between Islamic teaching and cultural traditions. Therefore, he stated that there is no multiculturalism in Saudi Arabia, but is only one major Islamic culture. Fayez refused to introduce himself as belonging to the culture of 
the people of Mecca, like many other participants, because of his belief this culture has some customs that contradict the Islamic teachings that he believes in. Fayez believed that religion and culture are overlapped and cannot be isolated from each other. On the line with the integration between culture and religion, Beyers (2017) agreed with Fayez and rejected the idea of one religion and several cultures presented by Ramadan (2010). Beyers mentioned that it is impossible to be a Muslim and belong to Western culture because the culture and religion are overlapped based on circumstantial conditions.

The current study also found that there was a group of participants who criticized multiculturalism in Saudi Arabia, and they believed that it is a step forward losing Arabic and Islamic identity. Bennett (2018) explained why some teachers and school administrators stand against multiculturalism. Bennett stated that the misconceptions about the definition of multiculturalism is part of the reason. A critical point against multiculturalism is that it leads to "moral anarchy" because there are no guiding principles or values to govern society. This moral anarchy might cause a conflict between multiculturalism and Islamic religious beliefs or Arabic identity.

\section{Multicultural Education}

Teachers' perceptions regarding multicultural education varied between a group who see that it contributes to improving students' performance, another group who argued that it benefits the teachers in developing their teaching practices, and the other who believed that it is a way to harm the Arabic and Islamic identity. Participants from Central Mecca Elementary agreed that multicultural education is a step for education development. On the other hand, not all participants from Eastern Mecca Elementary - a culturally diverse school - agreed about the advantage of multicultural education. 
The majority of the participants agreed that multicultural education is a necessity for education development in Saudi Arabia. Teachers such as Bandar, Khaled, and Mosh stated that students in a multicultural classroom perform much better compared to others in a monocultural classroom. The enthusiasm and variety of thought are all characteristics of a culturally diverse classroom that do not usually exist in a monocultural classroom. Multicultural education, moreover, plays a significant role in informing students of others from a different culture. All three teachers criticized the segregation between Saudi and non-Saudi students in school. Khaled, for example, stated that "Saudi students missed this multiculturalism" when separating them in morning schools. Bandar and Mosh also said that Saudi students' academic performance and cognitive skills were negatively affected by separation.

There was a second group of participants who stated that multicultural education benefits teachers as well as students. Fayez and Khaled argued that a multicultural classroom is a source of new knowledge for the teacher. Many Saudi teachers started their career in a region outside of their hometown, which provides an opportunity to learn about various cultures in Saudi Arabia. In a culturally diverse city such as Mecca, teachers learn about the culture of non-Saudi students. According to Khaled, he learned from his non-Arabic students how to count in different languages, and that could not happen for him if he did not see students as a source of knowledge. Fayez, moreover, believed that multicultural education is a way to develop teachers' performance. Multicultural education is a step forward to internationalizing the school curriculum when a teacher learns new teaching techniques and strategies that are used in other countries from international students. Therefore, Khaled and Fayez understood 
multicultural education as a way of professional development where teachers learn new knowledge and teaching strategies from their culturally diverse students.

In the situation of Eastern Mecca Elementary, both Yasser and Khaled argued that multicultural education contributes to reducing the quality of education because of the low economic status of the school neighborhood. Cultural diversity in Eastern Mecca Elementary is a cause of many problems as students learn from each other the bad habits that they only get in school. Because of the low level of education of many families, there will be a gap in the child's education and upbringing at home, and the greater reliance will be on the school that also fails to do its part due to the lack of cooperation between the family and the school. Yasser, who believed the relationship between culture and education is the correlation between the family's backgrounds and the students' performance, mentioned that the level of education and economic status determine whether multicultural education would improve education or not.

The attitudes of the participants towards multicultural education were not related to their understanding of cultural or multicultural concepts, but rather to the advantages that Saudi teachers and students gain from a multicultural classroom. For example, teachers from Central Mecca Elementary claimed that students and teachers in Saudi Arabia benefit from multicultural education. The classrooms lost enthusiasm, creativity, and diversity of thinking because of the segregation between Saudi and non-Saudi students. Students from the same cultural background mostly think in the same way, as was the case with the Central Mecca Elementary classrooms. On the other hand, teachers from Eastern Mecca Elementary argued that the impact of multicultural education in Saudi education depends on the family's backgrounds of non-Saudi students. Non-Saudi 
students from low family backgrounds negatively affect other students and the education system in Saudi Arabia, such as the case of Eastern Mecca Elementary.

\section{Implementation of Multicultural Education}

Teaching a culturally diverse class differs compared to a monocultural class. When I asked teachers from the two schools about teaching multicultural classes, their responses varied between a group of teachers who considered students' culture in teaching, and the other group did not see a need for considering students' culture in the classroom.

Teachers such as Bandar, Khaled, and Mosh explained that students' cultural backgrounds influence the learning process, thus it has to be included in their classroom teaching and activities. Bandar, for example, stated that teachers should know their students and be aware of their culture and prior knowledge to use it as a scaffold for future learning. When planning for a lesson, Bandar takes into consideration all his students' cultures, learning abilities, and prior knowledge. Many students, according to Bandar, move from their country or their schools to attend other schools. They experience a different school environment, and it is the role of the teacher to make students familiar with and love this new school environment. Therefore, allowing students to talk and express themselves and their culture is significant and helps the teachers to get to know more about their students.

Khaled and Mosh - mathematics teachers - agreed that the greatest difficulty in teaching non-Saudi students is the language difference, as the demographic of the Meccan population includes many non-Arab communities whose children are studying in public schools. To overcome the problem of the Arabic language among some students, 
Khaled and Mosh implemented the cooperative learning strategy where a student who is not fluent in the Arabic language will be in the same group with other students who are fluent in Arabic and share the mother tongue. However, Khaled and Mosh believed that the lack of Arabic language is not a significant obstacle in teaching mathematics, as it relies more on numbers and tangible tools than on Arabic texts. Mosh added that the Arabic language teachers are not prepared to teach non-Arabic speakers, and the school curriculum was designed for native Arabic students. Therefore, to overcome the Arabic language issue, Mosh suggested launching an intervention learning program for nonArabic speakers at lower grades as is applied in many Saudi universities.

Yasser was the only teacher who argued that there is no need for multicultural education in his classroom. His response was based on two elements. First, Yasser claimed that Saudi Islamic culture is a culture for all Saudi people, and many of nonSaudi students in his school are sharing the same culture with other Saudis because they were born and raised in Saudi Arabia. Second, Yasser was teaching a third-grade classroom, and he stated that non-Arab students do not face issues in the Arabic language. If any of the non-Arabic speaking students faced difficulty in the Arabic language, they should overcome this problem in first and second grades. Therefore, because Yasser shared his Saudi Islamic culture with all other people who grow up in Saudi Arabia, including his students, and because the students do not have difficulties in the Arabic language, Yasser mentioned that there is no need for multicultural education in his teaching practices. 


\section{School Relationship}

Building a friendly school relationship between all school members was a primary goal for teachers in the two schools. All teachers identified equity in education as an important sub-theme for school relationships. Bandar, for example, related that throughout his time as a teacher, he did not notice any discrimination against students based on their race or ethnicity to participate in school activities. Saeed, moreover, stated that in the school regulations, all students are equal and there is no preference for one race or culture over another. Arabic language may be an obstacle to communicating with some students, but this does not deprive them of their right to participate in school activities. All students have an equal opportunity to learn and participate in school activities. This equity in education is reflected in the interaction of students with each other when they realize that there is no preference for one over another, which contributes to creating a strong friendship between students.

Central Mecca Elementary launched a required program for the higher-level classrooms to inform them about the negative impact of bullying in peoples' lives and what is the appropriate behavior if they are exposed to it. The school aimed that program to establish a safe and friendly school environment that appreciates all students regardless of their cultural background. Bandar and Mosh explained how a culture of belonging works as a safe zone for some students. Bandar mentioned that political issues are a motivation for classroom arguments between students from different nationalities. The relationship between students is affected by some political decisions, especially in the event of crises. Political conflicts between India and Pakistan, for example, have caused a rift in the relationship between students from those countries. Despite this division 
between students, a robust national relationship is emerging that brings together citizens from each country separately. Mosh mentioned the same thing about the national relationships between students. He stated that students resort to their peers of the same culture or nationality when a problem occurs. If an Egyptian student, for example, has an argument with another student, he would ask the support from other peers from the same nationality. Banks (2010) stated that the identity of a cultural group increases when the group members feel threatened. Therefore, building a school environment that includes all students of different races and cultures is not sufficient for a student to feel safe in the event of crises, which makes him search for his safe zone as he surrounds himself with individuals of the same affiliation or nationality.

Teachers at Eastern Mecca Elementary had a different perspective on students' relationships at school. They agreed that the school is a safe environment and students have a strong friendship with each other. Yasser and Khaled implied that the school did not have a significant role in building this friendship between students. Many of the students live in the same neighborhood and their friendship started outside of the school in one of the community organizations such as mosques and Qur'an memorizing classes and playgrounds. Yasser said that his third-grade students were friends before they came to his classroom. They had known each other since they were in the first grade. Yasser and Khaled, moreover, mentioned that students' age is another factor for building friendships between students at the school. At an elementary level, students are too young to understand the meaning of racism and cultural and ethnic differences. "They are naturally friendly", according to Yasser. The other factor that assists teachers at Eastern Mecca Elementary to create a school environment that respects all students is that all 
students at the school were non-Saudi. They follow the school regulations more than the other Saudi students because they fear that violating the school rules will have consequences that they cannot afford. Therefore, they are keen on following the school regulations and avoiding making trouble inside the school.

The disparity between Saudi and non-Saudi students in the same neighborhood created a problem among students. Mosh said that the separation between students, who live in the same neighborhood, in two separate schools in two studying times caused a rift in the relationship between Saudi students and non-Saudis. While in the past they were friends, there was no time to meet inside the school. Even outside the school, when Saudi students return from school, non-Saudi students start their school day and end late in the evening. Friends no longer have the opportunity to meet in the community organizations such as mosques and the Qur'an memorization centers as they had before, due to the difference in school time between them.

\section{Equity in Education}

Providing a high-quality education is one of the essential services offered by the Saudi government to all students who live on its land. From an early age in the history of the country, the government has been intense to expand the establishment of new schools in all cities and villages and had brought in teachers from some Arab countries to keep up with the growing demand for formal education.

Free education is a right for everyone in Saudi Arabia, as agreed by all the participants. Fayez, for example, said that education and health services are rights that the government guarantees to all citizens. It is affirmed in the general objectives of education policy that the government is responsible for providing free education for all students. 
The free education that Saudi Arabia offers involves all students, regardless of their race and culture. Yasser agreed with Fayez and added that it is the right for non-Saudi to have free education and health services, like other Saudi citizens, since they have paid a residency fee. Khaled also stated that all students have the right to free education, and the Saudi government has provided this to all Saudis and non-Saudis students.

The process of school enrollment is similar for both Saudi and non-Saudi students. All students have to apply to school using the same electronic platform under the administration of the Ministry of Education. Students can select any school in the neighborhood and upload all the required documents online and receive the initial admission before visiting the school. The only difference between Saudi and non-Saudi students is that the enrollment for non-Saudi students requires a valid residency. However, the government excused students from some nationalities from valid residency as an understanding of the circumstances of difficulties of their life in their home countries. Yasser said that students from some nationalities could enroll in schools by their visitor visa, but they have to take a placement test if they do not have school reports that determine their level of study. Yasser and Khaled added that there is another group of students whose residency expired, and have financial difficulties in renewing it. This group of students has the full right to attend school and complete their studies.

Ensuring equal education for all students does not only mean equal opportunities to enroll in the school. Bandar mentioned that equity in Saudi education is not limited to school enrollment and activities, but it went beyond that to include participation in national and global competitions. There is no distinction between students based on their race or ethnicity in participating in activities at the school or country level. The country 
has witnessed many non-Saudi students who won a national competition and gained massive prizes.

The relationship between teachers and students from diverse nationalities is another significant element for education equity. All participants agreed that they had an excellent relationship with all students regardless of their race and nationalities. Mosh and Khaled, for instance, said that they build a strong relationship with students from different nationalities, and they have learned from non-Arabic students how to count in other languages. Bandar, moreover, mentioned that he has a strong relationship with many students of different nationalities, and he is in contact with many of them who have finished school and returned to their countries.

Bandar described the general impression among many Saudi teachers towards students of other nationalities, saying: “ المعلمين السعوديين يتعاطفون مع الطلاب الغير سعوديين يعني ”تعاطف كبير جدا وخصوصا من يعاني مثنلا من ضائقة مالية أو الأسرة تكون لا تستطيع توفير مصاريف أبنائهم. ("Saudi teachers sympathize with non-Saudi students, especially those who suffer from financial hardship, or if a family is unable to provide their children's expenses"). Yasser and Khaled agreed that many Saudi teachers do not differentiate in their performance between students based on their nationalities. However, the performance of some teachers varied based on the students' social class. Some teachers show a lack of interest in teaching and contempt for students, and this is not limited to non-Saudi students, but rather is present in many schools in low-income societies regardless of the ethnicity of students.

The segregation between Saudi and non-Saudi students that began in 2016 was a critical issue emphasized by all participants. As an educational reform, the Office of the 
Director of Education in Mecca closed many inadequate school buildings and moved students to newer facilities. The increase in the number of students versus schools led the Office of the Director of Education to use the restored school buildings in two schooling shifts, the first stated in the morning and the second in the evening time. The division of students in these two periods did not take into account the needs of students, as some teachers say, but was rather to facilitate administrative procedures, where all Saudi students were transferred to study in the morning period and non-Saudi students in the evening period.

The opinions of the participants regarding the separation between Saudi and nonSaudi students differed between a group who find it as a regulatory process, and the other group believed it deprives students of their rights. Teachers such as Fayez, Saeed, and Mosh argued that the segregation between students is for an organizational matter for a short period of time and the school system will return to the way it was before. In the evening schools, non-Saudi students were studying the same school curriculum from qualified Saudi teachers and using the same school facilities as the other morning schools. Yasser was the only participant who believed that the segregation between Saudi and non-Saudi students does not represent educational equity. Transferring non-Saudi students to evening schools without considering their personal needs deprives them of their right to equal educational opportunity.

\section{Interpretation}

One of the primary goals of the current study is to investigate Saudi educators' perceptions regarding multicultural education in Saudi Arabia. To examine the opinions and attitudes of participants toward multicultural education, I utilized Nieto's model of 
multicultural understanding (1994). Nieto defined multicultural education as a teaching philosophy and not a set of programs and course materials. The model of understanding multicultural education has four levels starting from tolerance, where teachers acknowledge diversity between students but have no clue about the relationship between cultural differences and students' academic achievements. The second level is accepting students' cultural differences, where teachers at this level acknowledge the differences between students, but they neither deny nor belittle the importance of these differences. The third level is respecting. Nieto argued, "when differences are respected, they are used as the basis for much of what goes on in schools" $(1994$, p. 5). Teachers at this level show high esteem for students' cultural diversity and create safe learning environments where students can share their stories and ideas about the role of their cultural group in developing society. It requires cooperation between parents, teachers, school administrators, and students to achieve this level of multicultural understanding. The fourth level is affirmation solidarity and critique, where students participate in an openended dialogue to reflect and critique their own culture and the culture of others in order to understand the differences of other cultures.

When using Nieto's model of understanding multicultural education to examine the participants' perceptions and attitudes toward multicultural education, it was found that their understanding of the concept varied among three levels in the model. The great number of the participants fell in the tolerance level, where they acknowledge the difference between students in their culture and language but fail to find a relationship between cultural differences and education. Yasser, for instance, argued that although all 
his students were non-Saudis, there are no cultural differences between him and his students nor between students with each other.

The second group of participants, including two teachers, was aligned with the acceptance level. All teachers in his group were mathematics teachers and they implemented a cooperative teaching strategy to help some students who had difficulties in the Arabic language to work with students from the same mother tongue. The teachers in this group stated that they learned many things from their students, such as counting in different languages.

The third group of participants, including one teacher, was lined up with the respect level. Bandar was the only teacher who implemented multicultural teaching practices to the level of respect. According to Bandar, when planning for a lesson, he considered all students concerning their cultural background and learning ability. NonSaudi students were given opportunities to share their stories and experience they have in their home countries. He, moreover, communicated with non-Saudi parents to learn about their culture and other jurisprudence Islamic schools. 


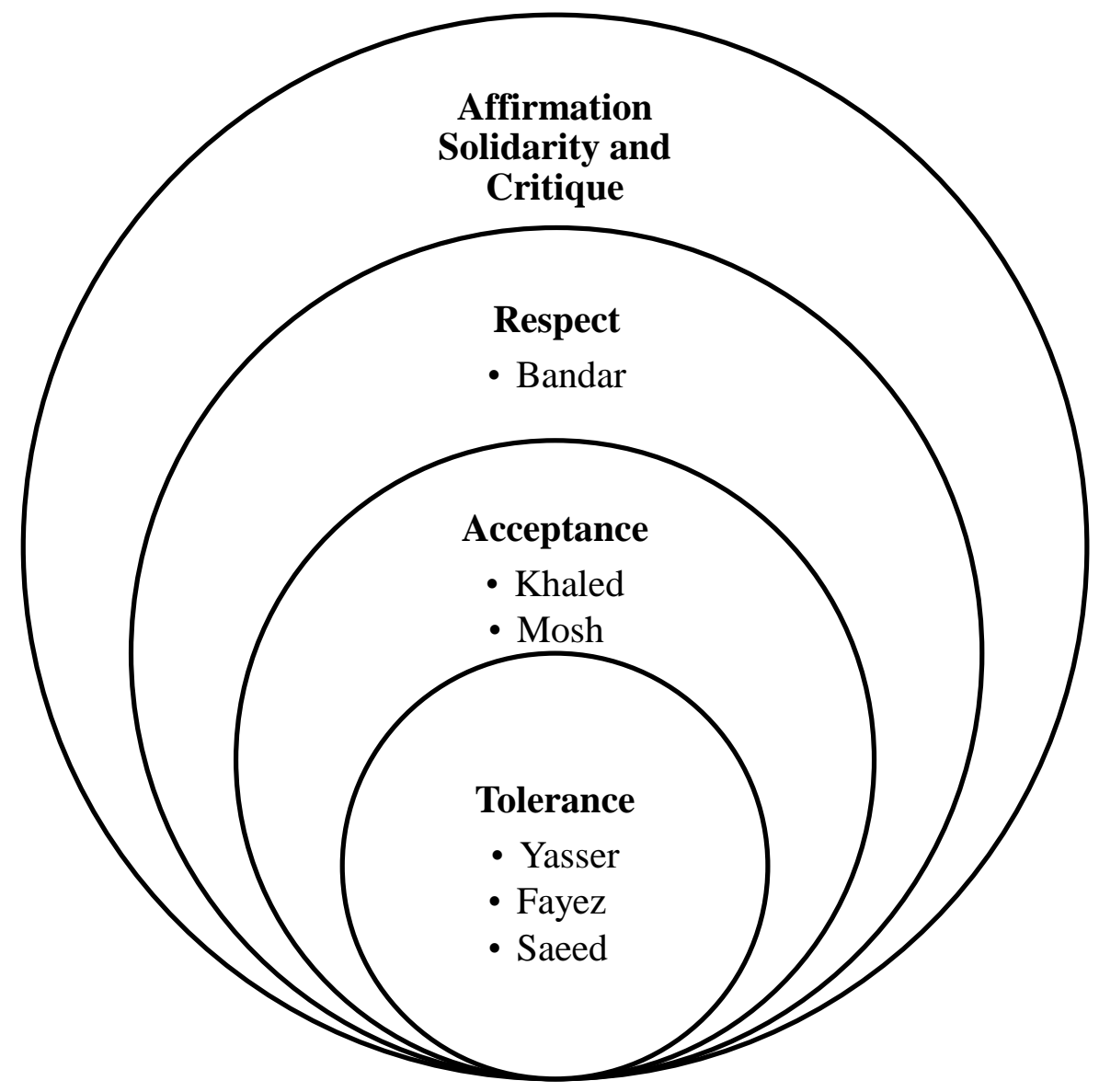

Figure 3. Level of understanding multicultural education

The finding of the teachers' understanding of multicultural education in the current study differs slightly from the outcome of other studies. Erbas (2017) examined the understanding of multicultural education for the pre-service teachers in Turkey, and he found that the initial response of all participants aligned with the second and the third level of Nieto's model. After studying a course in multicultural education, Erbas said that participants' understanding of the concept did not reach the highest level in the model, 
and primarily focused on the surface cultural elements such as food, stories, and celebrations. Agirdag, Merry, and Van Houtte (2016), moreover, conducted a mixedmethod study that included over 700 teachers to explore their understanding of multicultural education in Belgium. The researchers utilized Banks (2010) five dimensions model of multicultural education. The study found that teachers' understanding of multicultural education was consistent with the multicultural content integration dimension, which is limited to the celebration, holidays, and foods.

The finding of the current study also illustrated that teachers implement collaborative teaching strategy to overcome with Arabic language issues that face some students. In a multicultural classroom, language differences limit the effectiveness of interaction and using the relevant personal skills in a working group (Tielman et al., 2012). Students' cultural background influences their perceptions and interpretation of the learning environment. The lack of understanding of the culture of others might cause conflicts among students. In order to avoid conflicts and create an inclusive learning environment for all students, teachers can develop a sense of group identity that increases the effectiveness and interaction between the group members by sharing common learning goals for each group (Tielman et al., 2012).

Equity in education is another significant sub-theme that was highlighted by participants. Equity in education is at the heart of the education system in Saudi Arabia. The country, as the other UN Member States, involves developing the Sustainable Development Goals (SDGs) and the Education 2030 Framework for Action that aims to "ensure inclusive and equitable quality education and promote lifelong learning opportunities for all" (UNESCO, 2018, p. 11). The Saudi government has implemented 
three major streams to ensure equal educational opportunities for all groups of populations (Towards Saudi Arabia's Sustainable Tomorrow: First Voluntary National Review 2018 - 1439, 2018). The first stream focuses on adult education and the eradication of illiteracy. The government has launched summer campaign programs in remote areas to provide support in many aspects such as education, health, and agriculture. The second stream related to educating students with special needs, where the government established several centers for special needs that offer education and health supports. The third stream aimed to provide educational services to students in the southern border areas which are in the red unsafe boundary because of the conflict in Yemen.

Educational equity was evaluated from various perspectives, including the enrolments and accomplishments of students. International standardized tests such as TIMSS, PIRLS, and PISA are used to examine the extent of equity in education based on the academic success of students in various countries. In the status of Saudi education, there is no distinction between students based on their nationalities. All students have the right to free education and equal access to all sources of learning in the school. As immigrant students had the same quality of education as other Saudi students. Unlike many OECD countries, the PISA 2018 results showed that immigrant students perform higher than other Saudi students in reading where Saudi students scored 400 in the mean average and immigrant students scored 437 (OECD, 2019), which reflects the quality of education that non-Saudi students received. Investigating social segregation across schools was another goal of PISA 2018, which measure who children likely to communicate with peers from diverse cultural backgrounds. According to PISA 2018, the 
higher the score the more segregation between students across schools. The result showed that Saudi Arabia was below the average of OECD countries in social segregation (OECD, 2019). It can indicate that the school system in Saudi Arabia is inclusive for students from various cultural backgrounds, and they did not feel isolated in schools as more likely to communicate with peers from different cultures.

The social class difference was an anticipated finding of the current study. Participants emphasized the role of the family background and social classes on students' behavior and academic achievement in school. Teachers in a multicultural school stated that the low economic status of many families in the school neighborhood caused many teachers to view students with contempt and despise, as many of those teachers said that the students will not be better than their parents and will not have an important role in developing the community. The issue of social class difference also appeared in the level of the Office of the Director of Education in Mecca as they separate students between morning and evening schools based on their nationality and not their educational needs. Many participants did not notice any issue with this segregation as all students had equal education opportunities in terms of school curriculum and facilities.

\section{Professional Development}

The Ministry of Education is interested in training in-service teachers in order to provide the best educational services to students. The Ministry of Education has established an Educational Training Department in every Office of the Director of Education that aims to develop the knowledge, skills, and attitudes of the trainees to keep pace with educational and technical development, and improve the teaching and learning processes. The Educational Training Department in Mecca publishes a list of training 
courses, which is considered as a yearly plan for the department. This course list helps teachers to select their desired programs and include them in their school year plan.

Participants' perceptions regarding the services provided by the Educational Training Department agreed that it did not meet their needs. Teachers from both schools stated that many educational trainers were not qualified for that position. Many of them did not show enthusiasm during training, and they only share their presentation slides with attendees and read to them. For the low quality of the training programs, Yasser blamed the Office of the Director of Education, as they are responsible for assigning the trainers. Many of the trainers are teachers' supervisors, required to provide workshops and programs for teachers besides their regular duties of monitoring and developing teachers' performance in the classroom.

To provide better training services for the teachers, Yasser suggested that the Office of the Director of Education should assign full-time qualified trainers whose only responsibility is to work in developing teachers' performance by sharing with them new teaching strategies and methods. Fayez, moreover, suggested that each school should have its own training center where the coach comes and presents his program. Therefore, teachers do not need to leave their schools for a whole day to receive training.

When I asked participants if they have attended workshops or training programs that explain multicultural education and how to teach students in a culturally diverse classroom, they answered that there is no such program. Teachers at Eastern Mecca Elementary, for example, criticized the Office of the Director of Education, as it did not prepare them for teaching in an evening school. Yasser said that many teachers who teach in evening schools face issues related to students' cultures and languages, and they 
emphasized their need for training courses designed for evening schools' teachers.

Khaled, moreover, mentioned that teachers at the evening schools struggle with many students who do not understand the Arabic language, which creates a gap between the teacher and the students. He suggested designing a training course for the evening school teachers that teach them how to communicate with non-Arabic speakers' students. Yasser and Khaled stated that they had not seen any training program designed to inform teachers about teaching multicultural classrooms. Although there is a need for that, the Educational Training Department did not update the course topics to be compatible with the situation of the teachers.

Teachers at Central Mecca Elementary had their different opinion about the need for training courses on multicultural education. They all agreed that they had not attended any programs about multicultural education. Bandar argued that despite the variety of training program topics that are offered each year, there was nothing related to multicultural education. There is a vital need for such programs, as the country is witnessing an unprecedented transformation and opening up to the world. In Saudi Arabia, we receive Muslims from all over the world as well as non-Muslim tourists, so we must prepare our students adequately to deal with people from different cultures, as Bandar said. Mosh had a different perspective regarding the need for multicultural education training programs. He claimed that teachers in Central Mecca Elementary and other morning schools do not need to train to teach culturally diverse classrooms because all their students were Saudis and had the same culture. Fayez was the only participant who argued that the Educational Training Department had many training programs that fulfill a teacher's needs to teach a multicultural classroom. There were many topics about 
critical thinking and accepting students' ideas and ways of thought that are offered every year, and they are what teachers need in multicultural education.

\section{Interpretation}

Professional development for in-service teachers is crucial for both teachers and students. Several studies indicated that professional development is an effective tool to raise the competence of teachers so that they can create a great learning environment for students and supportive of other teachers (Al-Balawi \& Saeed, 2012; Alharbi \& Alshamrani, 2016; Badri et al., 2016; Phillips, 2008). To improve teachers' performance in classrooms, professional development has to be collaborative, long term and sustained, and intensive (Thomas R. Guskey \& Kwang Suk Yoon, 2009; Virginia Richardson, 2003). The necessity of professional development is for both experts and novice teachers to keep them updated with the continuously changing in the field of teaching and students' needs.

"Demonstrating knowledge of students" is one of the significant aspects that teachers need to consider when planning and preparing for teaching (Danielson, 2007). Because teachers prepare their lessons for students, it is required to know not only their teaching subject and pedagogy but also know their students' backgrounds. "Students also come to school with social and cultural characteristics that influence how they interpret events, participate in learning activities, and absorb new information" (Danielson, 2007, p. 48). Gay (2002) stated that knowing what to teach requires knowing about the students and subject matters. Because students' culture and background encompass many elements, teachers need to identify factors related to teaching and learning, such as the 
interaction between teachers and students and gender roles for implementing equity in the classroom.

Cultural diversity in schools has increased the need for multicultural education. One goal of professional development about multicultural education is to prepare teachers for teaching students from various cultural backgrounds (Hollins, 2008). However, Gay (2002) stated that many teachers are not well prepared to teach multicultural classrooms. Despite the increase in cultural diversity in schools, some professional programs still equivocate about including multicultural education.

The finding of the current study indicated that there is a need for professional training programs related to multicultural education. This finding similar to a few other studies that investigate the need for professional training in multicultural education. As was stated previously, Gay (2002) argued that many teachers are not equipped to teach a multicultural classroom. Furthermore, Badri and others (2016) analyzed the Teaching and Learning International Survey (TALIS; 2013) to understand the perceptions and needs of teachers in Abu Dhabi. The finding of the study shows that male teachers realized the need for professional development in school management and administration and a multicultural setting. Unlike Gay and Badri and others, many studies that investigate the professional requirements for Saudi teachers (Al-Balawi \& Saeed, 2012; Alharbi \& Alshamrani, 2016; Mansour et al., 2013) did not mention a professional development needs in multicultural education. The absence of professional development in multicultural education in Saudi Arabia is because of the following: first, the meaning of multiculturalism and the importance of multicultural education was not clear for many teachers. The finding of the study presented a different understanding of multiculturalism 
as some participants rejected the concept and stated that all Saudis and Muslims share the same culture. Second, many studies that investigated the teachers' needs for professional development applied a quantitative approach and collected the participants' responses by utilizing questionnaires that did not include items related to multicultural education. Therefore, the response of the participants of the current research as the need for professional development programs in teaching culturally diverse classrooms did not align with several studies that examined the professional needs of Saudi teachers.

\section{Conclusion}

The findings of the current study revealed the following conclusions. First, it can be concluded that participants' understanding of the meaning of culture is divided into three themes; there was a group of participants who believed that culture is a gained knowledge that an individual received it from the surrounding community. Another group of participants argued that culture is customs and traditions that an individual inherited for the older generations. The last group stated that culture is an integrated system that considers all life aspects.

The second finding of the study is that the relationship between culture and education was seen from three different perspectives. The first group of participants believed that students' cultural background matters and it influence learning and achievement at schools. The second argued that the matter is the family's background and not the culture of students. The third group of participants stated that the school's culture is what makes the difference in students' learning and it is what teachers could control.

The third finding of the current study is related to multiculturalism and multicultural education. Participants' perspectives regarding multiculturalism and 
multicultural education were divided into three viewpoints. The first group of participants believed that multiculturalism empowers the community and it improves students' achievements at schools. The second group argued that the advantage of multicultural education goes beyond students and it improves the teacher's performance in a classroom. The last group claimed that multiculturalism and multicultural education participate in losing the Islamic and Arabic identities for Saudi students.

The final finding is related to teachers' professional development. All participants agreed that training programs provided form the Educational Training Department did not reach their desire needs. They stated that the training programs and workshops were produced by educational supervisors who were not qualified to do so. The participants added that multicultural education was not given any attention, although there was a demand from many teachers in culturally diverse schools.

\section{Implications of the Study}

The findings of the current research have implications regarding multiculturalism and multicultural education in Saudi Arabia. The first implication indicated that the meaning of multicultural education that is used in the western world is not compatible with the culture of Islamic societies, including Saudi people. However, no study was found in the literature that explained multicultural education from an Islamic perspective. Gay stated that multicultural education "means different things to different people" (1994, p. 5). The finding of the current study presents the influence of Islamic religion in shaping the perceptions of many participants. The majority of the participants explained their culture from the Islamic point of view; Islamic culture or Meccan culture. This understanding of the cultural concept limits the meaning of multiculturalism and 
multicultural education to the Islamic perspective. However, multicultural education defined as an approach to school reform that aims to actualize educational equity for students from different cultural, ethnic, and linguistic groups (Banks, 2009a). The broadness of the meaning of multicultural education to include diversity in all groups such as gender, disability, and social class among other social and cultural differences has some limitations from the Islamic perspective.

The other reason that emphasized the need for multicultural education based on the Islamic worldview is the participants' implications of multicultural education. The model of understanding multicultural education showed that a great number of participants acknowledge students' differences in their culture and language but fail to explain the relationship between cultural differences and education. Some participants, for instance, claimed that there is no cultural gap between students and teachers in schools in Mecca as all students and teachers share the same Islamic and Saudi culture. Therefore, there is a need for developing a multicultural education philosophy for Arab and Muslim societies that take into account the Arabic and Islamic identities.

The second implication related to equity in education in Saudi Arabia. The country is one of the states involved in SDGs and Education 2030. SDGs include 17 goals in several aspects such as health, environment, and education. SDG 4 aims for quality education for all population groups (Towards Saudi Arabia's Sustainable Tomorrow: First Voluntary National Review 2018 - 1439, 2018). However, educators did not have a deep understanding of the concept of equity in education. The majority of the participants argued that the separation between Saudi and non-Saudi students was for organizational purposes to avoid overcrowding of students in classrooms. They said that 
separating students based on nationality does not diminish their educational rights; they all studying the same school curriculum, taught by qualified Saudi teachers, and use the same school facilities. The only difference is the schooling time. Nevertheless, avoiding overcrowding in classrooms can be done by dividing students into two schooling times based on their desires and not their nationalities. Therefore, teachers in Saudi Arabia need to be informed about equity in education and students' rights to empower all students to succeed.

The third implication of the study is the need for developing an Arabic learning program for non-Arabic speakers. Participants of the study illustrated how language difference has an impact on communication with non-Arabic speaking students. The increase in the number of non-Saudi students from different races other than Arabic emphasizes the need for establishing an Arabic learning program in public schools as it was found in higher education. Developing an Arabic learning program will benefit also Saudi students who face difficulties in language skills such as reading, writing, and comprehension. During the last two decades, a great number of Saudi students left the country with their families to study higher education abroad, which raised the number of Saudi children who face difficulty in reading, writing, and speaking skills in Arabic. The lack of an Arabic learning program for students with difficulties in Arabia language forced many parents to register their children in international schools that use their native language or English, as the case of many Saudi parents, as the main language of the school.

The fourth implication showed that teacher professional development programs need to be developed to prepare teachers to participate in building the future of the 
country. Saudi Arabia has a Vision 2030 (Saudi Vision 2030, n.d.) that aims to reduce dependence on oil by diversifying sources of income and making the country a global economic center and tourist destination. To achieve the goals, education must participate in the vision by preparing students for the future to live in a multicultural world that respects the rights of all and accepts their cultures. Therefore, teacher professional development programs should keep pace with the country's development needs and plans. The development of training programs on multicultural education is a necessity to prepare teachers and students to coexist and understand the value of other cultures from around the world.

\section{Limitations}

A limitation of the current study is the segregation between Saudi and non-Saudi students. When originally conceived, the sample was based on schools that included both Saudi and non-Saudi students in the same classrooms. However, the timing of the current study coincided with several school reform projects undertaken by the Office of the Director of Education in Mecca that aimed to improve the school environment. As one of a temporary solution to alleviate the overcrowding of students in schools, students were divided into two different periods. Saudi students were studying in the morning time and non-Saudis in the evening time. To overcome this limitation, a future study can be done in the city of Mecca, as one of the highest multicultural cities, after the educational projects are completed and the separation between Saudi and non-Saudi students in schools is over. 


\section{Recommendations for Future Research}

The current study investigated the understanding of multiculturalism and multicultural education among educators in Saudi Arabia. The findings of the present study were focused on boys' segregated schools. Formal education in Saudi Arabia separates students based on gender. There are special schools for boys that are taught by male teachers and other schools for girls, where teaching is restricted to female teachers. Future research can be done to examine the understanding of multiculturalism and multicultural education among educators in girls' schools.

The demography in Saudi Arabia varies between cities, where some cities are highly diverse than others. Therefore, the finding of the current study cannot be generalized to schools in other regions of Saudi Arabia. A suggestion for future research would be to implement similar research in urban cities and small towns that are less diverse.

The meaning of cultural diversity in the current study was limited to the difference in students' nationality, where Saudi students were considered as sharing the same culture. Although Saudi people are united by one language and belief, there is a great cultural diversity among Saudi citizens, as each region has its cultural characteristic. Future studies can develop a multicultural education model that aligns with the belief and background of Arab and Muslim countries.

The impact of classism and family background were highly stated in the study. Teachers explained that the difference in students' behaviors and achievement in school is related to the difference in their family's level of education and socioeconomic status. However, there is a lack of statistics and studies that investigate the issue of social class 
differences in the Saudi population. Future studies can examine the effect of social class differences between students in Saudi education.

The data of the current study was collected by conducting one way of data gathering: semi-structured interviews. The use of a single data collection method can introduce possible biases of some participants and limit presenting the full picture of multicultural education in Saudi Arabia. Future research can implement multiple data collection methods, such as observation and textual analysis. 


\section{Appendix}

Appendix A

\section{Question1:}

\section{Interview Protocol Matrix}

"What are Saudi educators' conceptions of culture and multicultural education?"

a. How do Saudi educators define multiculturalism and multicultural education?

b. How do educators explain the relationship between culture and learning?

c. How do they perceive non-Saudi students in their classrooms?

\begin{tabular}{|c|c|c|c|c|c|}
\hline \multirow[t]{2}{*}{ NO\# } & \multirow[t]{2}{*}{ Interview Question } & \multicolumn{3}{|c|}{$\begin{array}{l}\text { Research } \\
\text { Question }\end{array}$} & \multirow{2}{*}{$\begin{array}{l}\text { Type of } \\
\text { Question }\end{array}$} \\
\hline & & A & B & $\mathrm{C}$ & \\
\hline 1. & How would you like me to call you & & & & $\begin{array}{l}\text { Introductory } \\
\text { Questions }\end{array}$ \\
\hline 2. & $\begin{array}{l}\text { Tell me about yourself; Name, age, Teaching } \\
\text { subject and experience, degree, university, and } \\
\text { where you grew up. }\end{array}$ & & & & $\begin{array}{l}\text { Introductory } \\
\text { Questions }\end{array}$ \\
\hline 3. & $\begin{array}{l}\text { Tell me more about your school; the teachers, } \\
\text { students, facilities, and the community }\end{array}$ & & & & $\begin{array}{l}\text { Introductory } \\
\text { Questions }\end{array}$ \\
\hline 4. & $\begin{array}{l}\text { What is the thing that pops in your mind when you } \\
\text { hear the word culture? }\end{array}$ & $\mathrm{X}$ & $\mathrm{X}$ & & $\begin{array}{l}\text { Transition } \\
\text { Questions }\end{array}$ \\
\hline 5. & How would you define culture? & $\mathrm{X}$ & $\mathrm{X}$ & & $\begin{array}{l}\text { Transition } \\
\text { Questions }\end{array}$ \\
\hline 6. & To which culture do you belong? & $\mathrm{X}$ & $\mathrm{X}$ & & $\begin{array}{l}\text { Transition } \\
\text { Questions }\end{array}$ \\
\hline 7. & $\begin{array}{l}\text { Do you see a preference for your culture compared } \\
\text { to other cultures? }\end{array}$ & $\mathrm{X}$ & $\mathrm{X}$ & & $\begin{array}{l}\text { Transition } \\
\text { Questions }\end{array}$ \\
\hline 8. & $\begin{array}{l}\text { In the learning process, how do you see cultural } \\
\text { background influence students learning? }\end{array}$ & & $\mathrm{X}$ & & Key Questions \\
\hline 9. & $\begin{array}{l}\text { How do you see the relationship between cultural } \\
\text { background and learning? }\end{array}$ & & $\mathrm{X}$ & & Key Questions \\
\hline 10. & $\begin{array}{l}\text { Do you have non-Saudi students in your classroom? } \\
\text { How many? } \\
\text { Can you name their nationalities? }\end{array}$ & & & $\mathrm{X}$ & $\begin{array}{l}\text { Transition } \\
\text { Questions }\end{array}$ \\
\hline 11. & What do you know about their culture? & & & $\mathrm{X}$ & $\begin{array}{l}\text { Transition } \\
\text { Questions }\end{array}$ \\
\hline
\end{tabular}




\begin{tabular}{|c|c|c|c|c|}
\hline 12. & $\begin{array}{l}\text { How do you perceive non-Saudi students in your } \\
\text { classrooms? }\end{array}$ & & $X$ & Key Questions \\
\hline 13. & $\begin{array}{l}\text { What is the thing that pops in your mind when you } \\
\text { hear the word multiculturalism? }\end{array}$ & & & $\begin{array}{l}\text { Transition } \\
\text { Questions }\end{array}$ \\
\hline 14. & How would you define multiculturalism? & $\mathrm{X}$ & & $\begin{array}{l}\text { Transition } \\
\text { Questions }\end{array}$ \\
\hline 15. & How do you see multiculturalism in Saudi Arabia? & $\mathrm{X}$ & & Key Questions \\
\hline 16. & $\begin{array}{l}\text { In a country like Saudi Arabia, do you think there is } \\
\text { a need to take into account multiculturalism in } \\
\text { teaching and learning? }\end{array}$ & $\mathrm{X}$ & & $\begin{array}{l}\text { Transition } \\
\text { Questions }\end{array}$ \\
\hline 17. & How would you define multicultural education? & $\mathrm{X}$ & & Key Questions \\
\hline 18. & $\begin{array}{l}\text { Have you ever attended any professional seminar, } \\
\text { course or workshop related to multicultural } \\
\text { education? } \\
\text { If so, what was the purpose of it/them? }\end{array}$ & $\mathrm{X}$ & & $\begin{array}{l}\text { Closing } \\
\text { Questions }\end{array}$ \\
\hline
\end{tabular}


Question 2 (For teachers):

"What practices do educators employ with respect to multicultural education?"

a. What kind of teaching strategy do teachers use for teaching culturally diverse classrooms?

b. What is the nature of multicultural activities that teachers use in classroom instruction?

c. How do educators attempt to create a spirit of inclusion in a multicultural classroom?

\begin{tabular}{|c|c|c|c|c|c|}
\hline \multirow[t]{2}{*}{ NO\# } & \multirow[t]{2}{*}{ Interview Question } & \multicolumn{3}{|c|}{$\begin{array}{l}\text { Research } \\
\text { Question }\end{array}$} & \multirow{2}{*}{$\begin{array}{l}\text { Type of } \\
\text { Question }\end{array}$} \\
\hline & & $\mathrm{A}$ & B & $\mathrm{C}$ & \\
\hline 19. & $\begin{array}{l}\text { You said you have } \_ \text {non-Saudi } \\
\text { students, how do you see their academic } \\
\text { performance level? }\end{array}$ & & & & $\begin{array}{l}\text { Introductory } \\
\text { Questions }\end{array}$ \\
\hline 20. & $\begin{array}{l}\text { What subject are they good at and what } \\
\text { subject are they not good at? }\end{array}$ & & & & $\begin{array}{l}\text { Introductory } \\
\text { Questions }\end{array}$ \\
\hline 21. & $\begin{array}{l}\text { What kind of academic support they are } \\
\text { provided? } \\
\text { Do they have any issues in the Arabic } \\
\text { language? }\end{array}$ & $X$ & & & $\begin{array}{l}\text { Transition } \\
\text { Questions }\end{array}$ \\
\hline 22. & $\begin{array}{l}\text { How are you trying to engage them in the } \\
\text { learning activities? }\end{array}$ & $\mathrm{X}$ & $\mathrm{X}$ & $\mathrm{X}$ & Key Questions \\
\hline 23. & $\begin{array}{l}\text { How do you support your instruction with } \\
\text { regard to diversity in your classroom? } \\
\text { Please give me a specific example. }\end{array}$ & $\mathrm{X}$ & & & Key Questions \\
\hline 24. & $\begin{array}{l}\text { When preparing for the lesson, do you } \\
\text { consider non-Saudi students? How? }\end{array}$ & & $\mathrm{X}$ & & Key Questions \\
\hline 25. & $\begin{array}{l}\text { How do you see the relationship between } \\
\text { you and your students from all different } \\
\text { cultures? }\end{array}$ & & & $\mathrm{X}$ & Key Questions \\
\hline 26. & $\begin{array}{l}\text { How do you see the relationship between } \\
\text { students with others from different } \\
\text { cultures? }\end{array}$ & & & $\mathrm{X}$ & Key Questions \\
\hline 27. & $\begin{array}{l}\text { What is your role as a teacher in building } \\
\text { this relationship? }\end{array}$ & & & $\mathrm{X}$ & Key Questions \\
\hline 28. & $\begin{array}{l}\text { Do you think non-Saudi students feel safe } \\
\text { in their classroom? }\end{array}$ & & & $\mathrm{X}$ & Key Questions \\
\hline 29. & $\begin{array}{l}\text { Do they have the confidence to participate } \\
\text { and share their stories with other students? }\end{array}$ & & & $\mathrm{X}$ & Key Questions \\
\hline
\end{tabular}




\begin{tabular}{|l|l|l|l|l|l|}
\hline 30. & $\begin{array}{l}\text { Do you think that non-Saudi students have } \\
\text { the right to an equal education as any other } \\
\text { Saudi students? }\end{array}$ & $\begin{array}{l}\text { What kinds of changes in your school or } \\
\text { classroom do you think would better serve } \\
\text { the needs of diverse populations of } \\
\text { students? }\end{array}$ & & $\begin{array}{c}\text { Closing } \\
\text { Questions }\end{array}$ \\
\hline 32. & $\begin{array}{l}\text { As a teacher, do you feel it is important to } \\
\text { receive professional development that } \\
\text { focuses on multicultural education? Why? } \\
\text { Explain }\end{array}$ & $\begin{array}{c}\text { Closing } \\
\text { Questions }\end{array}$ \\
\hline 33. & $\begin{array}{l}\text { Do you feel that multicultural education can } \\
\text { increase or decrease educational quality in } \\
\text { Saudi Arabia? Why and how? }\end{array}$ & & & $\begin{array}{c}\text { Closing } \\
\text { Questions }\end{array}$ \\
\hline
\end{tabular}




\section{Questions 2 (for the school principals):}

"What practices do educators employ with respect to multicultural education?"

\begin{tabular}{|c|c|c|}
\hline NO\# & Interview Question & Type of Question \\
\hline 19. & $\begin{array}{l}\text { What is the percentage of non-Saudi students in your } \\
\text { school? }\end{array}$ & $\begin{array}{l}\text { Introductory } \\
\text { Questions }\end{array}$ \\
\hline 20. & $\begin{array}{l}\text { What are the challenges that students have at school? } \\
\text { - Is there any difference between Saudi and non- } \\
\text { Saudi students in these challenges? }\end{array}$ & Transition Questions \\
\hline 21. & What is the process of enrollment for Saudi students? & Key Questions \\
\hline 22. & $\begin{array}{l}\text { What is the process of enrollment for non-Saudi } \\
\text { students? }\end{array}$ & Key Questions \\
\hline 23. & Tell me about the school community. & Transition Questions \\
\hline 24. & $\begin{array}{l}\text { What is the role of the school in developing the } \\
\text { community? }\end{array}$ & Key Questions \\
\hline 25. & $\begin{array}{l}\text { Who are you communicating with parents? } \\
\text { - Is there any difference between Saudi and non- } \\
\text { Saudi parents? } \\
\text { - Who is more interactive with schools? }\end{array}$ & Key Questions \\
\hline 26. & $\begin{array}{l}\text { How do you see the relationship between you and your } \\
\text { students from all different cultures? }\end{array}$ & Key Questions \\
\hline 27. & Do you think non-Saudi students feel safe in school? & Key Questions \\
\hline 28. & $\begin{array}{l}\text { Do you think that non-Saudi students have the right to } \\
\text { equal education like other Saudi students? }\end{array}$ & Closing Questions \\
\hline 29. & $\begin{array}{l}\text { What kinds of changes in your school do you think } \\
\text { would better serve the needs of diverse populations of } \\
\text { students? }\end{array}$ & Closing Questions \\
\hline 30. & $\begin{array}{l}\text { As a school principal, do you feel it is important to } \\
\text { receive professional training on multicultural education? } \\
\text { Why? Explain }\end{array}$ & Closing Questions \\
\hline 31. & $\begin{array}{l}\text { Do you feel that multicultural education can increase or } \\
\text { decrease educational quality in Saudi Arabia? Why and } \\
\text { how? }\end{array}$ & Closing Questions \\
\hline
\end{tabular}


Appendix B

Checklist for Close Reading of Interview Protocol

Read questions aloud and mark yes or no for each item depending on whether you see that item present in the interview protocol. Provide feedback in the last column for items that can be improved.

\begin{tabular}{|l|l|l|l|}
\hline Aspects of an Interview Protocol & Yes & No & Feedback for Improvement \\
\hline \multicolumn{1}{|c|}{ Interview Protocol Structure } \\
\hline Beginning questions are factual in nature & & & \\
\hline $\begin{array}{l}\text { Key questions are the majority of the questions } \\
\text { and are placed between the beginning and ending } \\
\text { questions }\end{array}$ & & & \\
\hline $\begin{array}{l}\text { Questions at the end of interview protocol are } \\
\text { reflective and provide participant an opportunity } \\
\text { to share closing comments }\end{array}$ & & & \\
\hline $\begin{array}{l}\text { A brief script throughout the interview protocol } \\
\text { provides smooth transitions between topic areas }\end{array}$ & & & \\
\hline $\begin{array}{l}\text { Interviewer closes with expressed gratitude and } \\
\text { any intents to stay connected or follow up }\end{array}$ & & & \\
\hline $\begin{array}{l}\text { Overall, interview is organized to promote } \\
\text { conversational flow }\end{array}$ & & & \\
\hline \multicolumn{1}{|c|}{ Writing of Interview Questions \& Statements } \\
\hline $\begin{array}{l}\text { Questions/statements are free from spelling } \\
\text { error(s) }\end{array}$ & & & \\
\hline Only one question is asked at a time & & & \\
\hline $\begin{array}{l}\text { Most questions ask participants to describe } \\
\text { experiences and feelings }\end{array}$ & & & \\
\hline Questions are mostly open-ended & & & \\
\hline $\begin{array}{l}\text { Questions are written in a non-judgmental } \\
\text { manner }\end{array}$ & & & \\
\hline \multicolumn{1}{|c|}{ Length of Interview Protocol } \\
\hline All questions are needed & & & \\
\hline Questions/statements are concise & & & \\
\hline Questions/statements are easy to understand & & & \\
\hline
\end{tabular}




\title{
Appendix C
}

\section{IRB Approval}

\section{Andrews $\mathbb{Q}$ University}

February 11, 2020

Mohammed Alharbi

Tel: $740-590-5293$

Email: alharbi@andrews,edu

\begin{abstract}
RE: APPLICATION FOR APPROVAL OF RESEARCH INVOLVING HUMAN SUBJECTS
IRB Protocol \#: 20-012 Application Type: Original Dept: : Curriculum and Instruction

Review Category: Expedited Action Taken: Approved Advisor: Larry Burton

Title: Understanding multiculturalism in Saudi Education.
\end{abstract}

This letter is to advise you that the Institutional Review Board (IRB) has reviewed and approved your IRB application for research involving human subjects entitled:

"Understanding multiculturalism in Saudi Education" IRB protocol number 20-012 under Expedited category. This approval is valid until February 11, 2021. If your research is not completed by the end of this period you must apply for an extension at least four weeks prior to the expiration date. We ask that you inform IRB whenever you complete your research. Please reference the protocol number in future correspondence regarding this study.

Any future changes made to the study design and/or consent form require prior approval from the IRB before such changes can be implemented. Please use the attached report form to request for modifications, extension and completion of your study.

While there appears to be no more than minimum risk with your study, should an incidence occur that results in a research-related adverse reaction and/or physical injury, this must be reported immediately in writing to the IRB. Any project-related physical injury must also be reported immediately to the University physician, Dr. Katherine, by calling (269) 473-2222. Please feel free to contact our office if you have questions.

Best wishes in your research.

Sincerely,

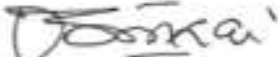

Mordekai Ongo, PhD.

Research Integrity \& Compliance Officer

Institutional Review Board -848s E. Campus Circle Dr Room BUL 234 - Berrien Springs, MI 49104-0355 Tel: (269) 471-6361 E-mail: irbsandrows.edu 


\section{Appendix D}

\section{Informed Consent Form}

Good morning (afternoon). My name is Mohammed Alharbi. Thank you for accepting my invitation to be part of my research study. I am doing a study to explore Saudi teachers' attitudes toward teaching multicultural classrooms. In this interview, I will ask you questions related to your job as a Saudi teacher. I do not aim to evaluate your teaching practices. The purpose of this interview is to obtain perceptions of your experiences in teaching culturally diverse classrooms. The information gleaned from this interview will be used only for this purpose. Ultimately, this study might assist administrators and teacher-supervisors in Saudi Arabia to understand teachers' perceptions of multicultural education, so they can provide professional development opportunities that emphasize the need for multicultural education approach in teaching. There are no desirable or undesirable answers. I would like you to feel comfortable with saying what you really think and how you really feel.

If you do not mind, I will be video-recording our conversation. The video file will be stored on a personal hard drive and I will be the only one who has access to the original recording. Before we begin, I want to inform you are voluntarily participating in this interview and you may skip questions you do not want to answer and you may stop at any time. I expect our interview to last between 60 to 90 minutes. 


\section{إقرار المشاركة في الدراسة}

$$
\text { السلام عليكم ورحمة الله وبركاته، }
$$

انا محمد بن عبد اللطيف الحربي، طالب دكتور اه في المناهج وطرق التدريس. أشكركم على قبول دعوتي للمشاركة في هذه الدر اسة. أقوم بدر اسة للتعرف على مو اقف المعلمين السعوديين تجاه تدريس الفصول الدر اسية ذات الثقافات المتعددة (متعددة الجنسيات). في هذه المقابلة ستكون الاسئلة متعلقة بعملك كمدرس سعودي في مدارس التعليم العام. لا أهدف في هذه الدر اسة لتقييم ممارساتكم التدريس و أدائكم داخل الفصل. الغرض من هذه المقابلة هو الحصول على تصور ات حول خبر اتك في تدريس الفصول الدر اسية المتنوعة ثقافيًا. سيتم استخدام المعلومات المستقاة من هذه المقابلة فقط لهذا الغرض. قد تساعد هذه الدر اسة الإداريين و المشرفين التربويين في المملكة العربية السعودية على فهم تصور ات المعلمين حول التعددية الثقافية في التعليم، حتى يتمكنو امن توفير فرص التطوير المهني التي تؤكد على الحاجة إلى التعددية النقافية في التعليم. لا توجد إجابات مر غوبة أو غير مر غوب فيها، جميع الإجابات مرحب بها.

إذا كنت لا تمانع، فسأقوم بتسجيل محادثتنا عبر الفيديو. سيتم تخزين ملف الفيديو على جهازي الثخصي وسأكون الوحيد الذي لديه حق الوصول إلى التسجيل الأصلي. أود أن أبلغكم بأنك تشارك طوعًا في هذه المقابلة، ويمكنك تخطي الأسئلة التي لا ترغب في الإجابة عليها ويمكنك التوقف في أب وقت. أتوقع أن تستمر مقابلتنا ما بين 


\section{Reference List}

Abdul Majid, M. A., Othman, M., Mohamad, S. F., Lim, S., \& Yusof, A. (2017). Piloting for Interviews in Qualitative Research: Operationalization and Lessons Learnt. International Journal of Academic Research in Business and Social Sciences, 7(4), 1073-1080.

Agirdag, O., Merry, M. S., \& Van Houtte, M. (2016). Teachers' Understanding of Multicultural Education and the Correlates of Multicultural Content Integration in Flanders. Education and Urban Society, 48(6), 556-582. https://doi.org/10.1177/0013124514536610

Al Thowaini, M. A. (2015). Can I see me? A study of pictorial representations in Saudi elementary textbooks and teacher and curriculum developers' perceptions of multiculturalism [Ph.D.]. http://search.proquest.com/pqdtglobal/docview/1710718793/abstract/11B759C90 AF14AE9PQ/1

Al-Balawi, A., \& Saeed, R. (2012). The Professional Development Needs of Mathematics Teachers in Saudi Arabia. Journal of Educational and Psychological Studies, 6(1), 114-132. https://doi.org/10.24200/jeps.vol6iss1pp114-132

Alghamdi, A. K. (2014). The Road to Culturally Relevant Pedagogy: Expatriate teachers' pedagogical practices in the cultural context of Saudi Arabian higher education. McGill Journal of Education, 49(1), 201-226. https://doi.org/10.7202/1025778ar

Alharbi, A., \& Alshamrani, S. (2016). Professional Development Needs for Intermediate Science Teachers in Oniza District in Saudi Arabia. Journal of Educational and Psychological Sciences, 272(3781), 1-40. https://doi.org/10.12816/0031955

Alnawar, H. J. (2015).Digital Commons@CSUMB Raising Teachers'Cultural Knowledge of Middle Eastern Students in The Classroom. http://digitalcommons.csumb.edu/caps_thes

AL-Tikrity, H., \& AL-Jubouri, A. (2019). Faisal bin AL-Hussein and the Arab Identity between Colonial Stress and Nationalists' Orders (1918-1920). Faisal bin ALHussein and the Arab Identity between Colonial Stress and Nationalists' Orders (1918-1920)., 26(10), 159-182. https://doi.org/10.25130/jtuh.26.2019.11

Andrews university: Institutional review board handbook. (2007).

https://www.andrews.edu/services/research/research_compliance/institutional_rev iew/handbook-revised-february-2017.pdf

Aronson, B., \& Laughter, J. (2016). The Theory and Practice of Culturally Relevant Education: A Synthesis of Research Across Content Areas. Review of Educational Research, 86(1), 163-206. https://doi.org/10.3102/0034654315582066 
Badri, M., Alnuaimi, A., Mohaidat, J., Yang, G., \& Al Rashedi, A. (2016). Perception of Teachers' Professional Development Needs, Impacts, and Barriers: The Abu Dhabi Case. SAGE Open, 6(3), 2158244016662901. https://doi.org/10.1177/2158244016662901

Banks, J. (1993). Multicultural Education: Historical Development, Dimensions, and Practice. Review of Research in Education, 19, 3-49. https://doi.org/10.2307/1167339

Banks, J. (2008). Teaching Strategies for Ethnic Studies (8 edition). Pearson.

Banks, J. (2009a). Multicultural education: Dimensions and paradigms. In J. Banks (Ed.), The Routledge international companion to multicultural education (pp. 9-32). Routledge, Taylor \& Francis Group.

Banks, J. (Ed.). (2009b). The Routledge international companion to multicultural education. Routledge, Taylor \& Francis Group.

Banks, J. (2010). Multicultural education: Characteristics and goals. In J. Banks \& C. Banks (Eds.), Multicultural education: Issues and perspectives (7th ed, pp. 3-30). Wiley.

Banks, J. (2013). The Construction and Historical Development of Multicultural Education, 1962-2012. Theory into Practice, 52(sup1), 73-82. https://doi.org/10.1080/00405841.2013.795444

Banks, J. (2015). Cultural Diversity and Education: Foundations, Curriculum, and Teaching. Routledge. https://doi.org/10.4324/9781315622255

Banks, J. A., \& Banks, C. (Eds.). (2010). Multicultural education: Issues and perspectives (7. ed). Wiley.

Banks, J., \& Banks, C. (Eds.). (2004). Handbook of research on multicultural education (2. ed). Jossey-Bass.

Bennabi, M. (2003). The Question of Culture. International Institute of Islamic Thought (IIIT).

Bennett, C. (2018). Comprehensive Multicultural Education: Theory and Practice (9 edition). Pearson.

Berk, L. E. (2013). Child development (9th ed). Pearson.

Bernard, H. R. (2006). Research methods in anthropology: Qualitative and quantitative approaches (4th ed). AltaMira Press.

Beyers, J. (2017). Religion and culture: Revisiting a close relative. HTS Teologiese Studies / Theological Studies, 73(1), 9. https://doi.org/10.4102/hts.v73i1.3864 
Castillo-Montoya, M. (2016). Preparing for Interview Research: The Interview Protocol Refinement Framework. The Qualitative Report, 21(5), 22.

Chen, F., Du, Y., \& Yu, M. (1991). Academic freedom in the people's republic of China and the United States of America. 29-33.

Coleman, J. S. (1988). Social Capital in the Creation of Human Capital. American Journal of Sociology, 94, S95-S120. JSTOR.

Creswell, J. W., \& Poth, C. N. (2018). Qualitative inquiry \& research design: Choosing among five approaches (Fourth edition). SAGE.

Danielson, C. (2007). Enhancing professional practice: A framework for teaching (2nd ed). Association for Supervision and Curriculum Development.

Deal, T. E., \& Peterson, K. D. (2016). Shaping School Culture. John Wiley \& Sons.

deMarrais, K. B. (2004). Qualitative interview studies: Learning through experience. In S. D. Lapan \& K. B. deMarrais (Eds.), Foundations for research: Methods of Inquiry in Education and the Social Sciences (pp. 51-68). Routledge.

El-Ghonemy, M. R. (2001). Affluence and Poverty in the Middle East. Routledge. http://ebookcentral.proquest.com/lib/qut/detail.action?docID=165081

El-Mesawi, M. E.-T. (2007). Religion, Society, and Culture in Malik Bennabi's Thought (pp. 213-256). https://doi.org/10.1002/9780470996188.ch13

Erbas, Y. H. (2017). A Qualitative Case Study of Multicultural Education in Turkey [Ph.D., Indiana University]. http://search.proquest.com/pqdtglobal/docview/1983520810/abstract/5E28DD28E 2D149C9PQ/33

Fayez. (2020). Understanding multiculturalism in Saudi education [Personal communication].

Fernyhough, C. (2014, January 24). Do Deaf People Hear an Inner Voice? Psychology Today. http://www.psychologytoday.com/blog/the-voices-within/201401/do-deafpeople-hear-inner-voice

Freire, P., \& Macedo, D. (2000). Pedagogy of the Oppressed, 30th Anniversary Edition (M. B. Ramos, Trans.; 30th Anniversary edition). Bloomsbury Academic.

Gay, G. (1994). A Synthesis of Scholarship in Multicultural Education. Urban Monograph Series. https://eric.ed.gov/?id=ED378287

Gay, G. (2002). Preparing for culturally responsive teaching. Journal of Teacher Education, 53(2), 106-116. 
Gay, G. (2010). Culturally responsive teaching: Theory, research, and practice. Teachers College.

General Authority for Statistics. (2019a). [Text]. General Authority for Statistics. https://www.stats.gov.sa/en

General Authority for Statistics. (2019b). Labor Force [Text]. General Authority for Statistics. https://www.stats.gov.sa/en/814

Gibney, M. J., \& Hansen, R. (Eds.). (2005). Immigration and asylum: From 1900 to the present. ABC-CLIO.

Grant, C. A. (2016). Depoliticization of the language of social justice, multiculturalism, and multicultural education. Multicultural Education Review, 8(1), 1-13. https://doi.org/10.1080/2005615X.2015.1133175

Grant, C. A. (Ed.). (2017). Research and multicultural education: From the margins to the mainstream. Falmer Press.

Grant, C. A., Elsbree, A. R., \& Fondrie, S. (2004). A decade of research on the changing terrain of multicultural education research. In C. A. M. Banks \& J. A. Banks (Eds.), Handbook of research on multicultural education (Vol. 2, pp. 184-207).

Grant, C. A., \& Millar, S. (2017). Research and Multicultural Education: Barriers, Needs, and Boundaries. In C. A. Grant (Ed.), Research and multicultural education: From the margins to the mainstream (pp. 6-17). Falmer Press.

Grant, C. A., \& Sleeter, C. E. (1986). Race, Class, and Gender in Education Research: An Argument for Integrative Analysis. Review of Educational Research, 56, 195211.

Grant, C. A., \& Sleeter, C. E. (2010). Race, Class, Gender, and Disability in the Classroom. In J. Banks \& C. Banks (Eds.), Multicultural education: Issues and perspectives (7th ed, pp. 59-80). Wiley.

Grant, C. A., \& Tate, W. F. (1995). Multicultural education through the lens of the multicultural education research literature. In J. A. Banks \& C. A. M. Banks (Eds.), Handbook of research on multicultural education (pp. 145-166).

Macmillan Pub. ; Prentice Hall International.

Hackman, H. W. (2005). Five Essential Components for Social Justice Education. Equity \& Excellence in Education, 38(2), 103-109. https://doi.org/10.1080/10665680590935034

Hamdan, A. K. (2014). The reciprocal and correlative relationship between learning culture and online education: A case from Saudi Arabia. International Review of Research in Open and Distance Learning; Athabasca, 15(1). 
http://search.proquest.com/docview/1634296117/abstract/8A412979B2C2477AP $\mathrm{Q} / 1$

Hassan, Z. A., Schattner, P., \& Mazza, D. (2006). Doing A Pilot Study: Why Is It Essential? Malaysian Family Physician: The Official Journal of the Academy of Family Physicians of Malaysia, 1(2-3), 70-73.

Herndon, B. C. (2007). An analysis of the relationships between servant leadership, school culture, and student achievement [Ph. D., University of Missouri-Columbia]. https://doi.org/10.32469/10355/4657

Hollins, E. R. (2008). Culture in school learning: Revealing the deep meaning. Routledge. http://site.ebrary.com/id/10228431

Hong, Y. (2009). A Dynamic Constructivist Approach to Culture: Moving from Describing Culture to Explaining Culture. In R. S. Wyer, C. Chiu, \& Y. Hong (Eds.), Understanding culture: Theory, research, and application (pp. 3-23). Psychology Press.

Howard, G. R. (2006). We Can't Teach What We Don't Know: White Teachers, Multiracial Schools. Teachers College Press.

Howard, J. (2000). Social Psychology of Identities. Annual Review of Sociology, 26(1), 367-393. https://doi.org/10.1146/annurev.soc.26.1.367

Itani, T. A. (2012). This Quran: THIS QURAN could not have been produced by anyone other than GOD. CreateSpace Independent Publishing Platform.

Johnson, M. B. (1999). Communication in the Classroom. https://eric.ed.gov/?id=ED436802

Johnson-Bailey, J., \& Drake-Clark, D. (2010). Race and Ethnicity in the Field of Adult Education. In P. Peterson, E. Baker, \& B. McGaw (Eds.), International Encyclopedia of Education (Third Edition) (pp. 77-82). Elsevier. https://doi.org/10.1016/B978-0-08-044894-7.00015-4

Kroeber, A. L., \& Kluckhohn, C. (1952). CULTURE: A critical review of concepts and definitions. FORGOTTEN Books.

Ladson-Billings, G. (1995). But That's Just Good Teaching! The Case for Culturally Relevant Pedagogy. Theory into Practice, 34(3), 159-165.

Ladson-Billings, G. (2013). The dreamkeepers: Successful teachers of African American children. Wiley.

http://ebookcentral.proquest.com/lib/sdloffice/detail.action?docID=1132872

Ladson-Billings, G. (2014). Culturally Relevant Pedagogy 2.0: A.k.a. the Remix. Harvard Educational Review; Cambridge, 84(1), 74-84,135. 
Lantolf, J. P. (2000). Sociocultural Theory and Second Language Learning. OUP Oxford.

Li, Z., \& Qiu, Z. (2018). How does family background affect children's educational achievement? Evidence from Contemporary China. The Journal of Chinese Sociology, 5(1), 13. https://doi.org/10.1186/s40711-018-0083-8

Lim, L., Tan, M., \& Saito, E. (2019). Culturally relevant pedagogy: Developing principles of description and analysis. Teaching and Teacher Education, 77, 4352. https://doi.org/10.1016/j.tate.2018.09.011

Mani, M. 'Abdallāh al-, \& Sabīt, 'Abdarraḥmān Sabīt as-. (1981). Cultural policy in the Kingdom of Saudi Arabia. Unesco.

Mansour, N., Alshamrani, S. M., Aldahmash, A. H., \& Alqudah, B. M. (2013). Saudi Arabian Science Teachers and Supervisors' Views of Professional Development Needs. Eurasian Journal of Educational Research, 51, 29-44.

Maxwell, J. A. (2013). Qualitative Research Design: An Interactive Approach (Third edition). SAGE Publications, Inc.

Merriam, S. B., \& Tisdell, E. J. (2016). Qualitative research: A guide to design and implementation (Fourth edition). John Wiley \& Sons.

Migration in an interconnected world: New directions for action. (2005). https://www.iom.int/jahia/webdav/site/myjahiasite/shared/shared/mainsite/policy_ and_research/gcim/GCIM_Report_Complete.pdf

Miles, M. B., Huberman, A. M., \& Saldaña, J. (2014). Qualitative data analysis: A methods sourcebook (Third edition). SAGE Publications, Inc.

Morris, M. B. (2015). Curriculum Studies Guidebooks: Volume 2- Concepts and Theoretical Frameworks (New edition edition). Peter Lang Inc., International Academic Publishers.

Nieto, S. (1994). Moving beyond tolerance in multicultural education. Teaching Tolerance.

Nieto, S. (2009). Multicultural education in the United States: Historical realities, ongoing challenges, and transformative possibilities. In J. A. Banks (Ed.), The Routledge International Companion to Multicultural Education (pp. 79-95). Routledge, Taylor \& Francis Group.

Nieto, S. (2010). Language, culture, and teaching: Critical perspectives (2nd ed). Routledge.

OECD. (2019). PISA 2018 Results (Volume II). https://www.oecdilibrary.org/content/publication/b5fd1b8f-en 
Omar, N., \& Noh, M. A. C. (2015). Islamic Education Teaching Practice Based on the Cultural Diversity of Students. Academic Journal of Interdisciplinary Studies, 4(1 S1), 135.

Patton, M. Q. (2015). Qualitative research \& evaluation methods: Integrating theory and practice (Fourth edition). SAGE Publications, Inc.

Phillips, P. (2008). Professional Development as a Critical Component of Continuing Teacher Quality. Australian Journal of Teacher Education, 33(1). https://eric.ed.gov/?id=EJ1069624

Quin, J., Deris, A., Bischoff, G., \& Johnson, J. (2015). The Correlation Between Leadership, Culture, and Student Achievement. The Online Journqal of New Horizons in Education, 5(2), 55-62.

Ramadan, T. (2010). What I Believe (1 edition). Oxford University Press.

Ratnapalan, L. (2008). E. B. Tylor and the Problem of Primitive Culture. History and Anthropology, 19(2), 131-142. https://doi.org/10.1080/02757200802320934

Saldaña, J. (2011). Fundamentals of qualitative research. Oxford University Press.

Saudi Vision 2030. (n.d.). Retrieved January 28, 2020, from https://vision2030.gov.sa/sites/default/files/report/Saudi_Vision2030_EN_2017.p df

Schiro, M. S. (2012). Curriculum Theory: Conflicting Visions and Enduring Concerns, 2nd Edition (2nd edition). SAGE Publications, Inc.

Schwarts, S. (2009). Culture Matters: National Value Cultures, Sources, and Consequences. In R. S. Wyer, C. Chiu, \& Y. Hong (Eds.), Understanding culture: Theory, research, and application (pp. 127-150). Psychology Press.

Seidman, I. (2006). Interviewing as qualitative research: A guide for researchers in education and the social sciences (3rd ed). Teachers College Press.

Shaffer, D. R. (2008). Social and Personality Development. Cengage Learning.

Suárez-Orozco, M., \& Suárez-Orozco, C. (2009). Globalization, immigration, and schooling. In J. Banks (Ed.), The Routledge international companion to multicultural education (pp. 62-76). Routledge, Taylor \& Francis Group.

Suh, E. E., Kagan, S., \& Strumpf, N. (2009). Cultural Competence in Qualitative Interview Methods with Asian Immigrants. Journal of Transcultural Nursing, 20(2), 194-201. https://doi.org/10.1177/1043659608330059 
Swallow, D. (2009). Happiness: East vs West differences in perceptions. http://www.deborahswallow.com/2009/08/19/happiness-east-vs-west-differencesin-perceptions/

Sze, K., \& Adetunji, R. R. (2012). Understanding Non-Verbal Communication across Cultures: A Symbolic Interactionism Approach. ResearchGate. https://www.researchgate.net/publication/255967701_Understanding_NonVerbal_Communication_across_Cultures_A_Symbolic_Interactionism_Approach

Thomas R. Guskey, \& Kwang Suk Yoon. (2009). What Works in Professional Development? The Phi Delta Kappan, 90(7), 495.

Tielman, K., den Brok, P., Bolhuis, S., \& Vallejo, B. (2012). Collaborative learning in multicultural classrooms: A case study of Dutch senior secondary vocational education. Journal of Vocational Education \& Training, 64(1), 103-118. https://doi.org/10.1080/13636820.2011.622448

Towards Saudi Arabia's Sustainable Tomorrow: First Voluntary National Review 20181439. (2018). https://sustainabledevelopment.un.org/content/documents/20230SDGs_English_R eport972018_FINAL.pdf

Tylor, E. B. (1871). Primitive Culture: Researches into the Development of Mythology, Philosophy, Religion, Art, and Custom (Vol. 1). J. Murray.

UNESCO. (2018). Handbook on Measuring Equity in Education. http://uis.unesco.org/sites/default/files/documents/handbook-measuring-equityeducation-2018-en.pdf

Van Nes, F., Abma, T., Jonsson, H., \& Deeg, D. (2010). Language differences in qualitative research: Is meaning lost in translation? European Journal of Ageing, 7(4), 313-316. https://doi.org/10.1007/s10433-010-0168-y

Virginia Richardson. (2003). The Dilemmas of Professional Development. The Phi Delta Kappan, 84(5), 401.

Vygotski1̆, L. S. (1978). Mind in society: The development of higher psychological processes (M. Cole, Ed.). Harvard University Press.

Waller, W. (2014). The Sociology of Teaching. Martino Fine Books.

Waters, J. T., Marzano, R. J., \& McNulty, B. (2004). Leadership that Sparks Learning. Educational Leadership, 61(7), 48.

Winerman, L. (2006). The culture-cognition connection: Recent research suggests that Westerners and East Asians see the world differently-literally. Https://Www.Apa.Org. https://www.apa.org/monitor/feb06/connection 
Yasin, F., \& Jani, M. (2013). Islamic education: The philosophy, aim, and main features. International Journal of Education and Research.

Yin, R. K. (2016). Qualitative research from start to finish (Second edition). The Guilford Press.

السويهري، ت. (2013). د. وقار : تصحيح أوضاع 500 ألف 》ابرماوي《ي في المملكة خطوة غير مسبوقة عالمياً

(Correcting the conditions of 500 thousand "Baramawi" in the Kingdom is an . http://www.alriyadh.com/834008 جريبة الرياض .unprecedented step globally)

$$
\text { الثيعاني، م. (2011). مدارس الجاليات الخيرية في مدينة مكة المكرمة وأثرها في الدعوة إلى الله. }
$$

(Community charitable schools in the city of Mecca and its impact on the advocacy to Allah.). https://static.alukah.net/Researches/Files/Rsrch_615/khiria.pdf

$$
\text { العربية . (2016) .تصحيح أوضاع } 70 \text { ألف طالب من الجاليات في مكة. العربية نت }
$$

(Correct the conditions of 70 thousand immigrant students in Mecca.)

تصحح-أوضاع-70_thtps://www.alarabiya.net/ar/saudi-today/2016/09/26/-

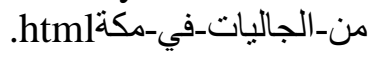

العيسى، أ. (2009). اصلاح التعليم في السعودية: بين غياب الرؤية السياسية وتوجس الثقافة الدينية وعجز الإدارة

التربوية التوائ vision, the apprehension of religious culture, and the inability of educational

$$
\text { دار الساقي. }
$$

عطار ، ع. (2004). مدارس الجالية الإسلامبية البورمبية الخيرية بككة المكرمة Burmese Muslim) Community Charitable Schools in Makkah.)

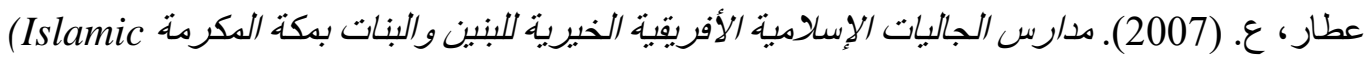
African Charitable School Communities for Boys and Girls in Mecca.) https://search.mandumah.com/Record/42287

صحيفة سبق، (2019) وصول أكثر من 6.9 مليون معتمر إلى المملكة وإصدار أكثر من 7.4 مليون تأثنيرة عمرة. (More than 6.9 million pilgrims arrive in the Kingdom and more than 7.4 million Umrah . https://sabq.org/LPsCMS صحيفة سبق الإلكترونية (visas were issued 


\section{CURRICULUM VITAE}

\section{Mohammed Alharbi}

$\underline{\text { Tel: }+1(740) 5905293}$

Email: Alharbi @ Andrews.edu

\section{Education}

Andrews University (Berrien Springs, MI)

$\mathrm{PhD}$. Curriculum and Instruction

Umm Al-Qura University (Mecca, Saudi Arabia)

Master in Curriculum and Instruction (Mathematics)

Teachers Preparation College (Mecca, Saudi Arabia)

Bachelor in Mathematics Teaching

\section{Teaching Experience}

Mathematics teacher (Middle school)

Yanbu, Jeddah, and Mecca School Districts

\section{Publications}

Alharbi, M. (2018). A Review of Education and the Arab Spring: Resistance, Reform, and Democracy. International Journal of Research in Educational Sciences, 1(2), 311-318. https://doi.org/10.29009/ijres.1.2.12 


\section{Professional Development}

Andrews University Teaching and Learning Conference

Title "Measuring Intelligence: Quantitative VS. Qualitative"

American Educational Research Association (AERA) Conference

Attending a conference

Andrews University Teaching and Learning Conference

Title "Culturally Relevant Pedagogy: Theory and Practice"

\section{Affiliations/Memberships}

Member of Inter-agency Network for Education in Emergencies 